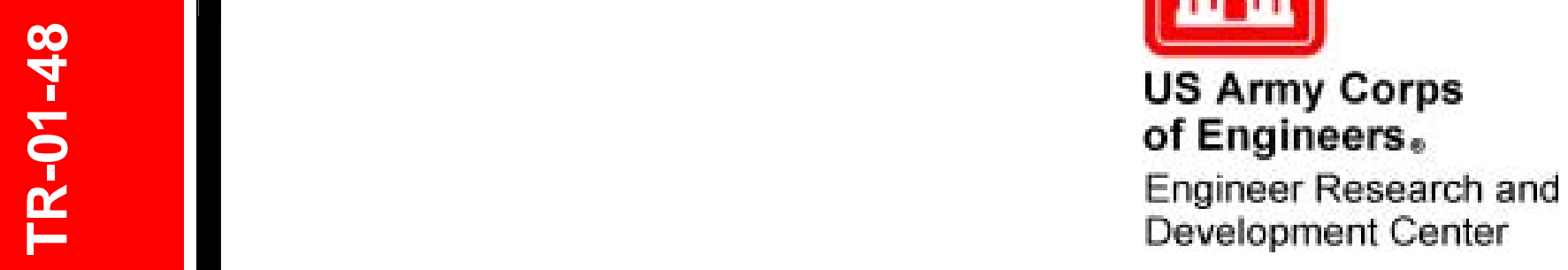

\title{
A Fundamental Study of Biofiltration Processes for VOC Removal From Waste Gas Streams
}

Byung J. Kim, Makram T. Suidan, Xueqing Zhu, and

November 2001 Cristina Alonso

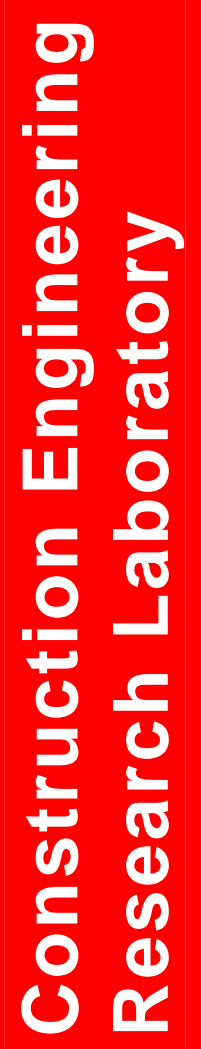




\section{Foreword}

This study was conducted for Headquarters, U.S. Army Corps of Engineers (USACE) under 622720A896, "Base Facilities Environmental Quality"; Work Unit CNE-T281, "Hazardous Organic Solvent." The technical reviewer was Chris Vercauten, Operations Support Command.

The work was performed by the Environmental Processes Branch $(\mathrm{CN})$ of the Installations Divisions (CN), Construction Engineering Research Laboratory (CERL). The CERL Principal Investigator was Dr. Byung J. Kim. The technical editor was Linda L. Wheatley, Information Technology Laboratory-Champaign. Dr. James Hay is the capability package manager for the Hazardous Air Pollutants Program. Michelle Hansen is Acting Chief, CN-E, and Dr. John T. Bandy is Chief, CN. The associated Technical Director is Gary W. Schanche, CVT. The Director of CERL is Dr. Alan W. Moore.

CERL is an element of the Engineer Research and Development Center (ERDC), U.S. Army Corps of Engineers. The Commander and Executive Director of ERDC is COL John W. Morris III, EN, and the Director of ERDC is Dr. James R. Houston.

DISCLAIMER: The contents of this report are not to be used for advertising, publication, or promotional purposes. Citation of trade names does not constitute an official endorsement or approval of the use of such commercial products. All product names and trademarks cited are the property of their respective owners. The findings of this report are not to be construed as an official Department of the Army position unless so designated by other authorized documents.

DESTROY THIS REPORT WHEN IT IS NO LONGER NEEDED. DO NOT RETURN IT TO THE ORIGINATOR. 


\section{Contents}

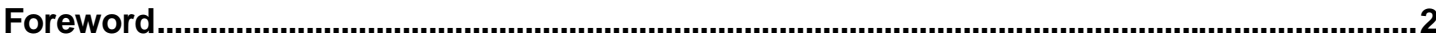

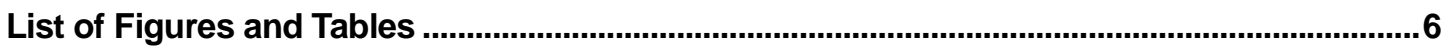

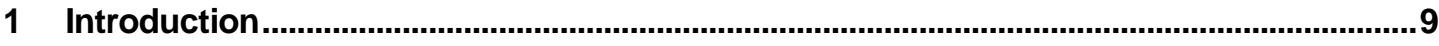

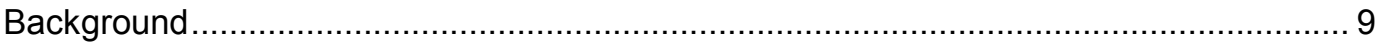

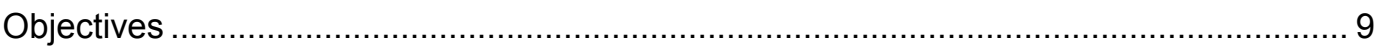

Scope

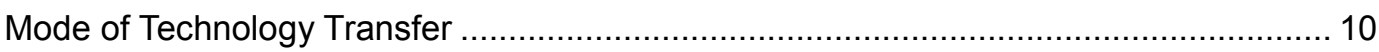

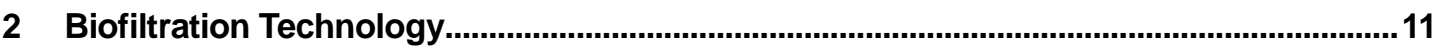

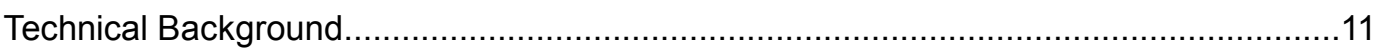

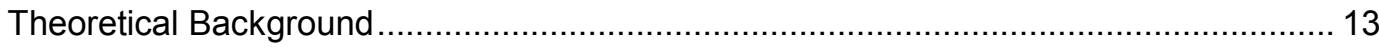

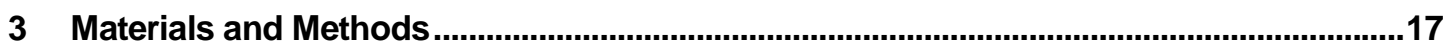

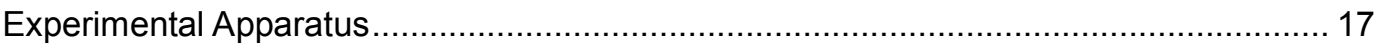

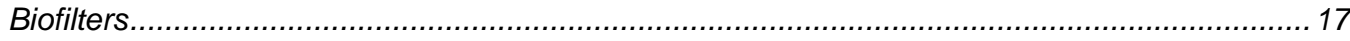

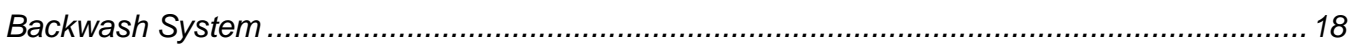

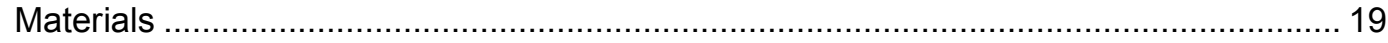

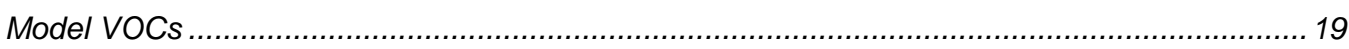

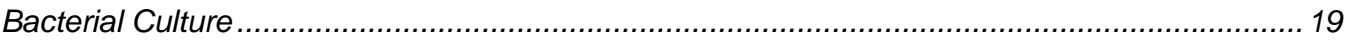

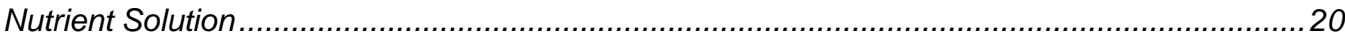

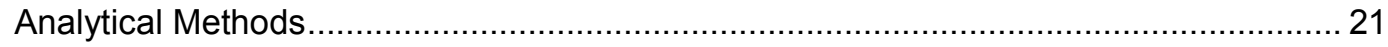

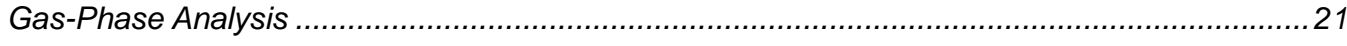

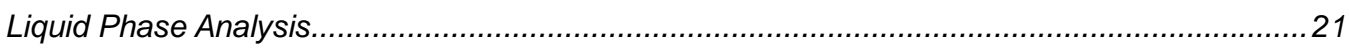

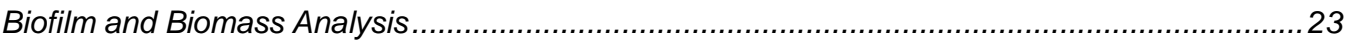

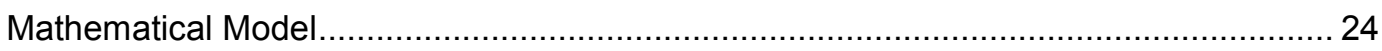

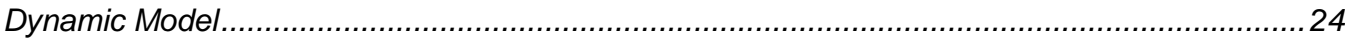

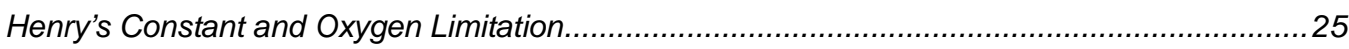

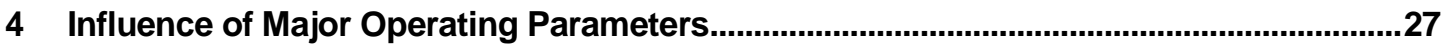

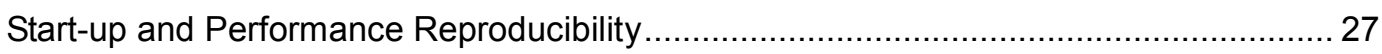

Ether Concentration and Loading ….................................................................... 28

Airflow Rate or Empty Bed Retention Time ........................................................... 29

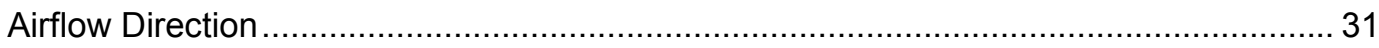

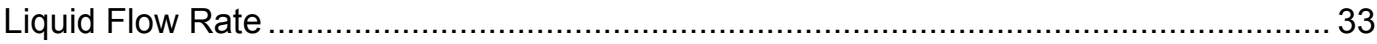




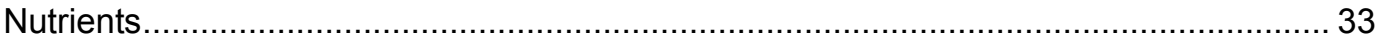

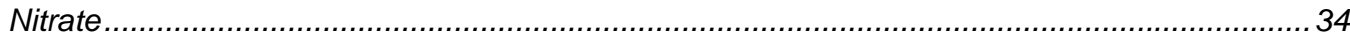

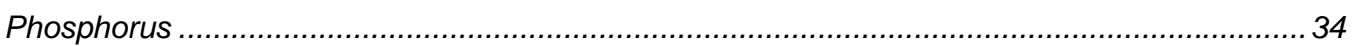

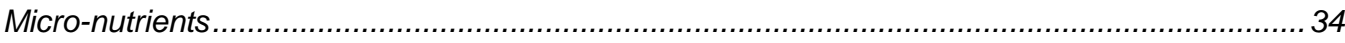

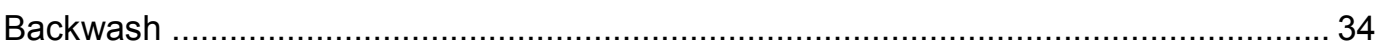

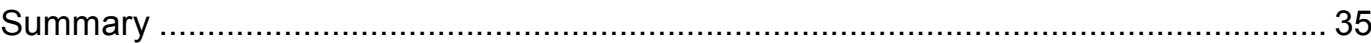

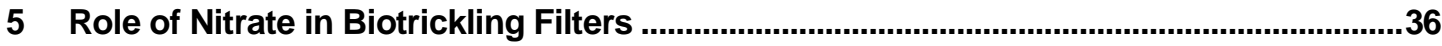

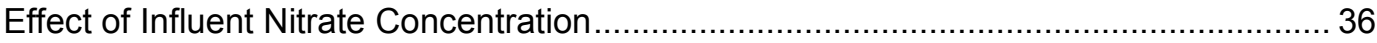

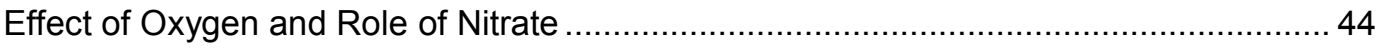

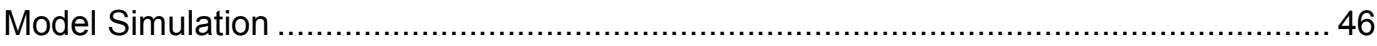

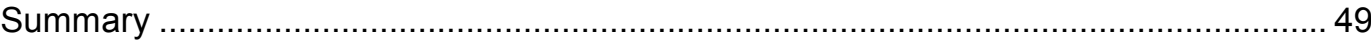

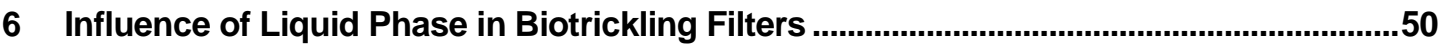

Effect of Draining After Backwashing and Flooding................................................. 50

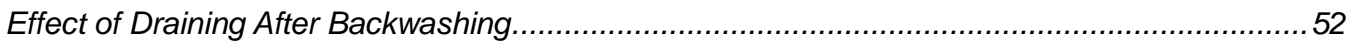

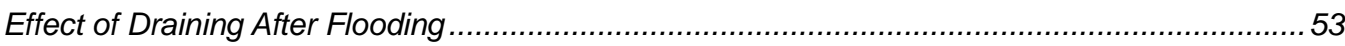

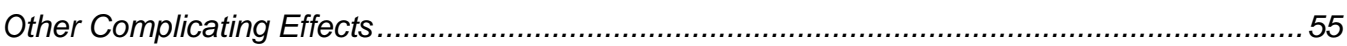

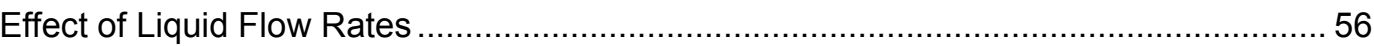

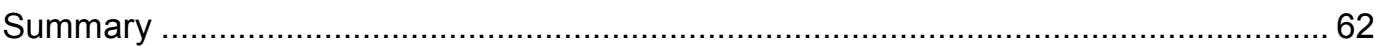

7 Biofilm Structure and Oxygen Transfer Within Biofilms in Biotrickling Filters...............63

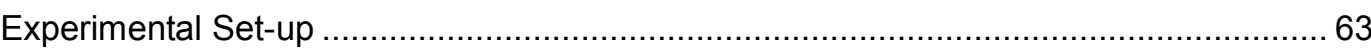

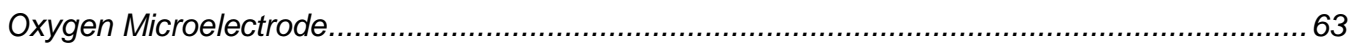

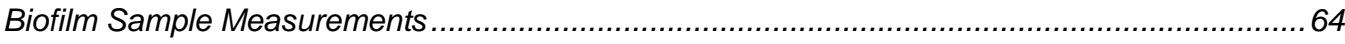

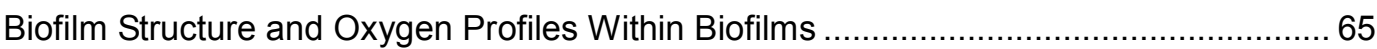

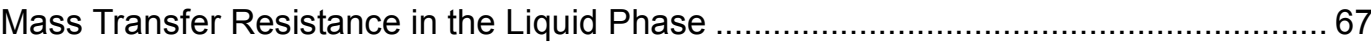

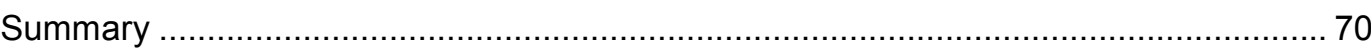

8 Effect of Henry's Constant on Biofilter Performance ......................................................

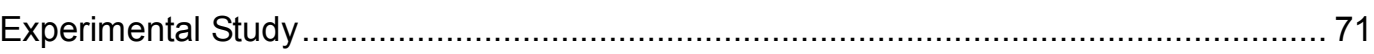

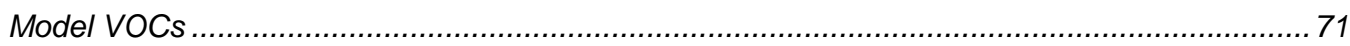

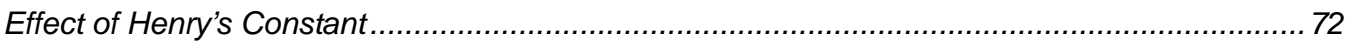

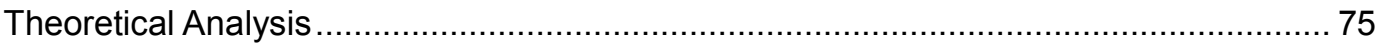

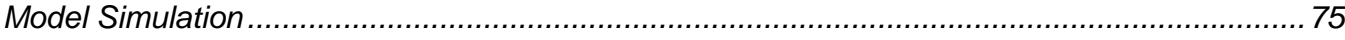

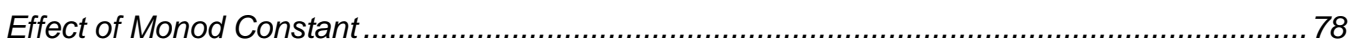

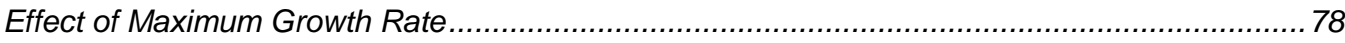

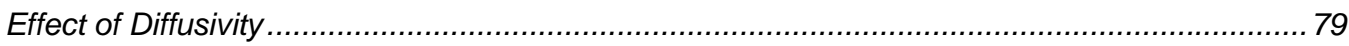

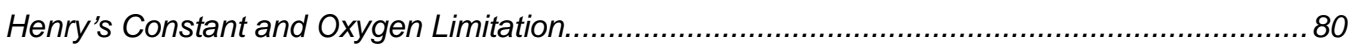

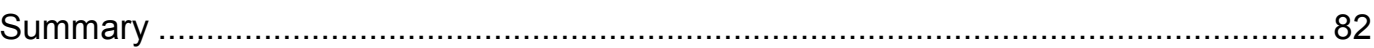

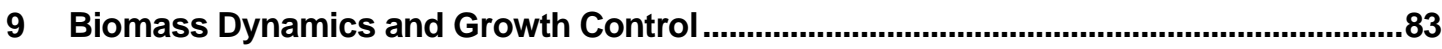

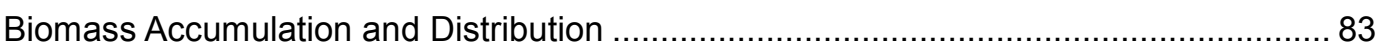




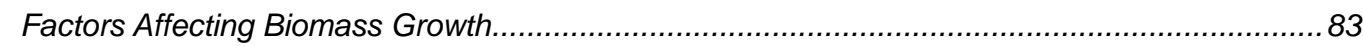

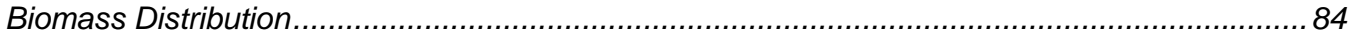

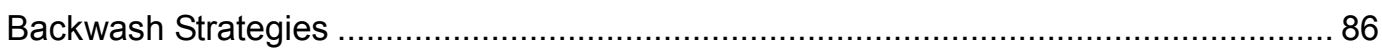

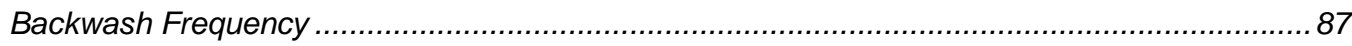

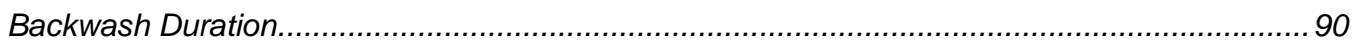

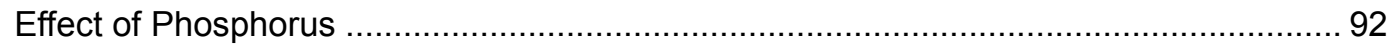

Effect of Phosphorus Limitation on Biomass Control............................................................. 92

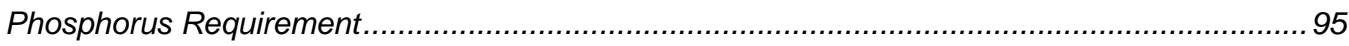

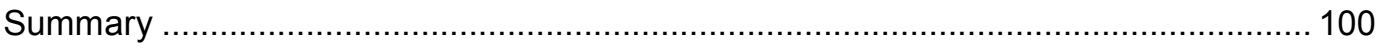

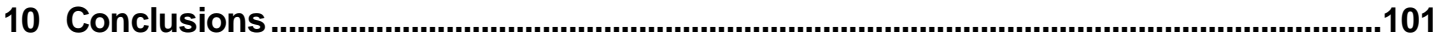

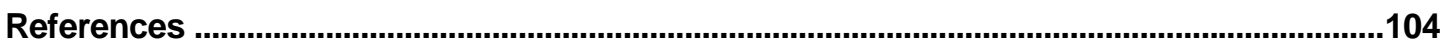

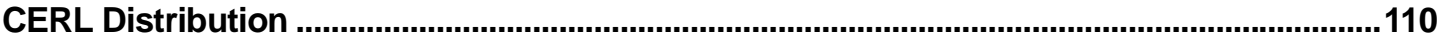

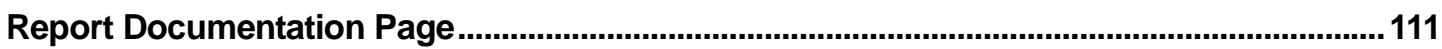




\section{List of Figures and Tables}

\section{Figures}

$1 \quad$ Representation of a biofilm model in a gas-phase biofilter............................... 14

2 Representation of an unsaturated biofilm in a gas-phase biofilter .................... 16

$3 \quad$ Schematic of the biotrickling filter system.................................................... 17

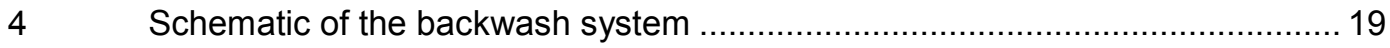

$5 \quad$ Biofilter performance during start-up of four biofilters at ether loading of 8.9 $\mathrm{kg} \mathrm{COD} / \mathrm{m}^{3} /$ day ................................................................................. 28

$6 \quad$ Effect of EBRT on biofilter performance at COD loading of $8.9 \mathrm{~kg}$

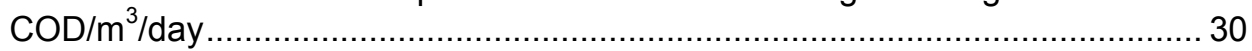

$7 \quad$ Effect of flow patterns on biofilter performance .............................................. 32

$8 \quad$ Ether concentration profiles for co-current and counter-current flow ................. 33

$9 \quad$ A typical biofilter performance during backwash cycles .................................... 35

10 Effect of influent concentration on biofilter performance at influent ether of

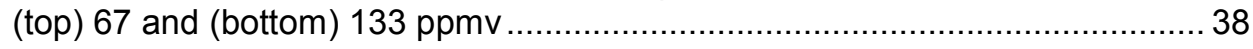

11 Effect of influent nitrate concentration on ether removal ................................. 39

12 Effect of logmean nitrate concentration on ether removal rate.......................... 40

13 Nitrate influence on concentration profiles of ether and $\mathrm{CO}_{2}$ along the medium depth

14 Effect of influent nitrate concentration on biofilter performance at influent ether of 200 and 267 ppmv.

15 Comparison of oxygen and nitrate effects on ether removal at COD loading of $3.6 \mathrm{~kg} / \mathrm{m}^{3} /$ day and influent ether concentration of $133 \mathrm{ppmv}$

Model simulations of the effect of influent nitrate concentration.

17 Overall biofilter performance with respect to ether removal during the study on draining effect after backwashing

Effect on ether removal of draining after backwashing

Effect of draining after flooding on ether removal.

Effect on ether removal of liquid draining rate after flooding. .55 
$25 \quad$ Effect of liquid flow rate on biofilter performance ......................................... 59

$26 \quad$ Effect of liquid flow on phospholipid content in biofilm ................................... 61

$27 \quad$ Effect of liquid flow rate on biofilm water content ........................................... 61

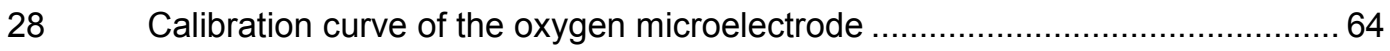

29 Microelectrode system with a biofilm pellet mounted on a diamond holder ........66

30 Profiles of oxygen concentrations within a thick biofilm taken from the top

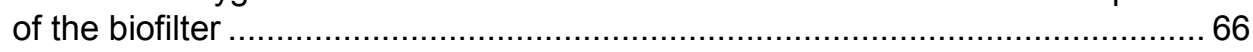

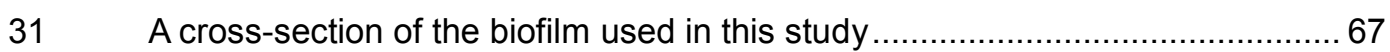

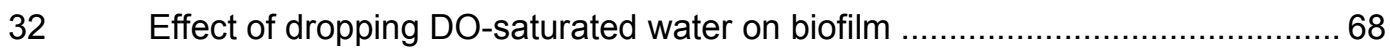

33 Comparison of oxygen profiles with biofilm in water and in air..........................69

$34 \quad$ Oxygen profiles within biofilms along the medium depth .................................69

35 Effect of Henry's constant on biofilter performance ......................................... 73

36 Influence of backwash on different VOC removal at VOC loading of 2

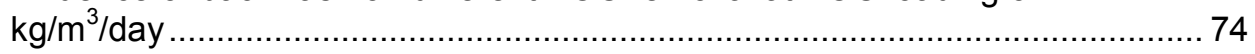

37 Effect of Henry's constant: data and model simulation.................................... 77

38 Effect of Monod constant vs effect of Henry's constant on VOC removal .......... 78

39 Effect of maximum growth rate vs effect of Henry's constant on VOC

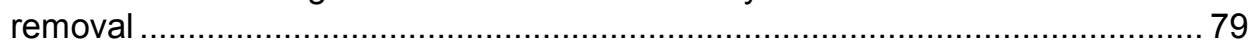

40 Effect of substrate diffusivity within biofilm vs effect of Henry's constant........... 80

$41 \quad$ Effect of VOCs Henry's constant on oxygen limitation .................................... 81

42 Biofilm thickness distribution at ether loading of $8.9 \mathrm{~kg} \mathrm{COD} / \mathrm{m}^{3} /$ day ............... 85

43 Biomass distribution and ether removal along the biofilters at ether loading

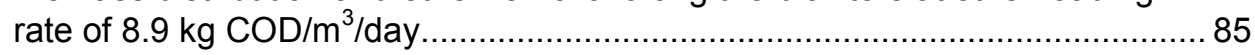

44 Removal efficiency with respect to backwash cycles at ether loading of 1.8 and $3.6 \mathrm{~kg} \mathrm{COD} / \mathrm{m}^{3} /$ day.

45 Effect of backwash frequency on ether removal at ether loading of 8.9 and $10.7 \mathrm{~kg} \mathrm{COD} / \mathrm{m}^{3} /$ day

Impact of backwash on ether removal.

47 Effect of backwash duration with respect to SS and VSS concentrations in backwash water.....

49 Comparison of biofilter performance with and without phosphorous in nutrient feed.

50 Biofilter performance under the condition of phosphorous absence at influent ether of 100 and 200 ppmv....

51 Effect of phosphorous absence on ether profiles along the medium depth ........96

52 Effect of influent phosphorous concentrations on ether removal at an ether loading rate of $8.9 \mathrm{~kg} \mathrm{COD} / \mathrm{m}^{3} /$ day....

53 Phosphorous effect on ether profiles along the medium depth at ether loading of $8.9 \mathrm{~kg} \mathrm{COD} / \mathrm{m}^{3} /$ day and EBRT of $25 \mathrm{sec}$.... 


\section{Tables}

1 Concentration of components in the nutrient feed (except for nitrate and

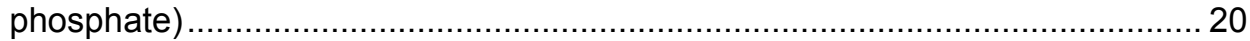

2 Summary of the results during ether loading variations at EBRT of $25 \mathrm{sec} \ldots \ldots . .29$

3 Summary of the results during influent EBRT variations ................................... 30

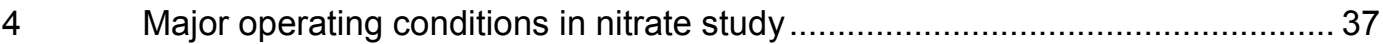

$5 \quad$ Carbon balance during influent nitrate variations (the percentages are relative to the total amount of removed ether)............................................. 42

$6 \quad$ Summary of the results during influent nitrate variations .................................. 44

$7 \quad$ Parameters used in determination of oxygen limitation (at $25^{\circ} \mathrm{C}$ ) ..................... 45

$8 \quad$ Parameters used in model simulation of nitrate effect ................................... 47

9 Major operating conditions in the study on draining effect after

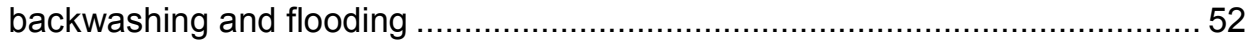

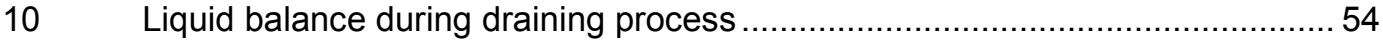

11 Major operating conditions in the study on the effect of liquid flow rate ............. 58

12 Henry's constants and some other properties for selected VOCs...................... 72

13 Major operating conditions in the study of Henry's constant effect .................... 72

14 Effect of Henry's constants on biofilter performance during the variations of

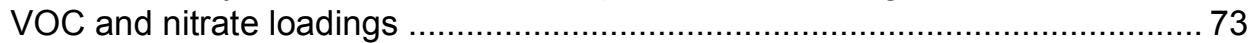

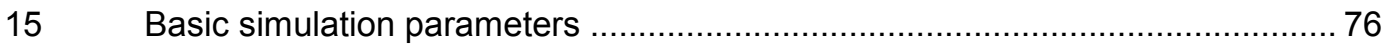

16 Effect of Henry's constant on biofilter performance: model simulation and

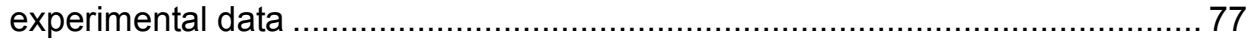

17 Determination of oxygen limitation: parameters and critical VOC concentrations

18 Effect of major operating conditions on biomass growth ................................. 84

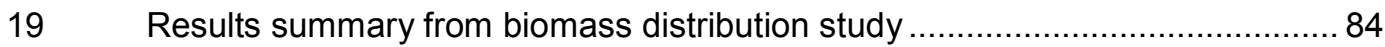

20 Major operating conditions in the study on backwash frequency ...................... 87

$21 \quad$ Major experimental parameters used in backwash duration test ....................... 91

22 Summary of the results during influent ether loading variations .......................93

23 Major operating conditions used in phosphorus limitation test.......................... 94

$24 \quad$ Major operating conditions used in phosphorus requirement test...................... 97

25 Summary of the results during the variations of the influent phosphorus concentrations 


\section{Introduction}

\section{Background}

A large portion of the priority pollutants regulated by the U.S. Environmental Protection Agency (EPA) are volatile organic compounds (VOCs). The U.S. Army generates large amounts of VOCs at many of its industrial operations. Most VOCs are deemed carcinogenic, and some are precursors to ozone production (Austin 1992). Large amounts of VOCs are emitted to the atmosphere from chemical industries, food processing industries, and waste management facilities (Dawson 1993). Passage of the Clean Air Act Amendments of 1990 has meant that control and removal of VOCs from contaminated gas streams have become of increasing concern in recent years (Lee 1991). Biological treatment, especially biofiltration, has emerged as a promising air pollution control (APC) technology for VOC removal because of its cost-effectiveness for certain waste gas streams when compared with other conventional VOC control options (Bohn 1992; Leson and Winer 1991; Ottengraf 1986).

\section{Objectives}

The main objective of this research was to develop an understanding of the fundamental characteristics of the biofiltration system. The specific objectives of this study were:

1. To determine the influence of some critical parameters on biofilter efficiency such as substrate load, gas flow rate or detention time, and flow patterns.

2. To study the mass transfer phenomenon in the biofiltration processes by determining the mass transfer resistance in the gas phase, liquid phase, and within the biofilm. Emphasis was on investigating how the biofilm structure in a gasphase biotrickling filter affects the mass transfer mechanisms.

3. To investigate the progression and mechanisms of a biomass accumulation, attrition, and removal processes. Emphasis was on the investigation of biomass accumulation and the development of a biomass control strategy. 
4. To develop a mathematical model of the biofilter that incorporates the findings of this study. This model will lead to better understanding of the processes involved in biofiltration.

\section{Scope}

This technical report attempted to deepen understanding of fundamentals of biofilter operation for air treatment through a bench-scale evaluation of a biotrickling filter. This report is a companion to ERDC/CERL TR-00-9, which provided fundamentals of the bioscrubber. ERDC/CERL developed a new generation biofilter (US Patent No. 6,171,853) based on fundamentals discussed in these reports.

\section{Mode of Technology Transfer}

This study will enable pilot-scale demonstration of new generation biofilter technology beginning in fiscal year 2002. This report will be made accessible through the World Wide Web (WWW) at URL: http://www.cecer.army.mil. 


\section{Biofiltration Technology}

\section{Technical Background}

Biofiltration is a relatively new air pollution control technology that uses microorganisms to degrade various pollutants. A waste gas stream is purified by passage through a biologically active medium under aerobic conditions. As the waste gas moves through the biofilter, organic compounds pass into the biofilms surrounding the supporting medium and are oxidized into mineral end products (e.g., water $\left[\mathrm{H}_{2} \mathrm{O}\right]$ and carbon dioxide $\left[\mathrm{CO}_{2}\right]$ ) or incorporated into the biomass.

The first applications of biofilters for APC used soil beds in the United States and West Germany to treat odorous off-gases in the 1950s (Leson and Winer 1991). Since the $1960 \mathrm{~s}$, biofiltration has been developed into a widely used APC technology in Europe. In Germany and the Netherlands, biofilters have been used to control VOCs and air toxic emissions from industrial facilities since the early 1980s. In recent years, interest in this technology in the United States has intensified due to increasingly stringent regulations. It is estimated that about 100 biofilters are in service in the United States, with the vast majority used for odor abatement (Severin, Shi, and Hayes 1993). Recently, the biofiltration of VOCs has gained popularity in wood products, pulp and paper, surface-coating, and ammunition industries. Biofiltration also holds promise for the treatment of air streams from the soil vapor extraction process for the cleanup of soil and groundwater contaminated with gasoline, jet fuel, and diesel fuel (Devinny, Deshusses, and Webster 1999). The biofiltration process has the advantages of low capital investment and low operating cost, and is environmentally safe when compared with other VOC control systems such as incineration and activated carbon adsorption, particularly if applied to waste gas streams with low VOC concentrations, typically less than 1,000 ppmv (Leson and Winer 1991).

Biofilters can be classified as either natural nutritive bed reactors or trickling bed biofilters (Ottengraf 1987; Severin 1993). Natural nutritive bed types or conventional biofilters use soil, compost, peat, bark, or a combination of these materials as supporting media for active microorganisms. The natural media provide nutrients necessary for microorganism growth. The major advantage of these systems is the extremely low cost of the materials used for construction. Limited process control and gradual media nutrient exhaustion, however, lead to 
less effective VOC removal than in biotrickling filter systems. A biotrickling filter consists of a column filled with a structured packing medium that has a relatively low specific area in order to create a large void area for gas passage and to minimize pressure drops. Most recently, synthetic media with good contact surface for biofilm formation are preferably used (Ottengraf 1986). A continuous and often recirculating nutrient feed is supplied at the top of the reactor (Ottengraf 1987; Diks and Ottengraf 1991). Therefore, a moving liquid phase exists in this system instead of the stationary phase of a natural nutritive bed biofilter. Biotrickling filters allow more uniform substrate and nutrient distribution, better pressure drop control, more consistent operation and higher VOC removal efficiency than conventional biofilters (Togna and Singh 1994). A major disadvantage, according to Severin, Shi, and Hayes (1993), is that VOC vapors must first be absorbed into the flowing liquid phase, which becomes the rate-limiting step for compounds with low water solubility. Diks and Ottengraf (1991), however, found that gas-liquid mass transfer resistance was negligible in this system for treating methylene chloride, a very poorly water-soluble compound.

Biofiltration, as a promising VOC-control technology, has been the subject of extensive research since the $1980 \mathrm{~s}$, and major design and operation criteria have been identified (Ottengraf 1986; Van Lith, David, and Marsh 1990; Hodge et al. 1991; Leson and Winer 1991). For most applications the optimal moisture content has been reported to range between 40 and 60 percent by wet weight (Van Lith, Leson, and Michelson 1997). The moisture effect also depends on substrates and packing media. Auria, Aycaguer, and Devinny (1998) showed that biofilter elimination capacity dropped substantially when the compost bed material was dried from 70 to 49 percent moisture content during the treatment of ethanol vapor. De Heyder et al. (1994) showed that the biodegradation of ethene, a poorly water soluble compound, in a packed granular activated carbon (GAC) bioreactor was improved after the bed was dried to a moisture content of less than 40 percent. They thought that the water layer was limiting the mass transfer of ethene into the biofilm. Criteria for a proper medium include a large reactive surface area and limited backpressure. Sorial et al. (1994a) compared three types of media for VOC treatment and found that a biofilter packed with the pelletized ceramic material achieved better removal efficiency than those with the channelized synthetic media and a compost mixture. Nutrient and $\mathrm{pH}$ control are also important, especially when a synthetic packing medium is used and halogenated compounds, which result in acidification of the system, are treated. Biotrickling filters with liquid recirculation were effectively used for methylene chloride treatment with $\mathrm{pH}$ adjustment in the recycle stream (Diks and Ottengraf 1991; Hartmans and Tramper 1991). 
Biofilters have also displayed very high removal efficiencies for various VOCs. Kempbell et al. (1987) showed that soil-bed biofilters are suitable for propane, isobutene, and n-butane removal. Hodge et al. (1991) studied the treatment of hydrocarbon fuel vapors in biofilters with four types of media. Miller and Canter (1991) investigated the control of aromatic VOCs by biofilters. According to Leson and Winer (1991), compounds that are typically well biodegraded include alcohols, ethers, aldehydes, ketones, and several common monocyclic aromatics. Recent research has focused on the feasibility of using biofiltration processes to treat less biodegradable xenobiotic compounds (Ottengraf et al. 1986). Speital and McLay (1993) reported on the use of biofilters for the treatment of waste gas containing chlorinated solvents.

Although extensive research on biofilters has been conducted in the last 10 years, most studies were limited to the observation of removal efficiency for certain VOCs or to the investigation of operating conditions. The biofiltration process has not been well understood because of the complexity of the system and lack of fundamental research. As a result, the acceptance of this technology is still uncertain in the United States.

\section{Theoretical Background}

The treatment of VOCs in biofilters involves the following basic processes, which are schematically illustrated in Figure 1.

1. Transport of the VOC and oxygen from the gas phase into the liquid phase.

2. Transport of the VOC, oxygen, nutrients, and other substrate (if needed) from the liquid phase to the surface of the biofilm.

3. Simultaneous diffusion and biotransformation of VOC, oxygen, nutrients, and other substrates within the biofilm.

These processes are also interrelated through the interaction of mass transfer and biological reactions. Two approaches have generally been used to study this system. The first approach involves using mathematical models to describe the system and to provide insight into the processes. The other involves an experimental investigation of biofiltration fundamentals. 


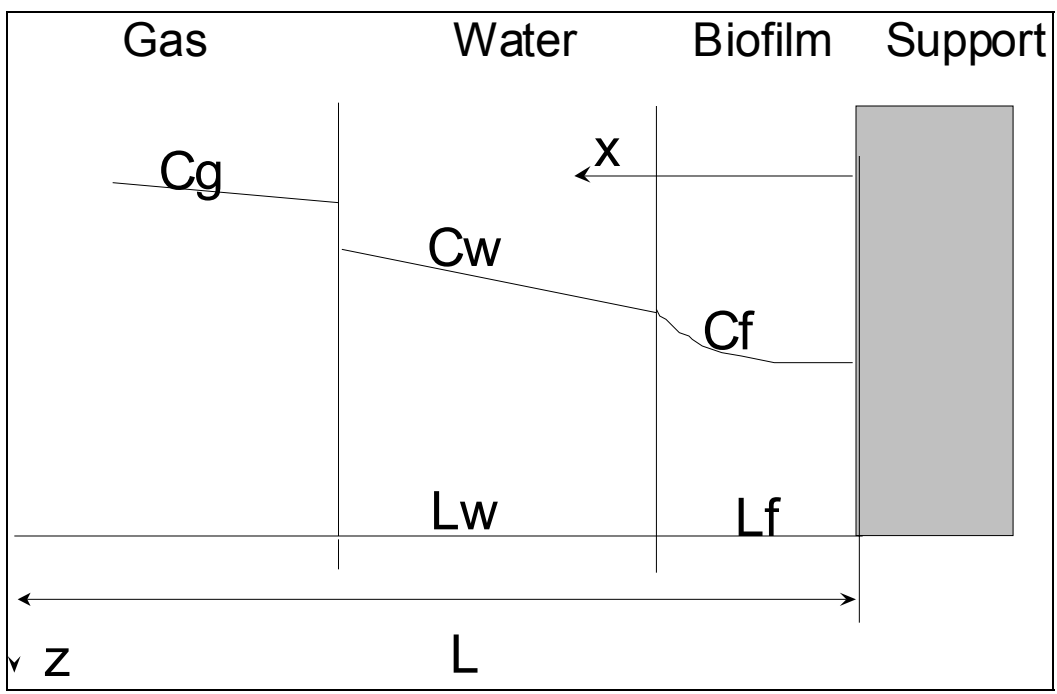

Figure 1. Representation of a biofilm model in a gas-phase biofilter.

Theoretical models of the biofiltration process have been described by several researchers (Ottengraf and Van den Oever 1983; Ottengraf 1986; Van Lith, David, and Marsh 1990; Diks and Ottengraf 1991; Utgikar, Shan, and Govind 1991; Shareefdeen et al. 1993; Ockeloen, Overcamp, and Grady 1996). Because of the complexity of the system, various assumptions were used to simplify the modeling. Commonly used assumptions include: the gas and liquid phase concentrations of VOC and oxygen are in equilibrium via Henry's Law; the rate net biomass production is at steady state; biofilm is homogenous; no physiological changes occur because the microorganisms are immobilized rather than suspended. Some researchers simply excluded the external mass transfer resistance from their models (Ottengraf and Van den Oever 1983; Shareefdeen et al. 1993). Most models considered only VOC as the limiting substrate and assumed no oxygen or nutrient limitation. The kinetics for cell growth and VOC degradation have been assumed to be zero order (Ottengraf and Van den Oever 1983; Diks and Ottengraf 1991); first order (Hodge and Devinny 1994; Utgikar, Shan, and Govind 1991); Monod expression (Ottengraf 1986); and Haldane expression (Shareefdeen et al. 1993). Some of these assumptions may be either oversimplified or highly questionable. For example, homogenous biofilms may not exist in biofilters, and zero order kinetics may not be valid for low gas-phase concentrations or VOCs with high Henry's constants. These models were shown to match bench-scale experimental results only when the biokinetic parameters were chosen to fit observed data. Development of state-of-the-art models, which can provide comprehensive process understanding and prediction, is still needed for biofiltration systems similar to those models developed for attached growth systems used for wastewater treatment (Williamson and McCarty 1976a,b; Rittmann and McCarty 1980; Suidan and Wang 1985; Suidan, Rittman, and Traegner 1987; Rittmann and Manem 1992). 
Fundamental experimental studies on biofiltration processes have been concerned mainly with the interfacial mass transfer phenomena, the progression and accumulation of biofilm, the kinetics of microbial transformations, and their interactions. Until now, only a few fundamental experimental studies were reported (Diks and Ottengraf 1991; Diks, Ottengraf, and Vrijland 1994; Hartmans and Tramper 1991; Johnson and Deshusses 1996; Kirchner, Schlacter, and Rehm 1989; and Kirchner, Kramer, and Rehm 1985; Kirchner, Wagner, and Rehm 1992). Kirchner and others (1989 and 1992) investigated the effects of VOC solubility and the oxygen diffusion rate on biofilter performance. They found that the diffusion of oxygen in the biofilm is rate limiting. Based on a short-term (48-hour protocol) test of biofilter elimination capacity for nine VOCs, Johnson and Deshusses (1996) indicated that the elimination capacities are correlated with Henry's constants and that the biofiltration of pollutants with dimensionless Henry's constant larger than $10^{-2}$ is difficult. Hartmans and Tramper (1991) studied mass transfer resistance in a biotrickling filter by investigating the effect of the liquid phase flow rate on dichloromethane removal. They found that the biofiltration process was mass transfer limited. A similar study on ammonia treatment by Smits, Ottengraf, and van den Heuvel (1995) showed that gas-liquid mass transfer was not rate limiting. No comprehensive study has been reported, however, on how biofilm structure and some fundamental parameters, such as Henry's constant, affect mass transfer and kinetics in gasphase biofilters. Unlike the case of wastewater treatment biofilm systems, biofilters for waste gas treatment are not saturated. A liquid layer may not be distinguishable outside the biofilm, and direct mass transfer to the nonwetted biofilm may occur. Figure 2 shows a more realistic schematic of a biofilm structure in biofilters. Mass transfer under this kind of biofilm configuration has not been well understood. Recently, several in situ technologies, such as microelectrode techniques and scanning confocal laser microscope (SCLM), have been used successfully to study the internal structures and functions of biofilms in wastewater treatment (Zhang 1994; Caldwell, Korber, and Lawrence 1992). These technologies will also be very useful tools for studying biofilms in the biofiltration system.

Another important topic that needs to be better understood in biofilter studies is the dynamics of biomass growth. Clogging of trickle bed biofilters due to excess biomass growth appears to be a serious operational problem (Van Lith, David, and Marsh 1990; Holubar, Andorfer, and Braun 1995). Periodic fluidization or backwashing was found to be an effective biomass management strategy for maintaining effective reactor efficiency and controlling headloss (Smith et al. 1994 and 1995; Sorial et al. 1994b). Diks, Ottengraf, and Vrijland (1994) indicated that a biological equilibrium or no net biomass accumulation can be achieved after 200 days of operation in a trickling bed biofilter, which may be related to the establishment of a certain microbial population and the use of a 
high liquid recirculating rate. Others reported ways of preventing clogging that include the addition of high concentrations of salts (Diks, Ottengfraf, and Vrijland 1994) and nutrient limitation (Holubar, Andorfer, and Braun 1995).

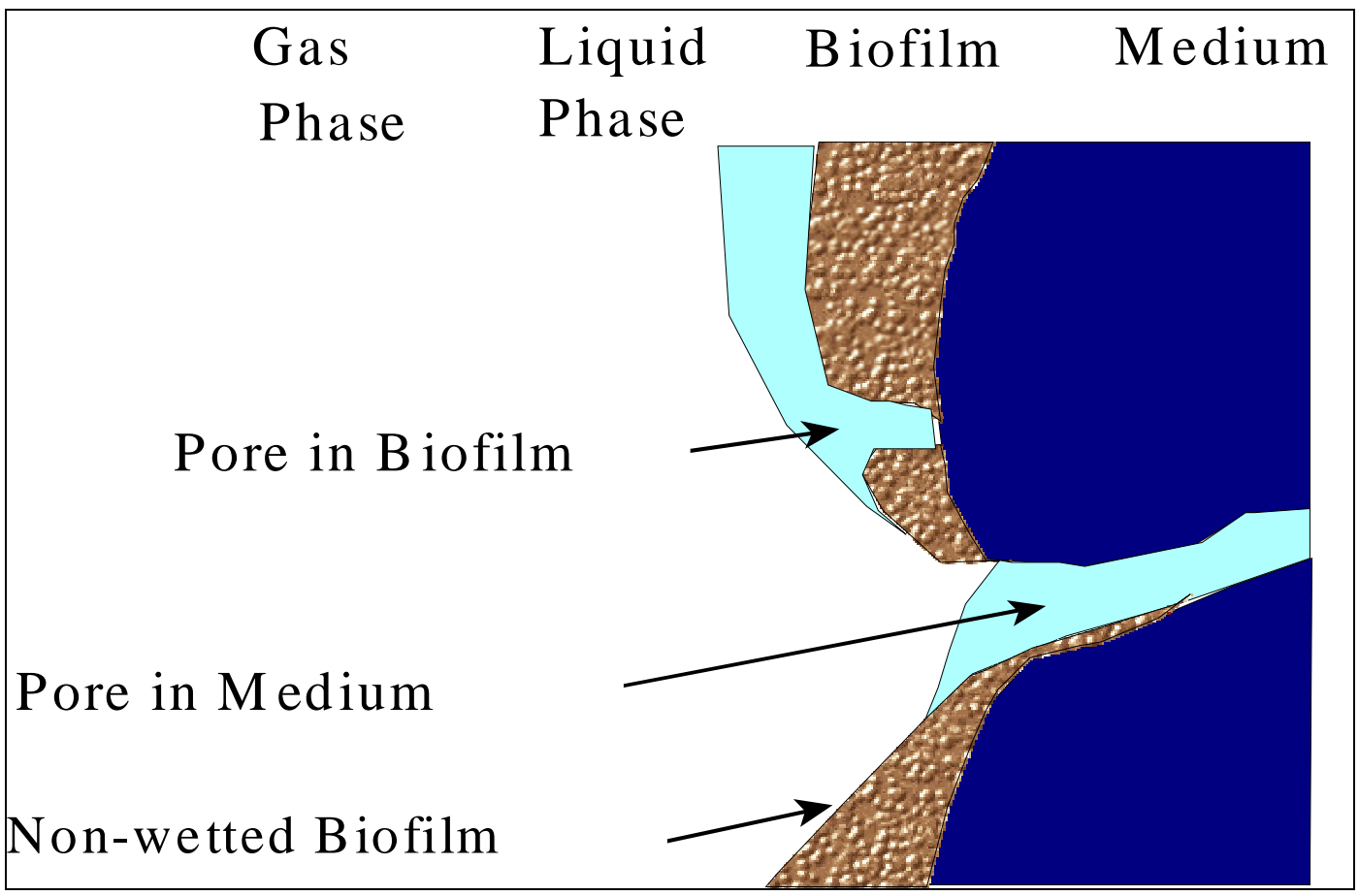

Figure 2. Representation of an unsaturated biofilm in a gas-phase biofilter. 


\section{Materials and Methods}

\section{Experimental Apparatus}

\section{Biofilters}

The experimental apparatus during the first 683 days of the operation consisted of two independent, parallel biotrickling filters. Two identical biofilters were constructed for a total, after 683 days, of four biofilters used in this study. Figure 3 shows a schematic diagram of the experimental system. Each reactor was constructed of seven circular glass sections (Ace Glass Inc., Vineland, NJ) with an internal diameter of $3 \mathrm{in}$. $(76 \mathrm{~mm})$ and a total length of $4 \mathrm{ft}(122 \mathrm{~cm})$. The sections were connected with high-pressure (75 psi [516.75 kPa]) clamps. Each section was equipped with a sampling port that extended to the center of the column. All biofilters were placed in a constant temperature chamber. Temperature in this chamber could be controlled in the range of 41 to $104{ }^{\circ} \mathrm{F}\left(5\right.$ to $40{ }^{\circ} \mathrm{C}$ ). Throughout this study, the temperature was maintained at $80^{\circ} \mathrm{F}\left(27^{\circ} \mathrm{C}\right)$.

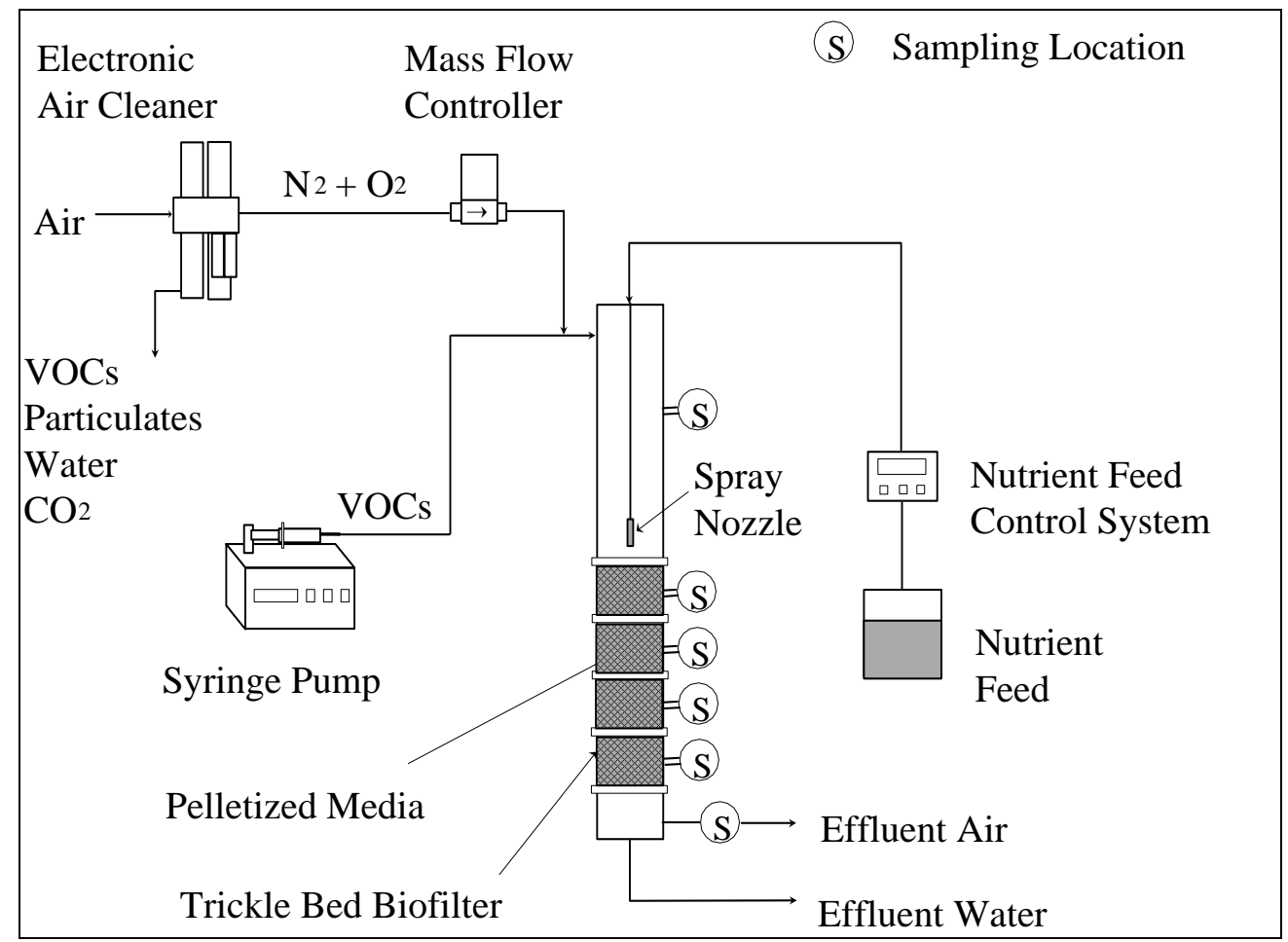

Figure 3. Schematic of the biotrickling filter system. 
When in operation, the air supplied to the biofilters was purified (complete removal of water vapor, oil droplets, $\mathrm{CO}_{2}$, VOCs, and particles) by passing through an electronic air cleaner (Balston \#75-62 FT-IR Purge Gas Generator, Haverhill, MA). After purification, the airflow to each biofilter was controlled by mass flow controllers (MKS Instruments, Andover, MA). The liquid VOC was injected with a syringe pump (Harvard Apparatus, Holliston, MA) into the air stream where it was vaporized and entered the biofilter through the topmost port. The nutrient feed was delivered from a 20-L feed tank by a Micropump (Cole-Parmer, Vernon Hills, IL) into each biofilter through a spray nozzle (Nozzle Systems, Lumark \#30, Winston, GA). A solenoid valve and a programmable logic controller (Eagle Signal, Gurnee, IN) controlled the amount of nutrient delivered. The experimental apparatus consisted of two nutrient delivery systems, each providing nutrient feed to two biofilters.

Each biofilter was packed with 6-mm diatomaceous earth pellets (Celite R-635 Bio-catalyst Carrier, Celite Corp., Lompoc, CA) to a depth of about $61 \mathrm{~cm}$. The media depth varied and increased slightly to $66 \mathrm{~cm}$ with biomass accumulation during this study. The selection of this packing medium was based on a previous study by Sorial et al. (1995). The top two sections of each reactor were free of media to provide sufficient space to fluidize the media during backwashing. The biofilters were operated in a co-current mode with both the air and nutrient flows directed downward throughout this study, except during the study of the effect of flow patterns on biofilter performance using co-current and countercurrent liquid and gas flows.

\section{Backwash System}

The biofilter apparatus was also equipped with a water and air backwash system for biomass management. Figure 4 shows schematic of the backwash system, which contained a cart on which were mounted three 20 -L tanks and a circulation pump (\#T415N14 1HP centrifugal pump, Gelber Industries, Aston, PA). When in use, the two outside tanks were initially filled with $18 \mathrm{~L}$ (three column volumes) of backwash water. The nutrient solution that has the same compositions as the feed to the biofilters was used as the backwash water in order to eliminate both osmosis effects on the attached biomass and nutrient loss within the media. Clean water was passed upwards from the clean water supply tank through the column achieving 60 to 80 percent fluidization. Compressed air was sometimes introduced with the water at the beginning of the backwash cycle to

help break and scour the media. The water was then allowed to recycle for a time (usually for 1 hour). Finally, the recycle was shut off and $18 \mathrm{~L}$ of clean nutrient solution was passed through the column as a rinse. 


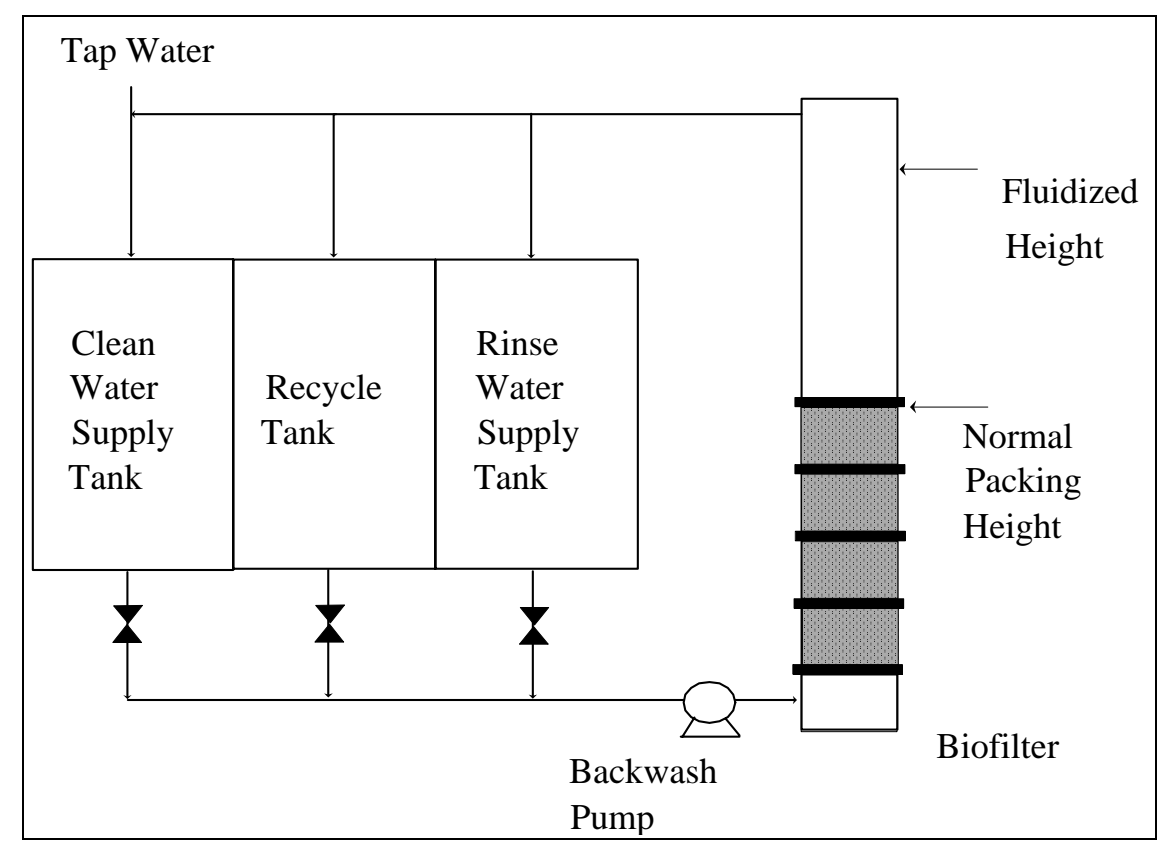

Figure 4. Schematic of the backwash system.

\section{Materials}

\section{Model VOCs}

Most of the research was conducted using diethyl ether $\left(\mathrm{C}_{2} \mathrm{H}_{5} \mathrm{OC}_{2} \mathrm{H}_{5}\right)$ as the model VOC. This compound was selected mainly because of its prevalence in wastewater emanating from the water dry process at the Radford (VA) Army Ammunition Plant (RAAP). Diethyl ether has a boiling point of $35^{\circ} \mathrm{C}$, a vapor pressure of $442 \mathrm{~mm}$ mercury $(\mathrm{Hg})$ at $20^{\circ} \mathrm{C}$, a high solubility in water of $69 \mathrm{~g} / \mathrm{L}$ at $20{ }^{\circ} \mathrm{C}$ and a dimensionless Henry's Constant of 0.034 at $25^{\circ} \mathrm{C}$. Some other VOCs of environmental concern (e.g., toluene, hexane and butanol) were used in the study of the effect of Henry's constant. Their properties will be summarized later in Chapter 8.

\section{Bacterial Culture}

The first two biofilters were seeded with an acclimated enriched aerobic microbial culture to treat ethyl ether. The microbial seed was initially taken from a bench-scale activated sludge system receiving 2,4-diamine toluene, ethanol, acetic acid, and diethyl ether. This enriched biomass in the two biofilters was used for seeding all four biofilters later in all the experiments when using ether as a model VOC. For the study of the effect of Henry's constant, mixed liquor taken from a local wastewater treatment plant was used as the seed culture. 


\section{Nutrient Solution}

The nutrient solution used in this study contained all the macro- and micronutrients and the buffers needed for cell growth and for maintaining $\mathrm{pH}$. The nutrient feed was prepared using deionized water and nitrate and phosphate salt, and four different concentrated nutrient solutions, which include Stock Salt Solution, Iron Stock Solution, Stock Vitamin Solution, and Buffer Solution (1M $\mathrm{NaHC}_{2} \mathrm{O}_{3}$ ). A typical composition of various components in the feed, except for the nitrate and phosphate concentrations, is listed in Table 1. The concentration of phosphorus was kept at $13.2 \mathrm{mgP} / \mathrm{L}$ throughout this study except during the study of phosphorous effect (Chapter 9$)$. It is noteworthy that nitrate $\left(\mathrm{NO}_{3}-\right)$ was selected as the nutrient nitrogen source in this study. This is mainly because of the superior biomass characteristics attributed to nitrate over ammonia as reported by Smith et al. (1994). The concentration of nitrate in feed varied from 34 to $4,000 \mathrm{mgN} / \mathrm{L}$ based on the objective of each study.

Table 1. Concentration of components in the nutrient feed (except for nitrate and phosphate).

\begin{tabular}{cc}
\hline Component & $\begin{array}{c}\text { Concentration } \\
\text { ( } \mathbf{m g} / \mathbf{L})\end{array}$ \\
\hline $\mathrm{B}^{+3}$ & 0.0005 \\
$\mathrm{CO}_{3}^{-2}$ & 34.3 \\
$\mathrm{Ca}^{+2}$ & 0.2699 \\
$\mathrm{Cl}^{-1}$ & 1.7947 \\
$\mathrm{Co}^{+2}$ & 0.0026 \\
$\mathrm{Cu}^{+2}$ & 0.0028 \\
$\mathrm{Fe}^{+3}$ & 0.0159 \\
$\mathrm{~K}^{+1}$ & 1.7427 \\
$\mathrm{Mg}^{+2}$ & 0.4338 \\
$\mathrm{Mn}^{+2}$ & 0.0049 \\
$\mathrm{Mo}^{+6}$ & 0.0042 \\
$\mathrm{NH}_{4}^{+1}$ & 0.0007 \\
SO & -2 \\
$\mathrm{Zn}^{+2}$ & 4.28 \\
p-Aminobenzoic Acid & 0.0058 \\
Biotin & 0.0011 \\
Cyanocobalamin (B 12$)$ & 0.0004 \\
Folic Acid & 0.00002 \\
Nicotinic Acid & 0.0004 \\
Pantothenic Acid & 0.0011 \\
Pyriodoxine Hydrochloride & 0.0011 \\
Riboflavin & 0.0023 \\
Thiamin Hydrochloride & 0.0011 \\
Thioctic Acid & 0.0011 \\
\hline & 0.0011 \\
\hline
\end{tabular}




\section{Analytical Methods}

\section{Gas-Phase Analysis}

Critical measurements for the gas phase include influent and effluent concentrations of VOCs, $\mathrm{CO}_{2}$, oxygen, and headloss.

- Ether concentrations: Gas-phase samples for VOC analysis were taken with gas tight syringes (Hamilton Co., Reno, NV) through low bleed and high puncture tolerance silicone gas silicone gas chromatograph (GC) septa (Supelco, Inc., Bellefonte, PA). These septa were installed in each sampling port located along the reactor length and replaced every week. The gas phase was analyzed for ether using a GC (HP 5890, Series II, Hewlett-Packard, Palo Alto, CA) equipped with a flame ionization detector (FID) (Hewlett-Packard, San Fernando, CA). Separation was done by using a 2-mm inside diameter (ID), 1.83-m glass column packed with 5 percent Carbowax on a 60/80 Carbopack B-DA (Supelco, Inc., Bellefonte, PA). The GC oven temperature was programmed from 50 to $120^{\circ} \mathrm{C}$ at $25^{\circ} \mathrm{C} / \mathrm{min}$ with a 0.7 -min hold at $120{ }^{\circ} \mathrm{C}$. Nitrogen was used as the carrier gas. The sample injection volume was 0.5 $\mathrm{ml}$ and the detection limit for this method was $0.1 \mathrm{mg} / \mathrm{L}$ for ether.

- Other VOCs: Gas-phase analysis for toluene, hexane, and butanol during the study of the effect of Henry's constants was conducted using the same GC, detector, and type of column as for ether analysis. The only difference was that the GC oven temperature was programmed from 120 to $170{ }^{\circ} \mathrm{C}$ at $40{ }^{\circ} \mathrm{C} /$ min with a 2.75 -min hold at $170^{\circ} \mathrm{C}$.

- Carbon dioxide and oxygen partial pressure: Determined using an HP 5890, Series II GC equipped with a thermal conductivity detector (TCD). A 3.2-mm ID, 3-m steel column packed with 45/60 molecular sieve (Hewlett-Packard, San Fernando, CA) was used in series with a 3.2-mm ID, 1.8-m steel column packed with 80/100 Hayesep Q (Hewlett-Packard) for the analysis of gas composition. The GC oven temperature was programmed from 50 to $80{ }^{\circ} \mathrm{C}$ at $10^{\circ} \mathrm{C} / \mathrm{min}$ with a 3.2 -min hold at $50{ }^{\circ} \mathrm{C}$ and a 1.5 -min hold at $80^{\circ} \mathrm{C}$. Helium served as the carrier gas at a flow rate of $30 \mathrm{~mL} / \mathrm{min}$, and the TCD detector was used with helium make-up gas at a flow rate of $35 \mathrm{~mL} / \mathrm{min}$. The sample injection volume was $2 \mathrm{ml}$.

- Headloss in the biofilter: Measured with a manometer (Dwyer Instruments, Inc. Michigan City, IN) and noted daily.

\section{Liquid Phase Analysis}

The liquid phase was analyzed for VOCs, inorganic carbon, organic carbon, ammonia and nitrate nitrogen, total phosphorus, volatile suspended solids (VSS), 
$\mathrm{pH}$. Liquid effluent was collected at the bottom of the reactors using a 1-L beaker.

- Ether concentrations: Ether in the liquid phase was initially analyzed by chromatographic separation on a 30-m megabore column (DB 624, J\&W Scientific, Folsom, CA) using an HP 5890, Series II GC equipped with a liquid sample concentrator (LSC 2000, Tekmar, Cincinnati, OH) and a photoionization detector (PID) (Model 4430, OI Corp., College Station, TX). The 5-ml samples were injected into the GC through the liquid sample concentrator accessory or the purging trap. GC oven temperature was programmed from 35 to $150{ }^{\circ} \mathrm{C}$ at $10^{\circ} \mathrm{C} / \mathrm{min}$ with a 10 -min hold at $35^{\circ} \mathrm{C}$ and a 4.5 -min hold at $150{ }^{\circ} \mathrm{C}$. Helium was used as the carrier gas at a flow rate of $8 \mathrm{~mL} / \mathrm{min}$. The detection limit for this method was $0.4 \mathrm{mg} / \mathrm{L}$ for ether. Since ether concentration in the liquid phase was mostly above $1 \mathrm{mg} / \mathrm{L}$, the analysis was later conducted using the same GC, detector, and column for ether analysis in the gas phase. GC oven temperature was programmed from 50 to $190{ }^{\circ} \mathrm{C}$ at 25 ${ }^{\circ} \mathrm{C} / \mathrm{min}$ with a 0.9 -min hold at $190{ }^{\circ} \mathrm{C}$. The injection volume was $1 \mathrm{~mL}$, and the detection limit for this method was $0.1 \mathrm{mg} / \mathrm{L}$ for ether.

- Other VOCs: Liquid phase analysis for toluene, hexane, and butanol during the study of the effect of Henry's constants was conducted using the same GC, detector, and type of column as used for ether analysis in the gas phase. The only difference was that the GC oven temperature was programmed from 120 to $190{ }^{\circ} \mathrm{C}$ at $40{ }^{\circ} \mathrm{C} / \mathrm{min}$ with a 4.0 -min hold at $190{ }^{\circ} \mathrm{C}$.

- Soluble organic and inorganic carbon content: Determined using a Shimadzu dissolved organic carbon (DOC) 5000 Analyzer (Shimadzu Corp., Tokyo, Japan). Samples were filtered through $0.22 \mathrm{M}$ organic free filters.

- Nitrate concentrations: Determined according to Method 4500-NO3 A of the Standard Methods (APHA 1992), using a Hewlett-Packard diode array spectrophotometer model 8452A. Samples for ammonia and nitrate nitrogen were filtered through $0.45 \mathrm{~mm}$ Magna Nylon filters (Micron Separation, Inc., Westboro, MA) prior to analysis.

- Ammonia concentration: Little ammonia was expected in the liquid effluent in this study since nitrate was used as the nitrogen nutrient source. Ammonia was measured occasionally to analyze the nitrogen balance. The analysis was performed by the electrode method according to the Standard Methods (APHA 1992).

- Total phosphorous: Analyzed according to Hach method \# 8190 (Hach 1992).

- $\mathrm{pH}$ : Analyzed using a 720 A Orion $\mathrm{pH}$ meter according to Method 4500-H+ B of the Standard Methods (APHA 1992). 


\section{Biofilm and Biomass Analysis}

- Total Suspended Solids (TSS): Measured on a weekly basis for the backwash water and occasionally for biofilm taken from the biofilters, according to Method 2540 D of the Standard Methods (APHA 1992).

- VSS: Measured on a weekly basis for the backwash water and occasionally for biofilm taken from the biofilters, according to Method $2540 \mathrm{E}$ of the Standard Methods (APHA 1992).

- Microscopic observation: An optical microscope was used to observe the general morphology of microorganism population and biofilm structures.

- SCLM observation: SCLM allows horizontal and vertical optical thin sectioning of hydrated biofilms (Caldwell, Korber, and Lawrence 1992a). It can also differentiates the viable cells, dead cells, matrix or spaces of a biofilm by utilizing different fluorescent markers (Caldwell, Korber, and Lawrence 1992b; Surman et al. 1996). In this study, a scanning confocal laser system (MRC1000, Biorad, Ltd., Hercules, CA) mounted on a Zeiss Axiophot microscope was used to examine viable biomass distribution along the depth of the biofilms taken from the biofilters. A Live/Dead Baclight bacterial viability kit (Molecular Probes Inc., Eugene, OR) was used as a fluorescent marker. The detailed procedure can be seen in Ebihara's work (1999).

- Microelectrode technology: The microelectrode technique is one of the most powerful analytical technologies that has been developed for characterizing chemical and metabolic activity gradients in biofilms (Zhang 1994). Due to their small size, microelectrodes allow the investigator to measure concentration change over the interval of micrometers and have been used for oxygen, sulfide, $\mathrm{pH}$, and redox potential analysis within biofilms ( $\mathrm{Fu} 1993$; $\mathrm{Yu}$ and Bishop 1997). In this study, an oxygen microelectrode was used to conduct in situ measurement of the distribution of oxygen within the biofilms. A detailed description of the method is presented in Chapter 7.

- Phospholipid analysis: Because lipid-bound phosphate exists only in the membrane of viable biomass and each cell has about the same amount of this type of phosphorus, phospholipid analysis has been used to represent the amounts of viable cells and biological activities in biomass. The analysis procedure was based on the method described by Findlay, King, and Watling (1989) and Du (1999).

- Biofilm thickness: Determined mostly through the measurement of biofilm volume. The procedures involved taking 20 medium biofilm pellets, saturating them with water, and measuring the volume of the saturated biofilm pellets using graduated cylinders. The biofilm pellets were then placed in a 550 ${ }^{\circ} \mathrm{C}$ oven for $60 \mathrm{~min}$. The clean pellets were again saturated with water, and the volume of the clean pellets was measured. The biofilm thickness was determined by calculating the average radius difference between the biofilm pellets and clean pellets, assuming the pellets are spherical. During the 
study of oxygen distribution within the biofilms, the biofilm thickness was measured using the microelectrode (see Chapter 7).

- Biomass yield (gVSS/gCOD removed): Observed net biomass yield was determined by measuring the amount of VSS washed out through backwashing. The biomass lost in the effluent liquid was also considered. However, it is negligible compare to that lost through backwashing. The amount of biomass washed out divided by the amount of VOC removed (represented by Chemical Oxygen Demand [COD]) is the observed biomass yield, assuming all the accumulated biomass has been removed through backwashing. This assumption was reasonable since the medium volume was relatively stable throughout this study. It is still possible, however, that this method may slightly underestimate the yield since some of the produced biomass may accumulate inside the porous medium.

- Water content in biofilms: Determined by measuring the difference between the wet weight and the dry weight (in $103^{\circ} \mathrm{C}$ oven overnight) of biofilm samples.

\section{Mathematical Model}

\section{Dynamic Model}

A comprehensive mathematical model was developed to describe the fundamental VOC degradation processes occurring in a biotrickling filter in this study. The simultaneous consumption of one limiting organic substrate (VOC pollutant), one limiting nutrient (nitrate) in nonhomogeneous biomass (active and inactive) by one type of microbial species, is mathematically formulated in the general model. Microbial growth is described by Monod kinetics. Decay and endogenous respiration were also considered. Biomass detachment was assumed to be proportional to the square of the biofilm thickness. Three phases were included in the system description: biofilm, water, and gas phases. All processes were assumed to be uniform across the biofilter cross section, and wall and end effects were neglected. The temperature in the biofilter and the physical properties of the gas and dissolved compounds were assumed to be constant. The dynamic equations describing mass transport in the reactor, and mass transport and reaction in the biofilm were derived and solved numerically using two geometric dimensions, $\mathrm{x}$ perpendicular to the biofilm support and $\mathrm{z}$ along the biofilter. In the formulation of the biofilter mass balance equations, the following assumptions were made: the biofilm is a stagnant phase; axial diffusion is negligible; all kinetic parameters and the bacterial density are constant along the biofilter; and no contaminant degradation occurs in the water and gas phases. The porous media of the packed bed reactor was defined as a bed of 
regularly packed equivalent spheres in dimensions having the same volume as the packing pellets. Due to the random packing, the flow path for the waste gas was considerably torturous, and the gas was assumed to be well mixed across the biofilter cross section. Consequently, the concentration of contaminant in the bulk gas was considered to be uniform at any given axial position. The goal of the model was to calculate the values of the significant system variables in the reactor. The VOC diffusivity in the biofilm $\left(D_{f}\right)$ was assumed to be a fraction $\left(r_{d}\right)$ of the diffusivity in water $\left(D_{w}\right)$. The biofilm representation is shown in Figure 1. The representative equations of the simplified version of this model, which only considers organic substrate as a limiting factor, are as follows:

$$
\begin{gathered}
\frac{C_{f}}{t}=D_{f} \frac{{ }^{2} C_{f}}{x^{2}}-\frac{\mu_{m} X_{f}}{Y}\left[\frac{C_{f}}{K_{s}+C_{f}}\right] \quad 0<x<L_{f} \\
\frac{C_{w}}{t}=D_{w} \frac{{ }^{2} C_{w}}{x^{2}} \quad v_{w} \frac{C_{w}}{z} \quad L_{f}<x<L_{f}+L_{w} \\
\frac{C_{g}}{t} \quad u_{0} \frac{C_{g}}{z} \quad J_{w} a_{f},\left.\quad J_{w} \quad D_{w} \frac{C_{w}}{x}\right|_{x} L_{f} L_{w} \\
@ x \quad L_{f}, \quad C_{f} \quad C_{w},\left.\left.\quad D_{f} \frac{C_{f}}{x}\right|_{x} L_{f} \quad D_{w} \frac{C_{w}}{x}\right|_{x} L_{f} \\
@ x \quad L_{f} \quad L_{w}, \quad C_{g} \quad H C_{w}
\end{gathered}
$$

where $C_{f}, C_{w}$, and $C_{g}$ are the VOC concentrations in biofilm, water, and gas respectively; $L_{f}$ and $L_{w}$ are the thickness of the biofilm and the water layer; $\mu_{m}$ is the maximum bacterial growth rate; $Y$ is the yield coefficient; $K_{s}$ is the Monod saturation constant; $X_{f}$ is the film bacterial density; $v_{w}$ is the water phase velocity; $u_{0}$ is the gas approach velocity; $a_{f}$ is the surface area available for contaminant diffusion into the biofilm; $J_{w}$ is the flux of VOC into the water layer, and $H$ is the contaminant's Henry's constant. More detailed descriptions and discussions of this model can be found in Alonso (1999) and Alonso et al. (1997a, 1998, and 2000).

\section{Henry's Constant and Oxygen Limitation}

Under aerobic conditions, oxygen serves as the primary electron acceptor in VOC oxidation and biomass growth. Oxygen has been found to be flux limiting at 
high influent VOC concentration (Kirchner, Wagner, and Rehm 1992). Williamson and McCarty $(1976 a, b)$ proposed a relationship for determining whether the reaction within a biofilm is flux limited by a substrate or oxygen. The oxygen limitation within the biofilm will occur if:

$$
C_{w, s}>\frac{D_{o} v_{s} M W_{s}}{D_{s} v_{o} M W_{o}} C_{w, o}
$$

where $C_{w, o}$ and $C_{w, s}$ are concentrations of oxygen and substrate in the liquid film or at the biofilm surface, $D_{w, o}$ and $D_{w, s}$ are the diffusion coefficients of oxygen and substrate in liquid phase or in the biofilms, $v_{o}$ and $v_{s}$ are the stoichiometric reaction coefficients, $M W_{o}$ and $M W_{s}$ are molecular weights of oxygen and substrate. Assuming Henry's law applies at the liquid-gas interface, this criterion for oxygen limitation within the biofilm in a gas-phase biofilter can be related to Henry's constant as:

$$
C_{g, s}>\frac{D_{w \rho} v_{s} M W_{s}}{D_{w, s} v_{o} M W_{o}} C_{w \rho} H
$$

where $C_{g, s}$ is the VOC concentration in the gas phase $(\mathrm{mg} / \mathrm{L})$. VOC concentration in gas phase is usually expressed as partial pressure or ppmv. Assuming ideal gas conditions, the expression (Eq 8) becomes:

$$
p_{s}>\frac{10^{3} D_{w, \rho} v_{s} R T}{D_{w, s} v_{o} M W_{o}} C_{w, \rho} H
$$

where $p_{s}$ is the VOC partial pressure in the gas phase (ppmv), $R$ is the gas law constant $\left(0.082 \mathrm{atmL} / \mathrm{mol}{ }^{\circ} \mathrm{K}\right)$, and $T$ is absolute temperature $\left({ }^{\circ} \mathrm{K}\right)$. This criterion was used in this study to assess the possibility of oxygen limitation in biotrickling filters and to help understanding the experiment results. 


\section{Influence of Major Operating Parameters}

Operating parameters such as VOC loading, retention time, and water content play key roles in biofilter performance. Determining the influence of these parameters is essential for process understanding, modeling, and design. In this chapter, emphasis is placed on identifying principle operating parameters that affect biofiltration and discussing their influence based on the results of this study. The effects of some of these factors will be discussed in more detail in later chapters.

\section{Start-up and Performance Reproducibility}

Results from this study show that biotrickling filters can be easily started. Throughout this study, the biofilters were started and restarted several times. Each time the biofilters reached steady performance within 1 to 4 weeks depending on start-up conditions such as seed culture and loadings, indicating that biotrickling filters were relatively simple to operate and flexible in use.

The first two biofilters were started up at influent ether concentrations of 67 ppmv, gas flow rates of $6 \mathrm{~L} / \mathrm{min}$ or $8.64 \mathrm{~m}^{3} /$ day, and an empty bed retention time (EBRT) of 25 seconds, resulting in ether loadings of $1.8 \mathrm{~kg} \mathrm{COD} / \mathrm{m}^{3} /$ day. Each biofilter received $1 \mathrm{~L}$ per day of nutrient feed with a nitrate concentration of 67 $\mathrm{mg} \mathrm{NO}$-N/L. The ether removal efficiencies exceeded 99 percent within 2 weeks. During the first 2 months of reactor operation, the performance stability and performance reproducibility between the two columns were examined. Similarity of the ether removal efficiencies and the contaminant profiles along the media depth between Columns A and B during this time indicate that both columns operated and performed in a similar manner. This performance reproducibility was also achieved during the start-up of the four biofilters later in this study as shown in Figure 5. This basic reference was used to properly evaluate and compare the effect of variations in operating parameters on biofilter performance. 


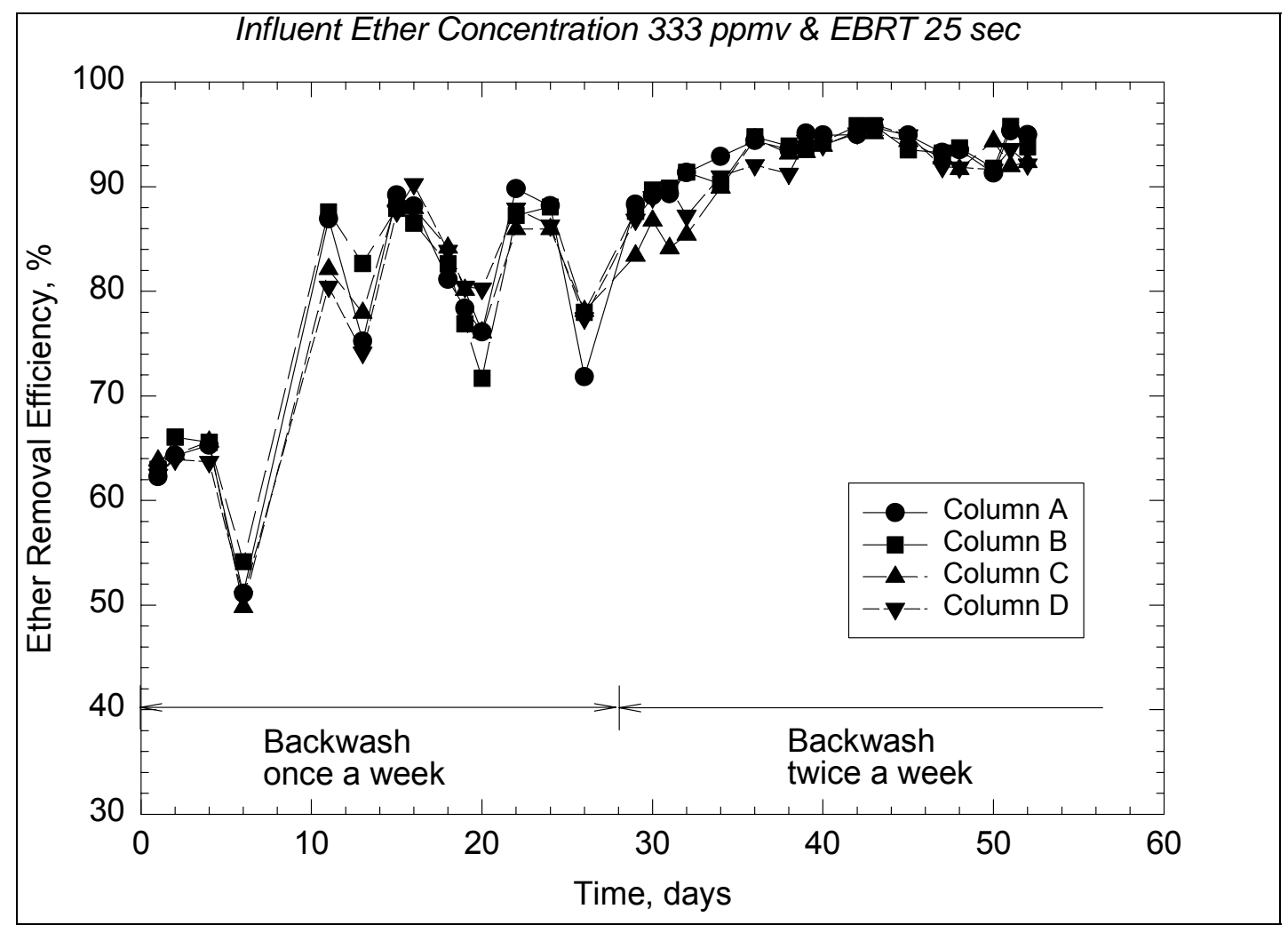

Figure 5. Biofilter performance during start-up of four biofilters at ether loading of $8.9 \mathrm{~kg}$ $\mathrm{COD} / \mathrm{m}^{3} /$ day.

\section{Ether Concentration and Loading}

After the biofilters reached quasi-steady state, biofilter performance under a wide range of influent ether concentrations and organic loading rates was studied. Between days 72 and 521 of operation, the influent concentrations of ether to Columns A and B were varied from $67 \mathrm{ppmv}$ to $400 \mathrm{ppmv}$ which resulted in COD volumetric loading rates ranging from 1.8 to $10.7 \mathrm{~kg} / \mathrm{m}^{3} /$ day. Influent nitrate concentrations were varied from 34 to $2,134 \mathrm{mgN} / \mathrm{L}$. Table 2 summarizes the results. The biofilters were operated at a very low EBRT of $25 \mathrm{sec}$ and a nutrient flow rate of $1 \mathrm{~L} /$ day. The results showed that the summarized biotrickling filters can achieve more than 90 percent ether removal at influent ether concentrations of up to $400 \mathrm{ppmv}$ or the organic loading rate of $10.8 \mathrm{~kg} \mathrm{COD} / \mathrm{m}^{3} / \mathrm{day}$. To achieve this performance, optimal operating conditions are required that relate to the organic loading rate. An influent COD:N ratio of 30:1 and a backwash frequency of once a week for influent COD loading from 1.8 to $7.1 \mathrm{~kg} / \mathrm{m}^{3} /$ day and twice a week for COD loading from 8.9 to $10.7 \mathrm{~kg} / \mathrm{m}^{3} /$ day are recommended. It also can be seen that the biomass yield was only between 0.04 to 0.09 gVSS/gCOD and increased with the increase of influent loadings. The low biomass yield indicates that a high endogenous respiration existed within the 
biofilms. Higher ether elimination capacity is expected when EBRT (see next section) or loading is increased in these biofilters. Biomass control and more frequent backwash may become an operational problem at higher loadings, however.

Table 2. Summary of the results during ether loading variations at EBRT of $25 \mathrm{sec}$.

\begin{tabular}{ccccc}
\hline $\begin{array}{c}\text { Influent Ether } \\
\text { Loading } \\
\text { (kg COD/m/day) }\end{array}$ & $\begin{array}{c}\text { Influent Ether } \\
\text { Concentration } \\
\text { (ppmv) }\end{array}$ & $\begin{array}{c}\text { Average Yield } \\
\text { (gVSS/gCOD) }\end{array}$ & $\begin{array}{c}\text { Ether Removal } \\
\text { Efficiency at Optimal } \\
\text { Conditions* } \\
\text { (\%) }\end{array}$ & $\begin{array}{c}\text { Elimination } \\
\text { Capacity } \\
\text { (kg COD/m } / \text { day) }\end{array}$ \\
\hline 1.8 & 67 & 0.044 & $99.9 \pm 0.1$ & 1.8 \\
3.6 & 133 & 0.039 & $99.0 \pm 2.2$ & 3.6 \\
5.3 & 200 & 0.072 & $98.9 \pm 2.4$ & 5.2 \\
7.1 & 267 & 0.066 & $97.7 \pm 2.6$ & 6.9 \\
8.9 & 333 & 0.084 & $94.0 \pm 4.3$ & 8.4 \\
10.7 & 400 & 0.088 & $90.0 \pm 5.8$ & 9.6 \\
\hline
\end{tabular}

*Optimal conditions: (a) Influent COD:N = 30; (b) backwashing once a week for COD loading from 1.8 to $7.1 \mathrm{~kg} / \mathrm{m}^{3} /$ day and twice a week for COD loading from 8.9 to $10.7 \mathrm{~kg} / \mathrm{m}^{3} / \mathrm{day}$

\section{Airflow Rate or Empty Bed Retention Time}

Empty bed retention time is defined as the empty bed medium volume divided by the airflow rate. Although EBRT overestimates the actual treatment time, it is a commonly used parameter because it is easy to calculate. The actual retention time, which can be defined as the total medium volume multiplied by the medium porosity, is divided by the airflow rate. The porosity of the medium in the two biofilters was measured at 0.34 . So the actual retention time was $8.5 \mathrm{sec}$ for the EBRT of $25 \mathrm{sec}$ used in this study.

The effect of the EBRT on biofilter performance with constant organic loading rates was studied from day 602 to day 683 of the operation. The organic loading rate was kept at $8.9 \mathrm{~kg} \mathrm{COD} / \mathrm{m}^{3}$-day, and the EBRT and influent VOC concentrations were varied by manipulating the gas flow rate. The biofilters were operated at a liquid flow rate of $1 \mathrm{~L} /$ day, a nitrate concentration of $1,067 \mathrm{mg} / \mathrm{L}$, and a backwash frequency of twice a week. Biofilter performance during this period is shown in Figure 6. Table 3 summarizes the results.

The two biofilters were initially operated at an EBRT of 25 sec. Both biofilters achieved 95 percent average ether removal. On day 634, the influent gas flow rates were changed from $6 \mathrm{~L} / \mathrm{min}$ to $3 \mathrm{~L} / \mathrm{min}$ for Column A and $12 \mathrm{~L} / \mathrm{min}$ for Column B, resulting in an EBRT of $50 \mathrm{sec}$ for Column A and $12.5 \mathrm{sec}$ for Column B, respectively. As Figure 6 shows, ether removal efficiency immediately increased to 99 percent on average for Column A and decreased to 89 percent on average 
for Column B. During this same period, some changes were noticed in the biofilters with respect to biomass growth. In Column A, the biofilm pellets were stickier and biomass growth was faster than in Column B. On day 662 of the operation, the influent gas flow rates were further changed from $3 \mathrm{~L} / \mathrm{min}$ to $1.5 \mathrm{~L} / \mathrm{min}$ for Column A and from $12 \mathrm{~L} / \mathrm{min}$ to $18 \mathrm{~L} / \mathrm{min}$ for Column $\mathrm{B}$, resulting in an EBRT of $100 \mathrm{sec}$ for Column A and $8.3 \mathrm{sec}$ for Column B. Again, the ether removal efficiency increased to 99.8 percent on average for Column A and decreased to 84.5 percent on average for Column B. The biomass yield also increased with the increase in retention time. The improvement of biofilter performance with a reduced airflow rate can be attributed to the increase of mass transfer driving force, since lower airflow rates lead to higher EBRTs and influent ether concentrations.

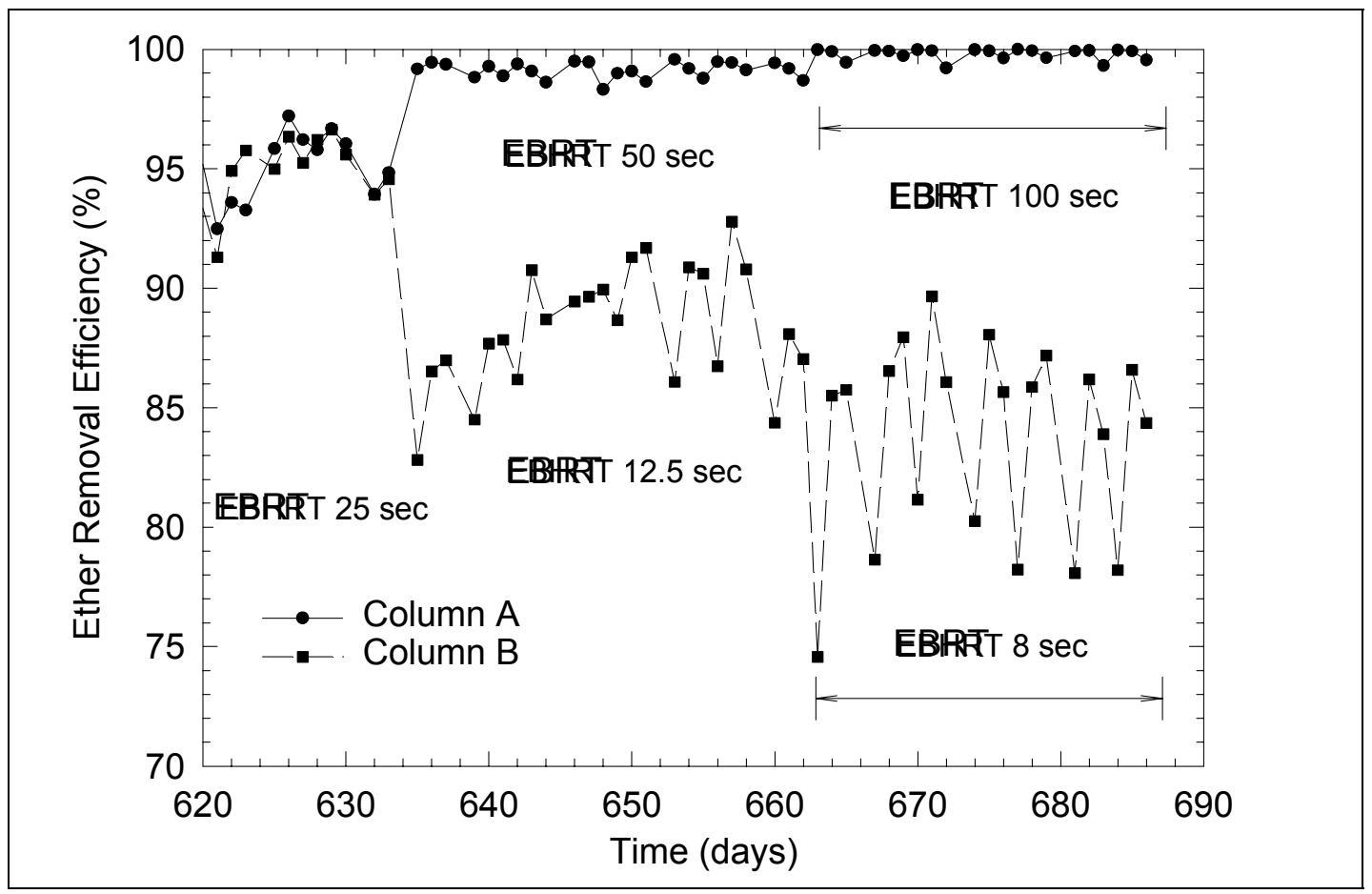

Figure 6. Effect of EBRT on biofilter performance at COD loading of $8.9 \mathrm{~kg} \mathrm{COD} / \mathrm{m}^{3} / \mathrm{day}$.

Table 3. Summary of the results during influent EBRT variations.

\begin{tabular}{rcccc}
\hline $\begin{array}{r}\text { EBRT } \\
(\mathbf{s e c})\end{array}$ & $\begin{array}{c}\text { Influent Air } \\
\text { Flow Rate } \\
\text { (L/min) }\end{array}$ & $\begin{array}{c}\text { Influent Ether } \\
\text { Concentration } \\
\text { (ppmv) }\end{array}$ & $\begin{array}{c}\text { Average Ether } \\
\text { Average Yield } \\
\text { (gVSS/gCOD) }\end{array}$ & $\begin{array}{c}\text { Averal Efficiency } \\
\text { (\%) }\end{array}$ \\
\hline 8.3 & 18.0 & 111 & 0.037 & 84.5 \\
12.5 & 12.0 & 167 & 0.036 & 89.4 \\
25.0 & 6.0 & 333 & 0.065 & 95.1 \\
50.0 & 3.0 & 667 & 0.080 & 99.1 \\
100.0 & 1.5 & 1,333 & 0.120 & 99.8 \\
\hline
\end{tabular}

Ether Loading $8.9 \mathrm{~kg} \mathrm{COD} / \mathrm{m}^{3} /$ day. Backwashing twice a week. 
Generally, EBRT can be increased by either reducing the gas flow rate or increasing the medium volume. In practice, however, the gas flow rate is often difficult to manipulate, and reactor volume becomes the only variable to increase. Larger reactor volume leads to higher cost. Based on the results of this study and considering the cost factor, an optimal EBRT range of $25 \mathrm{sec}$ to $1 \mathrm{~min}$ is recommended.

\section{Airflow Direction}

Biofilter operation can be classified into co-current flow when both gas and nutrient streams are introduced at the top of biofilter and counter-current flow when the gas stream is introduced at the bottom. Most existing studies have shown that co-current flow is superior to counter-current (Sorial et al. 1993a; Devinny, Deshusses, and Webster 1999). The advantage of co-current flow was attributed to better moisture control, nutrient distribution, and less stripping effect. For these reasons the co-current mode was used for the biofilter operation in most of this study. Some studies have shown, however, that there is no difference between biofilter performance under the two flow patterns (Diks and Ottengraf 1991; Hartmans and Tramper 1991). There are also a number of success stories of biofilters operating in a counter-current pattern (Devinny, Deshusses, and Webster 1999). It is still not well understood how different flow patterns affect the biofiltration process. The results from this study have shown that the majority of the biomass was concentrated within the top two sections of the columns and most ether was also removed within these two sections when the biofilters were operated at co-current mode. This uneven utilization of the medium led us to further exploration of the possibility of other operating flow patterns. An experiment was conducted at the end of this study to investigate the effect of the flow pattern on biofilter performance.

Two biofilters were operated at an influent ether concentration of $267 \mathrm{ppmv}$, a liquid flow rate of $1 \mathrm{~L} /$ day, an airflow rate of $6 \mathrm{~L} / \mathrm{min}$ or an EBRT of $25 \mathrm{sec}$, resulting in ether loading of $7.1 \mathrm{~kg} \mathrm{COD} / \mathrm{m}^{3} /$ day. One biofilter (Column A) was operated in co-current mode with both air and nutrient flows directed downward. The other biofilter (Column B) was operated in counter-current mode with airflow directed upward. Figure 7 shows that biofilter performance for the countercurrent column was higher throughout this study. During the first 82 days of operation, both biofilters were backwashed once every 4 weeks. The average ether removal efficiency was 53.7 percent in Column A and 60.3 percent in Column B. The difference was even more significant during the first 2 weeks of each backwash cycle. Between days 83 and 115 of the operation, the backwash frequency was increased to once a week for both reactors. The average ether removal was increased to 72.2 percent in Column A and 82.2 percent in Column B. 


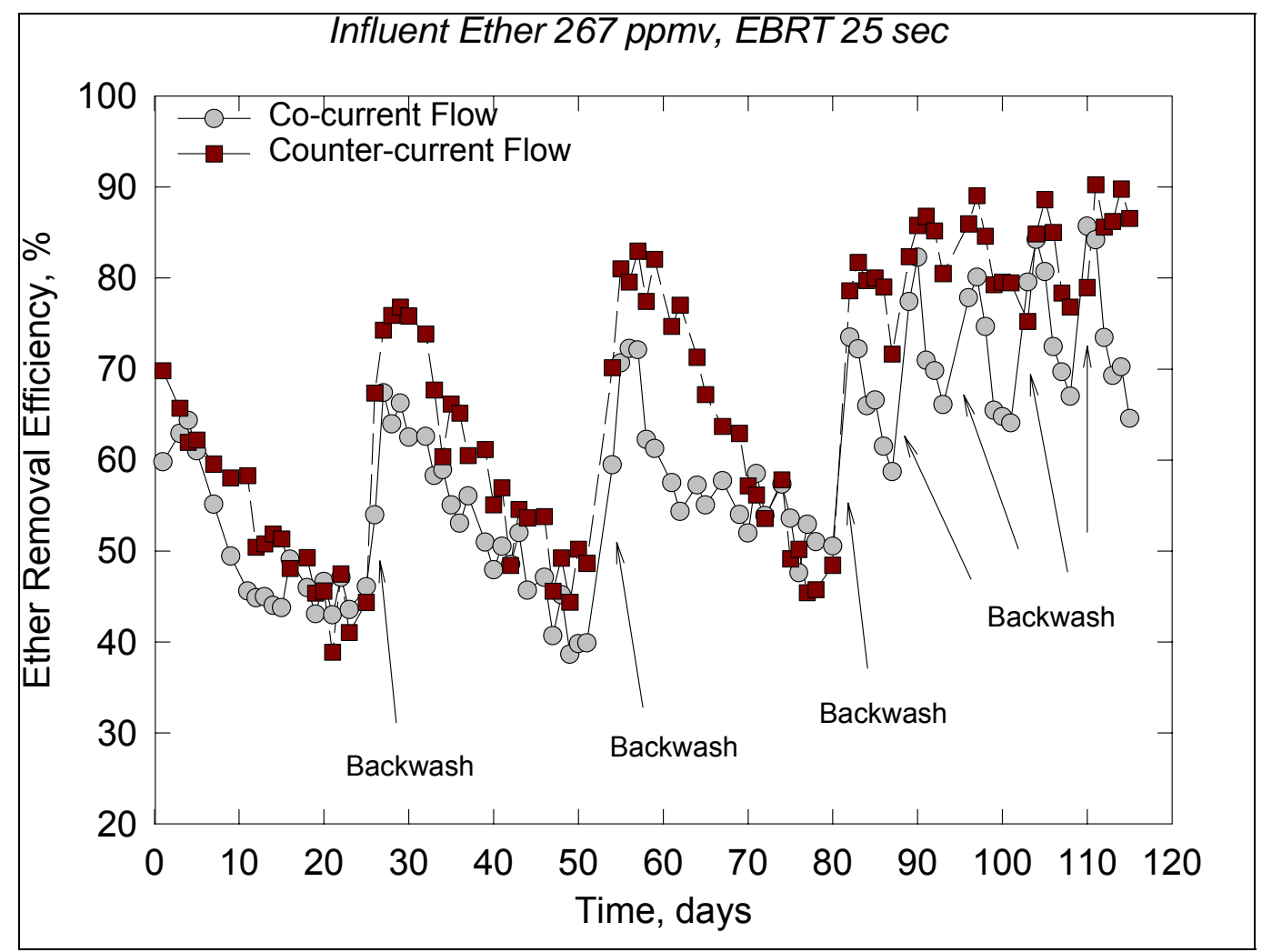

Figure 7. Effect of flow patterns on biofilter performance.

Figure 8 compares typical ether concentration profiles along the medium depth for both biofilters. For Column A with co-current operation, most ether was degraded in the first two sections of the column, while ether removal was more evenly distributed for Column B with counter-current operation. This result is because of the co-current biofilter structure, where both ether and nutrient solution enter the biofilter from the top, leading to a higher active biomass accumulation in the top portion of the column. On the other hand, the active biomass was more evenly distributed along the column in the counter-current biofilter, which leads to better biofilter performance.

The different conclusions obtained in this study when compared to results published by other researchers may also relate to the compound being treated. The counter-current operation is believed to have more stripping effect, resulting in poorer biofilter performance. However, the stripping effect may not be as significant for highly soluble VOCs such as the ether used in this study when compared to less soluble VOCs such as toluene. A few alternating airflow direction systems have been proposed for better control moisture and biomass accumulation (Kinney et al. 1996; Bodker and Rydin 1996). Further study is needed to fully assess the effect of airflow patterns. 


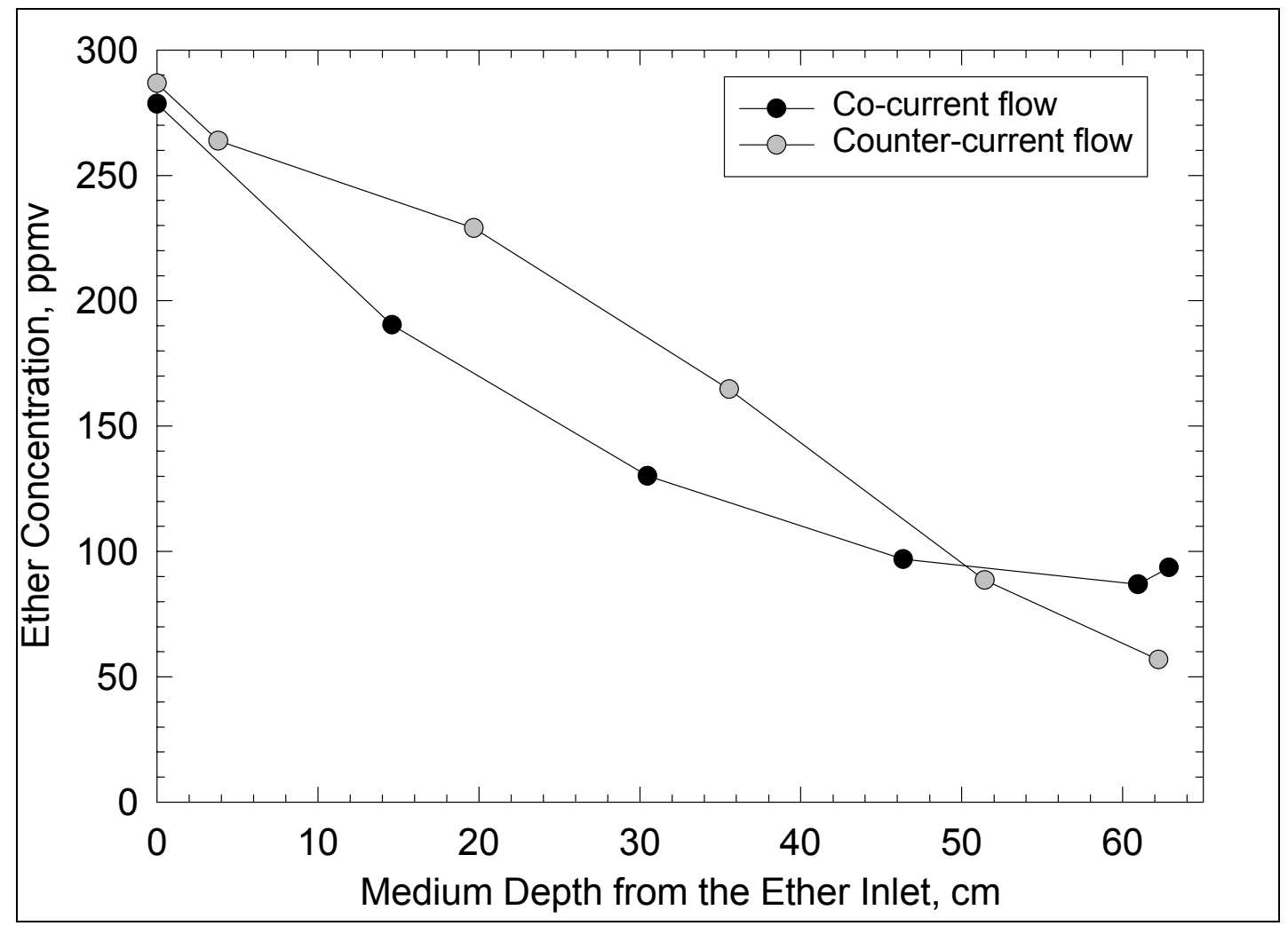

Figure 8. Ether concentration profiles for co-current and counter-current flow.

\section{Liquid Flow Rate}

The liquid phase plays a critical role in both mass transfer processes and biological reactions in biotrickling filters. This study showed that changes in the liquid flow rate have little immediate effect on biofilter performance, suggesting mass transfer resistance through the liquid phase for ether or oxygen was negligible. A higher liquid flow rate gradually leads, however, to an improved biofilter performance through the change of biofilm formation and the improvement of biological activities. The results are presented in detail in Chapter 6 .

\section{Nutrients}

Nutrient supply is essential for maintaining microbial activities in biofilters, particularly in biotrickling filters, which use synthetic packing materials. The effect of nutrients was studied extensively in the research reported here. 


\section{Nitrate}

The diffusion of nitrate was found to be rate limiting for ether removal in the biofilters. An optimum COD:N ratio of 30:1 was recommended based on this study. The role of nitrate is discussed in detail in Chapter 5.

\section{Phosphorus}

The study found that ether removal efficiency was not significantly affected when influent-P concentration was more than $3.3 \mathrm{mgP} / \mathrm{L}$ or influent COD:P ratio was below 6667:1. Limiting phosphorus also may not be a practical way to control biomass growth and reduce backwash frequency. The study on the effect of phosphorus is presented in detail in Chapter 9.

\section{Micro-nutrients}

Besides nitrate and phosphate, the nutrient solution used in this study also contained all the micro-nutrients (salts and vitamins) and buffers needed for cell growth and for maintaining $\mathrm{pH}$ levels. The composition of these micro-nutrients in the feed is listed in Table 1. The supply of these micro-nutrients was assumed sufficient. This assumption was also verified when the two biofilters were operated at the high COD loading rate of $8.9 \mathrm{~kg} / \mathrm{m}^{3} /$ day. When the concentration of these micro-nutrients was quadrupled for 2 weeks, no change in biofilter performance was observed.

\section{Backwash}

The results from this study indicated that periodic backwash is an effective strategy for removing excess biomass and to maintain an efficient long-term operation. Figure 9 shows a typical performance during backwash cycles. The biofilter performance is shown to have dropped significantly immediately after backwashing followed by a recovery to optimal performance within 1 day. Removal of VOCs remained stable for a certain period of time depending on organic loading. Biomass accumulation caused the performance to drop significantly at the end of the cycle. With another backwash, the performance recovered. The causes for the initial drop in performance after backwashing are presented in Chapter 6, and the study on optimal backwash strategies is discussed in Chapter 9. 


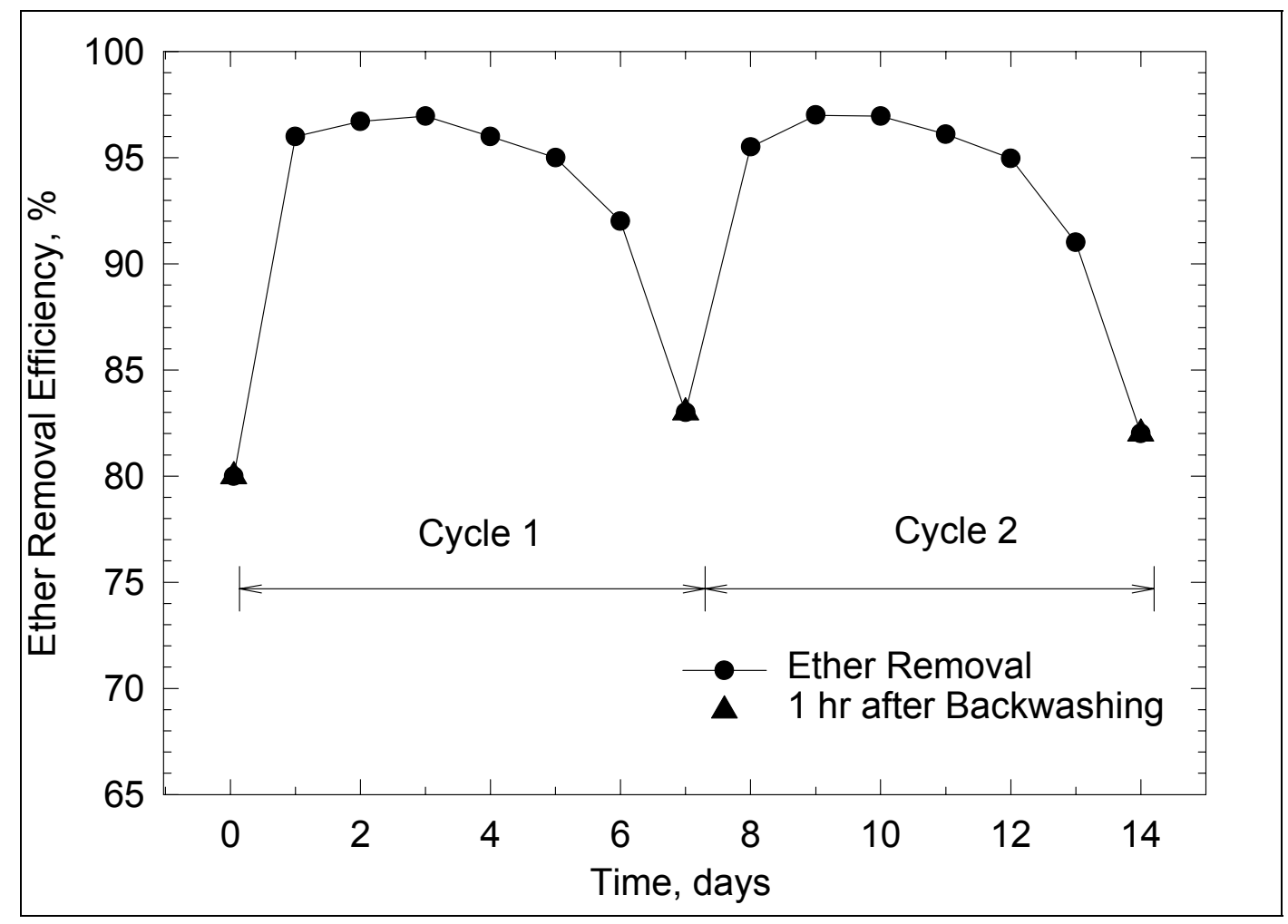

Figure 9. A typical biofilter performance during backwash cycles.

\section{Summary}

The results from this study show that biotrickling filters can achieve more than 90 percent ether removal, at a low empty bed retention time of $25 \mathrm{sec}$, and at organic loading rates up to $10.8 \mathrm{~kg} \mathrm{COD} / \mathrm{m}^{3} /$ day.

The start-up process of the biotrickling filters is quick and simple. The biofilters can reach steady performance in 1 to 4 weeks depending on start-up loadings.

Biofilter performance improved with increases in EBRT. Based on the results of this study and considering the cost factor, an optimal EBRT range of $25 \mathrm{sec}$ to 1 min is recommended for biofilter design.

The study on the influence of flow pattern shows that biofilter performance under counter-current flow mode was higher than under co-current flow mode for treating ether. Further research is still needed, however, to fully assess the effect of airflow patterns.

Other major operating parameters that affect biofiltration were also identified. These factors, including liquid flow rate, and nitrate and backwash strategies, will be discussed in detail in later chapters. 


\section{Role of Nitrate in Biotrickling Filters}

Nutrient supply is critical for microbial metabolism in biofiltration systems. Studies have found that nutrient availability may well limit biofilter performance even in compost-based or natural nutritive units (Weckhuysen, Vriens, and Verachtert 1993; Morgenroth et al. 1996). For biotrickling filters, which use synthetic packing materials, the addition of nutrients is always necessary. Little information has been reported on the effect of nutrient concentrations on biofilter performance. Almost all the existing studies on biotrickling filters assumed that sufficient nutrients were supplied and that, since excess nutrients were added, they were not limiting factors. This chapter presents a study investigating the effects of the concentration of nitrate in the nutrient feed on biofilter performance under a wide range of organic loading rates. Special attention was given to the role of nitrate in the biotrickling filter: whether nitrate affects biofilter performance by serving as a growth-controlling nutrient or as an electron acceptor for the respiration of ether. The experimental results were then simulated using the comprehensive mathematical model described in Chapter 3.

\section{Effect of Influent Nitrate Concentration}

Two identical biofilters, designated as Column A and Column B, were used in this study. Table 4 summarizes the study's major operating parameters. The four influent ether concentrations studied were 67, 133, 200, and $267 \mathrm{ppmv}$. Four influent nitrate concentrations were investigated for each ether loading, which ranged from 33 to more than $2000 \mathrm{mg} \mathrm{N} / \mathrm{L}$. The EBRT was kept at $25 \mathrm{sec}$ throughout this experiment, which resulted in ether loading ranges from 1.8 to $7.1 \mathrm{~kg} \mathrm{COD} / \mathrm{m}^{3} /$ day. The biofilters were backwashed once a week to remove excess biomass and maintain performance.

Initially, the two biofilters were started up at influent ether concentrations of 67 ppmv, gas flow rates of $6 \mathrm{~L} / \mathrm{min}$ or $8.64 \mathrm{~m}^{3} /$ day, and an empty bed retention time of $25 \mathrm{sec}$, resulting in ether loadings of $1.8 \mathrm{~kg} \mathrm{COD} / \mathrm{m}^{3} /$ day. Each biofilter received $1 \mathrm{~L} /$ day of nutrient feed with a nitrate concentrations of $67 \mathrm{mg} \mathrm{NO} \mathrm{N}_{3} \mathrm{~N} / \mathrm{L}$, resulting in a COD to nitrogen $(\mathrm{N})$ ratio of $67: 1$. The ether removal efficiency was over 99 percent within 2 weeks. 
Table 4. Major operating conditions in nitrate study.

\begin{tabular}{ll}
\hline Influent Ether Concentrations, ppmv & $67-267$ \\
Influent Nitrate Concentrations, mg NO $3-\mathrm{N} / \mathrm{L}$ & $34-2138$ \\
Empty Bed Retention Time, sec & 25 \\
COD Loading Rate, $\mathrm{kg} \mathrm{COD/m}$ /day & $1.8-7.1$ \\
Influent Air Flow Rate, $\mathrm{m}^{3}$ /day & 8.64 \\
Nutrient Liquid Flow Rate, L/day & 1.0 \\
Backwash Frequency, $1 /$ week & 1 \\
\hline
\end{tabular}

Between day 72 and 304 of operation, the influent concentration of ether to Columns $\mathrm{A}$ and $\mathrm{B}$ were $67 \mathrm{ppmv}$ and $133 \mathrm{ppmv}$, respectively, resulting in COD volumetric loading rates of 1.8 and $3.6 \mathrm{Kg} / \mathrm{m}^{3}$-day. Four influent nitrate concentrations were studied to evaluate the effect of nitrate on ether removal efficiency. All other operating parameters remained constant. Figure 10 shows the biofilter performance during this period. The experimental results regarding nitrate effect at influent ether concentrations of 67 and 133 ppmv are also summarized in Figure $11 \mathrm{a}$ and $11 \mathrm{~b}$.

On day 72 of continuous operation, the influent ether concentration to Column B was doubled to 133 ppmv. The removal efficiency in Column A remained stable at 99.7 percent. The removal efficiency in Column B, however, immediately dropped, yielding an average removal efficiency of 88.4 percent. The presence of nitrate in the effluent demonstrated that there was an excess of nitrate in the column feed, thereby indicating that the nitrate supply in the aqueous phase was sufficient.

On day 144 the nitrate concentration in the nutrient feed was decreased to half of the original concentration in order to determine limiting nitrate concentrations. Reducing the nitrate in the nutrient feed resulted in a decrease in performance in both columns. The decrease in removal efficiency was not as severe in Column A as it was in Column B. At the end of 2 weeks (day 161) the ether removal efficiency was reduced from above 99 percent to 87 percent in Column A and to 58 percent in Column B. No nitrate was detected in Column B effluent, indicating that Column $\mathrm{B}$ had reached its nitrate limitation. The steady decrease in performance also indicated Column B was headed toward failure. On day 162 the nitrate concentration in the feed was restored to $67 \mathrm{mgN} / \mathrm{L}$. Performance in the reactors increased to 99 percent removal efficiency in Column A and around 75 percent in Column B. When the nitrate concentration in the nutrient feed was doubled to $133 \mathrm{mgN} / \mathrm{L}$ on day 179 , removal efficiencies increased to 95 percent in Column B.

On day 193 the influent concentration of nitrate was increased to $267 \mathrm{mgN} / \mathrm{L}$. Performance in both columns stabilized at above 99 percent ether removal. Figure 
11a shows that the influent versus effluent nitrate line is parallel to the dash line with a slope of 1 when the influent nitrate concentration is greater than 67 $\mathrm{mgN} / \mathrm{L}$, which demonstrates that nitrate consumption was constant as the ether removal was over 99 percent during this period. The slope for Column B (Figure $11 b)$ is lower than 1 . The increase in nitrate consumption is consistent with the increase in ether removal.

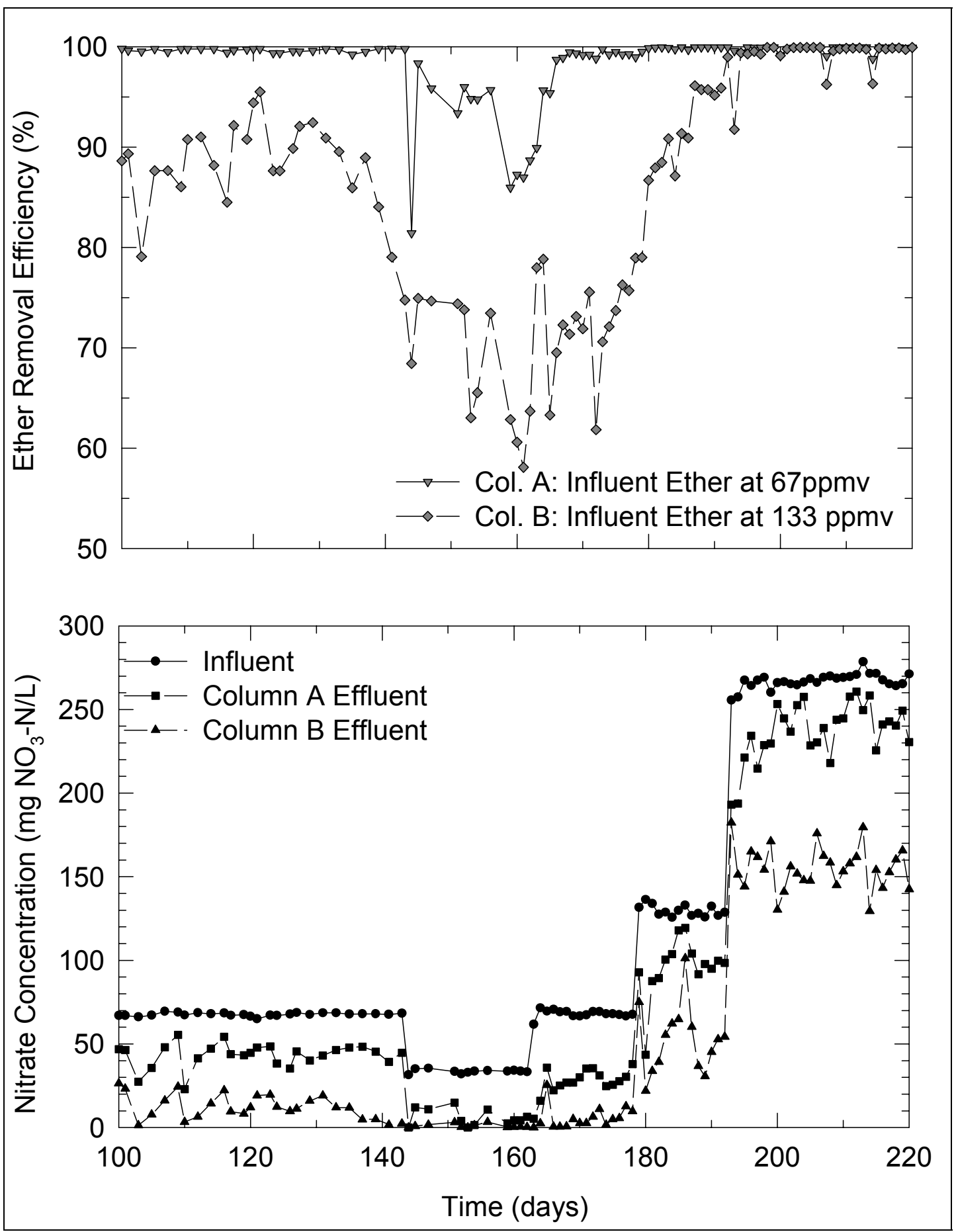

Figure 10. Effect of influent concentration on biofilter performance at influent ether of (top) 67 and (bottom) 133 ppmv. 


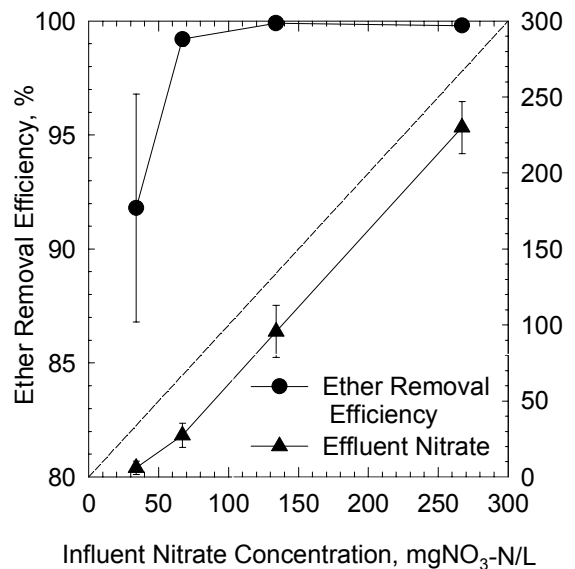

a) Influent Ether $67 \mathrm{ppmv}, 1.8 \mathrm{Kg} \mathrm{COD} / \mathrm{m}^{3}$-day

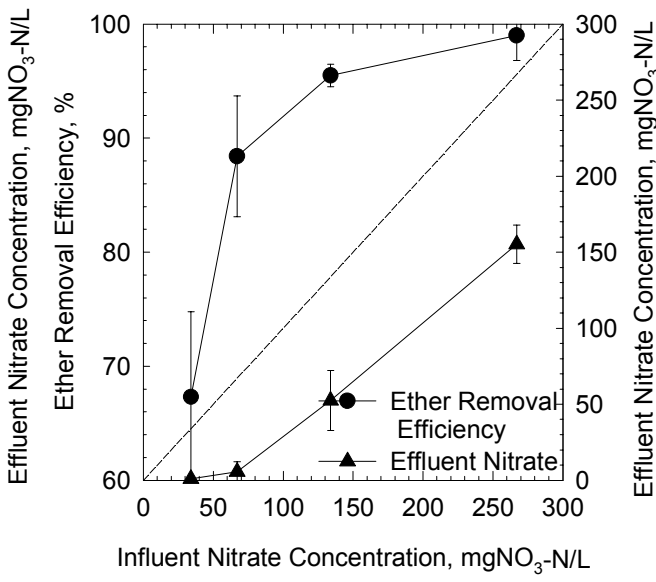

b) Influent Ether $133 \mathrm{ppmv}, 3.6 \mathrm{Kg} \mathrm{COD} / \mathrm{m}^{3}$-day

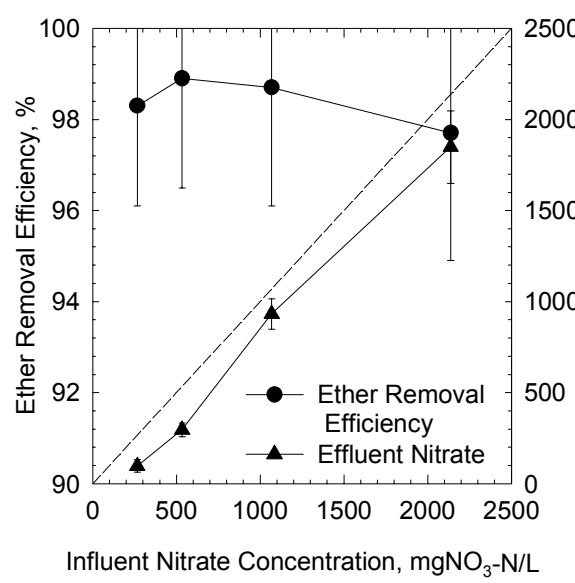

c) Influent Ether 200 ppmv, $5.3 \mathrm{Kg} \mathrm{COD} / \mathrm{m}^{3}$-day

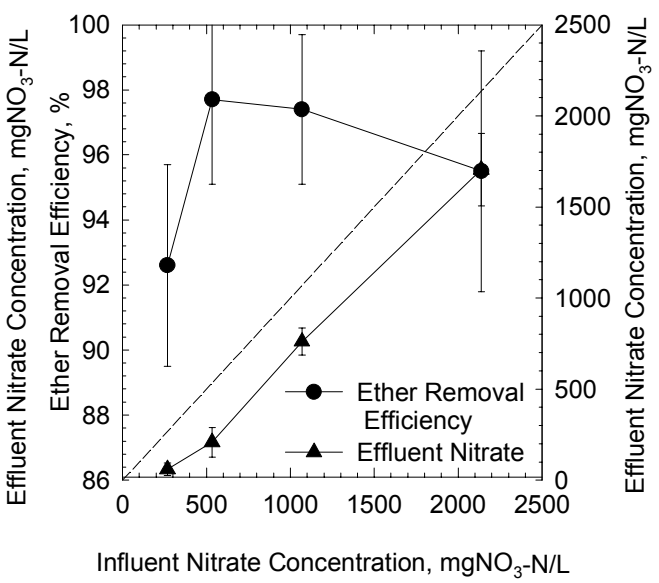

d) Influent Ether $267 \mathrm{ppmv}, 7.1 \mathrm{Kg} \mathrm{COD} / \mathrm{m}^{3}$-day

Figure 11. Effect of influent nitrate concentration on ether removal.

For the case where the influent nitrate concentration was lowest, the drop in performance can be attributed to nutrient limitation as indicated by little nitrate measured in either column effluents. At the higher influent nitrate concentrations, however, excess nitrate persists in the effluent at a concentration exceeding $10 \mathrm{mgN} / \mathrm{L}$. Studies aimed at revealing the effect of nitrate concentration on the uptake kinetics of organic matter have shown that reaction rate is not affected when nitrate concentration is maintained at levels exceeding $2 \mathrm{mgN} / \mathrm{L}$ 
(Venosa et al. 1994). The increase in performance observed here suggested that, although the concentration of nitrate in the aqueous film exceeded $10 \mathrm{mg} / \mathrm{L}$, its diffusion into the biofilm may have limited its availability. Figure 12 shows the effect of log mean concentration of nitrate on ether removal. The logarithmic mean concentration $\left(\left(\mathrm{C}_{\mathrm{in}}-\mathrm{C}_{\text {out }}\right) / \ln \left(\mathrm{C}_{\mathrm{in}} / \mathrm{C}_{\text {out }}\right)\right)$ is a measure of average mass flux or the mean driving force for diffusional mass transfer at some surface (Bird, Stewart, and Lightfoot 1960). Figure 12 shows that the ether removal rate increased steadily with the increase in the nitrate diffusional driving force in Column B. This indicates that mass transfer resistance for nitrate in the biofilter is rate limiting. The fairly stable ether elimination capacity for the three influent nitrate concentrations in Column A was a result of over 99 percent ether removal efficiency at those levels.

The concentration profiles along the media depth with respect to ether and $\mathrm{CO}_{2}$ for influent ether concentrations of 67 and 133 ppmv are illustrated in Figure $13 \mathrm{a}$ and $13 \mathrm{~b}$, respectively. The reduction in ether along the media depth is accompanied with an increase in $\mathrm{CO}_{2}$, indicating that ether is being mineralized and not simply biotransformed into an intermediate product. Even though the removal efficiency of ether remained at over 99 percent in Column A during this period, the ether elimination capacity within the first section of the biofilter increased with increasing influent nitrate concentration. This result again supports the hypothesis that the diffusion of nitrate into the biofilm is the ratelimiting factor in biofilter performance.

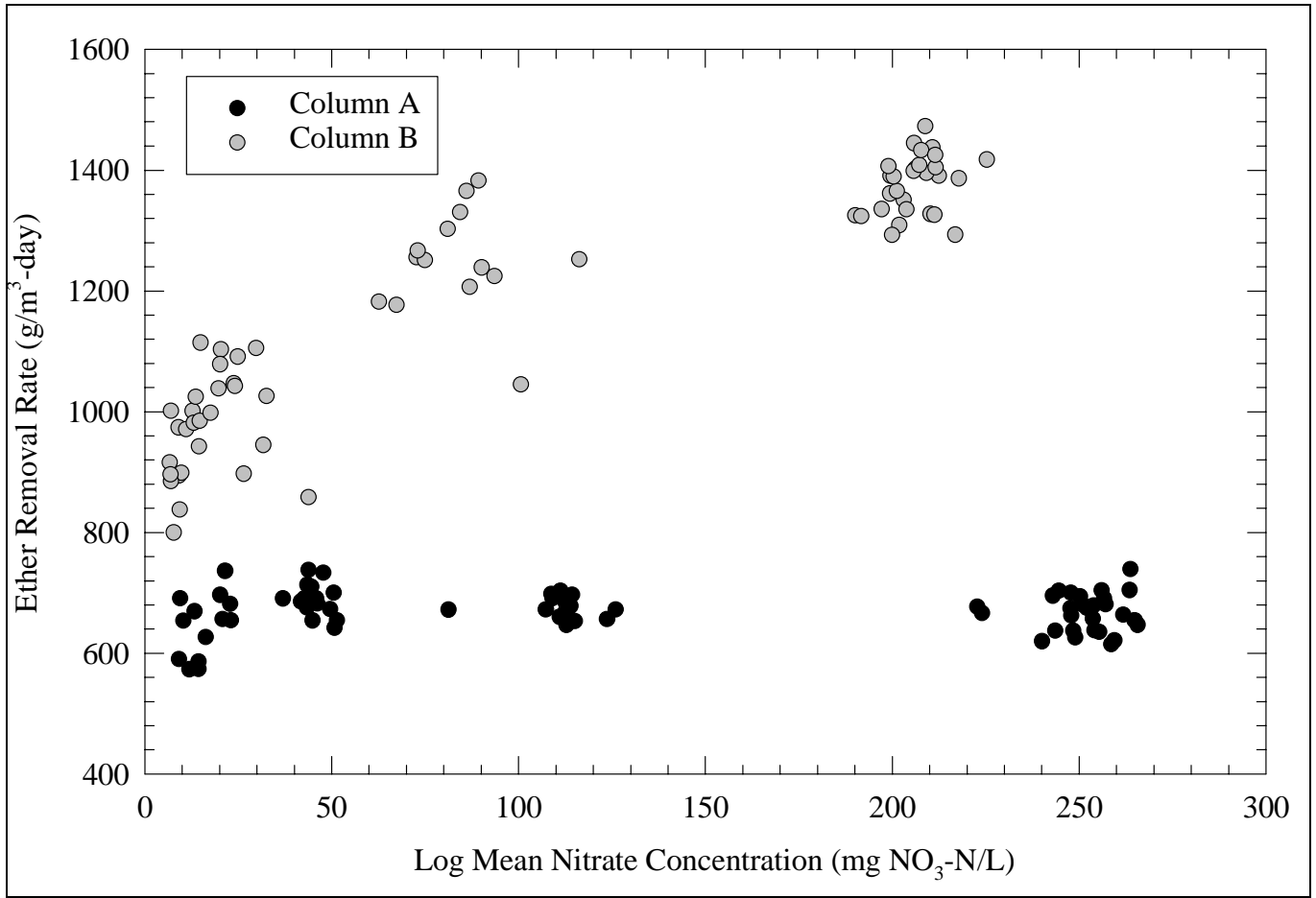

Figure 12. Effect of logmean nitrate concentration on ether removal rate. 


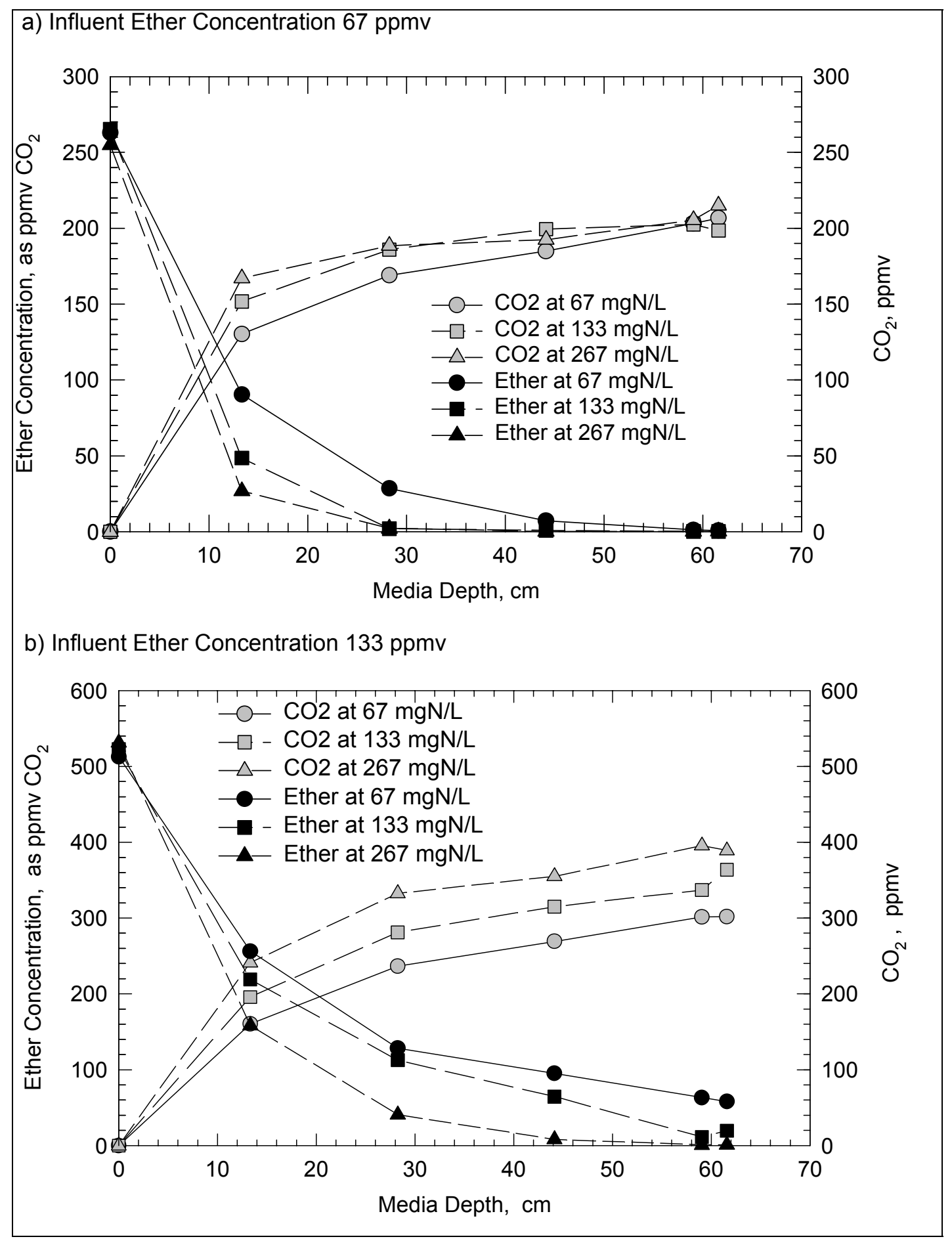

Figure 13. Nitrate influence on concentration profiles of ether and $\mathrm{CO}_{2}$ along the medium depth.

A carbon mass balance was performed on the carbon equivalent of the ether consumed and the carbon produced within the biofilter. The carbon produced consisted of $\mathrm{CO}_{2}$ in the gas phase, the inorganic carbon content in the effluent water, and the carbon equivalent of the VSS lost from the system. The concentration of ether in the aqueous effluent was found to be negligible throughout this study. Table 5 summarizes the carbon balance results. As the nitrate 
concentration in the influent increases, the $\mathrm{CO}_{2}$ produced also increases, indicating that more ether is completely oxidized into $\mathrm{CO}_{2}$ in both columns. Only a small portion of the ether that is removed is unaccounted for, suggesting that fairly complete oxidation of ether has been achieved in this system.

To further examine the effect of nitrate concentrations at higher organic loadings, the influent concentrations of ether to Columns A and B were increased to 200 ppmv and 267 ppmv after day 305, resulting in COD volumetric loading rates of 5.3 and $7.1 \mathrm{~kg} / \mathrm{m}^{3} /$ day respectively. Four more influent nitrate concentrations were studied to evaluate the effect of nitrate concentration on ether removal. Biofilter performance during this period is illustrated in Figures 14 and $11 \mathrm{c}$ and $\mathrm{d}$.

After increasing the influent ether concentrations for an influent nitrate concentration of $267 \mathrm{mgN} / \mathrm{L}$, the removal efficiency dropped from 99.8 to 98.3 percent in Column A, and from 99.0 to 92.6 percent in Column B. With a further increase in the influent nitrate concentration to 533 and then $1059 \mathrm{mgN} / \mathrm{L}$, the ether removal efficiency was again improved to 98.9 and 98.7 percent in Column A, and to 97.7 and 97.4 percent in Column B. The improved performance in response to increased influent nitrate concentration again demonstrates that the diffusion of nitrate into the biofilm is rate determining. For the period between day 375 and day 402, the influent nitrate concentration was further increased to 2,134 $\mathrm{mgN} / \mathrm{L}$. The ether removal efficiency, however, was found to decrease from 98.7 to 97.7 percent in Column A and from 97.4 to 95.6 percent in Column B. This indicates that inhibition may have occurred when the nitrate concentration is higher than 2,000 mgN/L. Gee, Pfeffer, and Suidan (1990) observed similar nitrate inhibition while nitrifying high strength ammonia wastewater.

Table 5. Carbon balance during influent nitrate variations (the percentages are relative to the total amount of removed ether).

\begin{tabular}{|c|c|c|c|c|c|}
\hline & $\begin{array}{c}\text { Influent Nitrate } \\
\text { Concentration } \\
(\mathrm{mg} / \mathrm{L})\end{array}$ & $\begin{array}{c}\text { Carbon Dioxide } \\
\text { in Gas Phase } \\
(\%)\end{array}$ & $\begin{array}{c}\text { Inorganic } \\
\text { Carbon in } \\
\text { Liquid Phase } \\
(\%)\end{array}$ & $\begin{array}{c}\text { Volatile } \\
\text { Suspended } \\
\text { Solid } \\
(\%)\end{array}$ & $\begin{array}{l}\text { Unaccounted } \\
\text { Carbon } \\
(\%)\end{array}$ \\
\hline \multirow[t]{3}{*}{ Column A } & 66.7 & 70.8 & 2.0 & 9.1 & 18.1 \\
\hline & 133 & 71.7 & 4.5 & 5.1 & 18.7 \\
\hline & 266 & 82.3 & 4.7 & 11.4 & 1.6 \\
\hline \multirow[t]{3}{*}{ Column B } & 66.7 & 58.7 & 2.7 & 9.7 & 28.9 \\
\hline & 133 & 71.4 & 4.5 & 6.7 & 17.4 \\
\hline & 266 & 73.9 & 5.3 & 5.1 & 15.7 \\
\hline
\end{tabular}




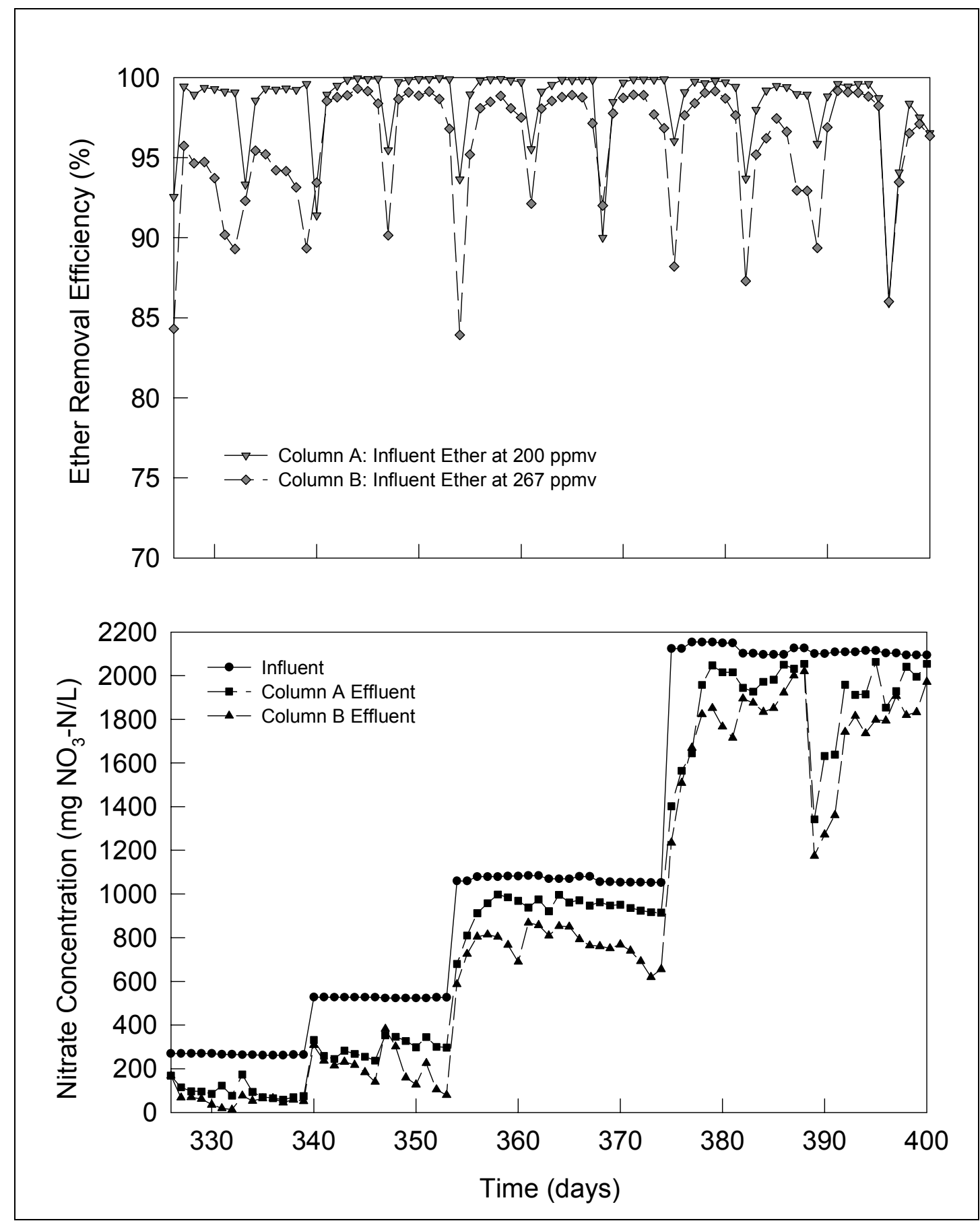

Figure 14. Effect of influent nitrate concentration on biofilter performance at influent ether of 200 and 267 ppmv.

Table 6 summarizes the relationship between COD:N ratio and the corresponding ether removal efficiency. The results show that the biotrickling filter achieved the best ether removal efficiencies at a COD:N ratio of about 30 for all the four COD loading rates examined in this study. 
Table 6. Summary of the results during influent nitrate variations.

\begin{tabular}{|c|c|c|c|}
\hline $\begin{array}{l}\text { Influent Ether } \\
\text { Concentration } \\
\text { (ppmv) }\end{array}$ & $\begin{array}{l}\text { Influent Nitrate } \\
\text { Concentration } \\
\left.\text { (mg NO}{ }_{3}-\mathrm{N} / \mathrm{L}\right)\end{array}$ & Influent COD : N Ratio & $\begin{array}{c}\text { Ether Removal Efficiency } \\
(\%)\end{array}$ \\
\hline \multirow{4}{*}{67} & 34 & $133: 1$ & $91.8 \pm 5.0$ \\
\hline & 67 & $67: 1$ & $99.2 \pm 0.3$ \\
\hline & 133 & $33: 1$ & $99.9 \pm 0.1$ \\
\hline & 267 & $17: 1$ & $99.8 \pm 0.1$ \\
\hline \multirow{4}{*}{133} & 34 & $267: 1$ & $67.3 \pm 7.5$ \\
\hline & 67 & $133: 1$ & $88.4 \pm 5.3$ \\
\hline & 133 & $67: 1$ & $95.5 \pm 1.0$ \\
\hline & 267 & $33: 1$ & $99.0 \pm 2.2$ \\
\hline \multirow{4}{*}{200} & 267 & $50: 1$ & $98.3 \pm 2.2$ \\
\hline & 533 & $25: 1$ & $98.9 \pm 2.4$ \\
\hline & 1,067 & $12: 1$ & $98.7 \pm 2.6$ \\
\hline & 2,134 & $6: 1$ & $97.7 \pm 2.8$ \\
\hline \multirow{4}{*}{267} & 267 & $67: 1$ & $92.6 \pm 3.1$ \\
\hline & 533 & $33: 1$ & $97.7 \pm 2.6$ \\
\hline & 1,067 & $17: 1$ & $97.4 \pm 2.3$ \\
\hline & 2,134 & $8: 1$ & $95.6 \pm 3.7$ \\
\hline
\end{tabular}

\section{Effect of Oxygen and Role of Nitrate}

Nitrate can serve as a growth-controlling nutrient or as an electron acceptor for the respiration of ether when oxygen is limited. To study which mechanism was dominant for the improvement of ether removal in this study, the effect of the partial pressure of oxygen on biofilter efficiency was studied between day 221 and day 303 of this study.

An experiment to estimate critical ether concentration leading to oxygen limitation was first conducted using the criteria established in the section on Henry's Constant and Oxygen Limitation, p 25. Based on Equation 9 and using parameters listed in Table 7, oxygen could be a limiting factor in the biofilters when ether concentration is above $84 \mathrm{ppmv}$ at $25^{\circ} \mathrm{C}$ or $81 \mathrm{ppmv}$ at $27^{\circ} \mathrm{C}$, which is the temperature maintained throughout this study. The effect of oxygen was then evaluated at $133 \mathrm{ppmv}$, an ether concentration potentially leading to oxygen limitation. Figure 15 shows the effect of increased nitrate or oxygen partial pressure on the effectiveness of the biofilter in treating ether. 
Table 7. Parameters used in determination of oxygen limitation (at $25^{\circ} \mathrm{C}$ ).

\begin{tabular}{ll}
\hline$H_{\text {ether }}$ (Dimensionless) & 0.034 \\
$\mathrm{D}_{\text {ether in water }, \mathrm{cm}^{2} / \mathrm{sec}}$ & $9 \times 10^{-6}$ \\
$\mathrm{D}_{\text {oxygen in water }, \mathrm{cm}^{2} / \mathrm{sec}}$ & $2.1 \times 10^{-5}$ \\
$\mathrm{C}_{\mathrm{o}}, \mathrm{mg} / \mathrm{L}$ & 8.24 \\
$v_{\mathrm{s}}$ & 1 \\
$v_{\mathrm{o}}$ & 6 \\
\hline
\end{tabular}

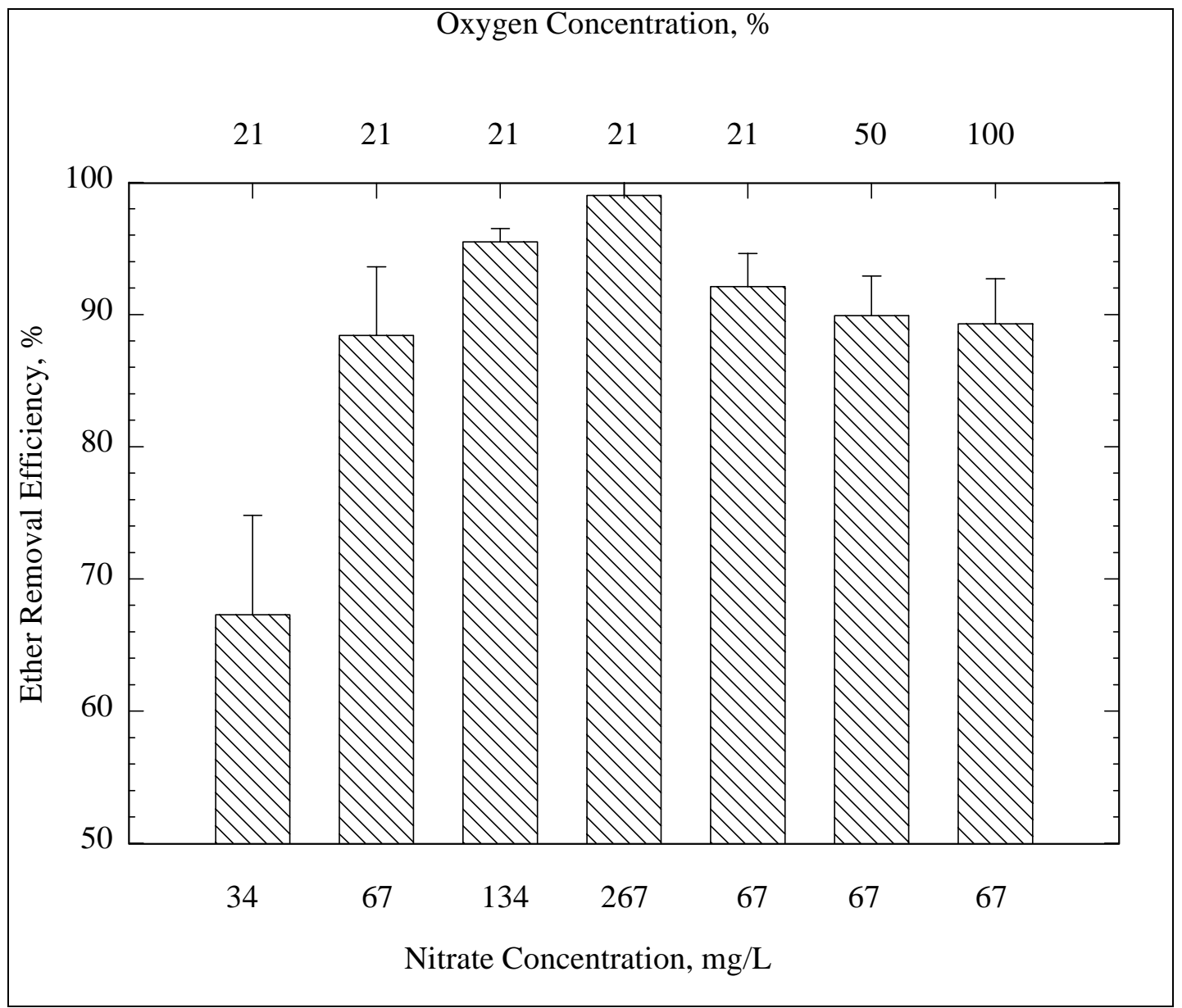

Figure 15. Comparison of oxygen and nitrate effects on ether removal at COD loading of 3.6 $\mathrm{kg} / \mathrm{m}^{3} /$ day and influent ether concentration of $133 \mathrm{ppmv}$.

After studying the effect of increased concentrations of nitrate on biofilter performance, the nitrate concentration was decreased from $267 \mathrm{mgN} / \mathrm{L}$ back to $67 \mathrm{mgN} / \mathrm{L}$ on day 221 . The ether removal efficiency dropped immediately to an average 92 percent, which was consistent with results obtained previously for the same nitrate concentration. On day 235 the influent concentration of oxygen in the feed to Column B was increased from 21 percent (ambient air) to 50 percent and then to 100 percent on day 249 while maintaining an influent ether concentration of $133 \mathrm{ppmv}$ and a feed nitrate concentration of $67 \mathrm{mg} \mathrm{NO} 3 \mathrm{~N} / \mathrm{L}$. 
The performance of the biofilter was not significantly affected and ether removal efficiency slightly decreased from an average of 92 percent to 90 and 89 percent. The removal efficiency of ether improved later to more than 99 percent for the same COD volumetric loading rate when the influent nitrate concentration was again increased to 134 and $267 \mathrm{mgN} / \mathrm{L}$. These results suggest that oxygen was not rate limiting and that nitrate was limiting the process as a growth nutrient. The results also suggest that resistance to the transport of nitrate into the biofilm led to nutrient limitations in the deeper layers of the biofilm. These limitations suggest that, in gas-phase biofilters, the mass transfer of substrates in the gas phase (such as ether and oxygen) may not be limited by the liquid phase as in a wastewater system because direct mass transfer to a non-wetted biofilm may occur. On the other hand, since substrates in the liquid phase like nitrate can only be transported into the biofilm through the wetted areas, the mass transfer limitation is more serious.

\section{Model Simulation}

The biofilter mathematical model described in Chapter 3 was used to simulate the performance of the biofilter and to support the conclusions obtained from experimental results. These experimental data suggested a strong dependence of the reactor performance on the influent nitrate concentration, with the limiting effect of nitrate being relative to its role as a nutrient. This limitation could be due to mass transfer or to kinetic limitations. The answer to this question was provided by the mathematical model and experimental results. Because microbial growth could be nutrient limited, nitrate was included in the reaction rate in the same way as the carbon source, using the Monod expression. Experimental studies analyzing the effect of nitrate concentration on uptake kinetics of organic matter showed that the Monod constant for nitrate was not higher than 2 $\mathrm{mgN} / \mathrm{L}$. Model simulations using this result revealed that the reaction rate could not be kinetically limited by nitrate. Therefore, the diffusion of nitrate into the biofilm was the rate-limiting step of the biodegradation process.

The system parameters that were not known and could not be measured were estimated using the observed data. Nonlinear parameter estimation with minimization of the sum of squares of the weighted differences between the measured and calculated values was used here. The weights were the standard deviations of the measured values. The estimated parameters were: Monod constant for ether $\left(K_{S}\right)$ and for nitrate $\left(K_{N}\right)$, yield coefficient $(Y)$, maximum specific growth rate $\left(\mu_{m}\right)$, nitrogen fraction in active and inactive biomass $\left(i_{X a}, i_{X i}\right)$, decay coefficient $\left(k_{d}\right)$, endogenous respiration constant $(b)$, biomass density in the biofilm $\left(X_{f}\right)$, the biofilm/water diffusivity ratio for substrate and for nitrate $\left(r_{s}, r_{N}\right)$, and 
the detachment velocity $\left(u_{u d e t}\right)$. The values of the estimated model parameters and the other parameters used in the model are in Table 8. The experimental data used in the parameter estimation included the biofilter ether removal efficiency, the effluent nitrate concentrations for Columns A and B, and the four different influent nitrate concentrations. Ether removal efficiency profiles along the media depth for influent ether concentration 67 and $133 \mathrm{ppmv}$ and for influent nitrate concentrations 67,133 , and $267 \mathrm{mgN} / \mathrm{L}$ were also used in the parameter estimation. Figure 16 presents the average of the experimental measurements with the corresponding standard deviations. It also shows the model predicted values obtained with the estimated parameters. The fit of the model solution to the experimental data was reasonably good, so the mathematical model of the biofilter was able to predict the effect of influent nitrate concentration in biofilter performance.

Table 8. Parameters used in model simulation of nitrate effect.

\begin{tabular}{|c|c|}
\hline \multicolumn{2}{|l|}{ Values from the literature } \\
\hline Nitrate Diffusivity in water, $D_{w N}$ & $2.0 \times 10^{-5} \mathrm{~cm}^{2} / \mathrm{sec}$ \\
\hline Ether Diffusivity in water, $D_{w s}$ & $0.9 \times 10^{-5} \mathrm{~cm}^{2} / \mathrm{sec}$ \\
\hline Ether Diffusivity in air, $D_{g s}$ & $0.09 \mathrm{~cm}^{2} / \mathrm{sec}$ \\
\hline Ether Henry's constant, $H$ & $0.034(\mathrm{mg} / \mathrm{L})_{\mathrm{g}} /(\mathrm{mg} / \mathrm{L})_{\mathrm{w}}$ \\
\hline \multicolumn{2}{|l|}{ Estimated values } \\
\hline Ether Monod kinetic constant, $K_{s}$ & $0.9 \mathrm{mg} \mathrm{COD} / \mathrm{L}$ \\
\hline Nitrate Monod kinetic constant, $K_{N}$ & $10.0 \mathrm{mg} \mathrm{N} / \mathrm{L}$ \\
\hline Maximum growth rate, $\mu_{m}$ & 0.13 day $^{-1}$ \\
\hline Yield coefficient, $Y$ & $0.47 \mathrm{mg} \mathrm{COD} / \mathrm{mg}$ COD \\
\hline Nitrogen fraction in active biomass, $i_{x a}$ & 0.017 mg N/mg COD \\
\hline Nitrogen fraction in inactive biomass, $i_{X i}$ & $0.0017 \mathrm{mg} \mathrm{N} / \mathrm{mg}$ COD \\
\hline Decay coefficient, $k_{d}$ & $4.0 \times 10^{-5}$ day $^{-1}$ \\
\hline Endogenous respiration constant, $b$ & $4.0 \times 10^{-5}$ day $^{-1}$ \\
\hline Biofilm/water diffusivity ratio for ether, $r_{S}$ & 20 \\
\hline Biofilm/water diffusivity ratio for nitrate, $r_{N}$ & 0.03 \\
\hline Biomass density in the biofilm, $\rho$ & $37.5 \mathrm{~g} \mathrm{COD} / \mathrm{L}$ \\
\hline Detachment coefficient, $\mathrm{C}_{\text {udet }}$ & $3.510^{-6} \mathrm{~cm}^{-1} \mathrm{sec}^{-1}$ \\
\hline
\end{tabular}

To show that the limitation of nitrate was due to mass transfer resistance, the same equation traditionally used for mass transfer oxygen limitations (Williamson and McCarty 1976a,b) can be used. For the simplest case of steady-state biofilm with no decay, for a biofilm to have nitrate mass transfer limitations the following relationship must hold:

$$
Y i_{X a} \frac{D_{w S}}{D_{w N}} \frac{r_{S}}{r_{N}} \frac{S_{s}}{N_{S}}>1
$$

where $Y$ is the yield coefficient, $i_{X a}$ is the fraction of nitrogen in biomass, $D_{w S}$ and $D_{w N}$ are the diffusion coefficients in water for ether and nitrate, $r_{S}$ and $r_{N}$ are the 
ratio between the diffusivities in the biofilm and in water for ether and nitrate, and $S_{s}$ and $N_{s}$ are the concentrations of ether and nitrate at the biofilm-water interface. The diffusivity of nitrate and ether in water were estimated as $2 \times 10^{-5}$ $\mathrm{cm}^{2} / \mathrm{sec}$, and $0.9 \times 10^{-5} \mathrm{~cm}^{2} / \mathrm{sec}$, respectively. Based on experimental results in this study, the average of $Y i_{X a}$ was $0.008 \mathrm{mg} \mathrm{NO}{ }_{3}-\mathrm{N} / \mathrm{mg}$ ether-COD and the average of the log mean concentrations for ether and nitrate were $0.97 \mathrm{mg}$ ether-COD/L and $80.2 \mathrm{mg} \mathrm{NO} \mathrm{N}_{3} \mathrm{~N} / \mathrm{L}$. After these values were substituted in the equation, a relation of $r_{S} / r_{N}>625$ was obtained, suggesting that the diffusivity of ether is proportionally higher than that of nitrate in the biofilm. This result again suggests that, in gas-phase biofilters, the mass transfer limitation for substrates in the liquid phase is more substantial than that for substrates in the gas phase.

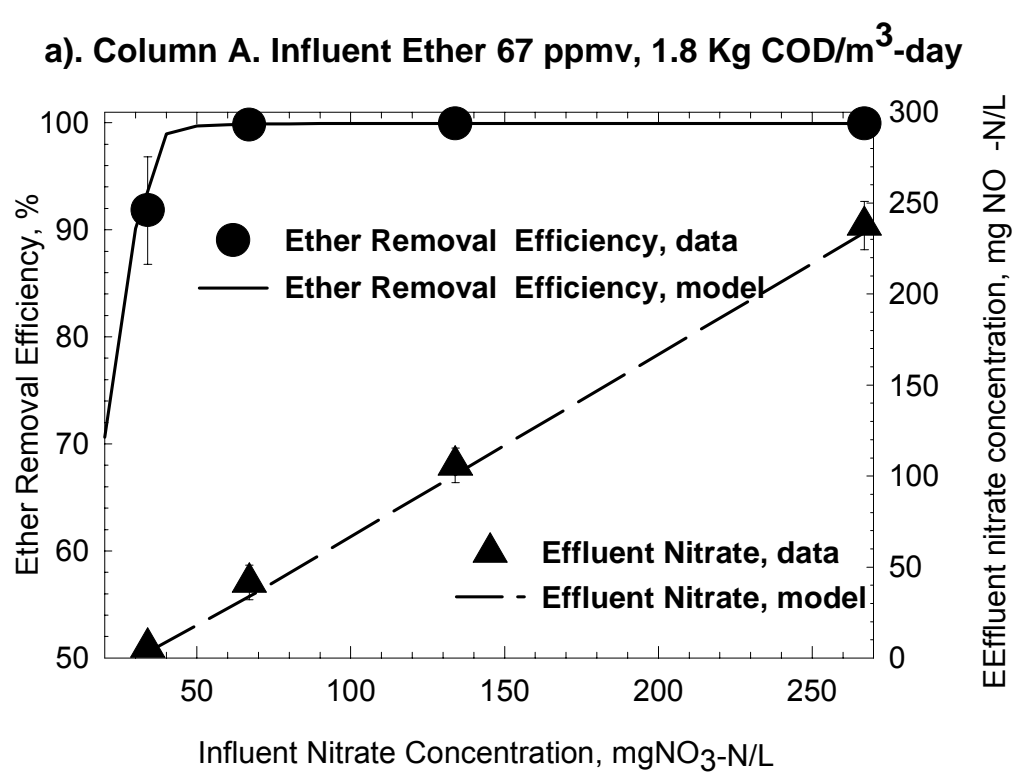

b). Column B. Influent Ether 133 ppmv, $3.6 \mathrm{Kg} \mathrm{COD} / \mathrm{m}^{3}$-day

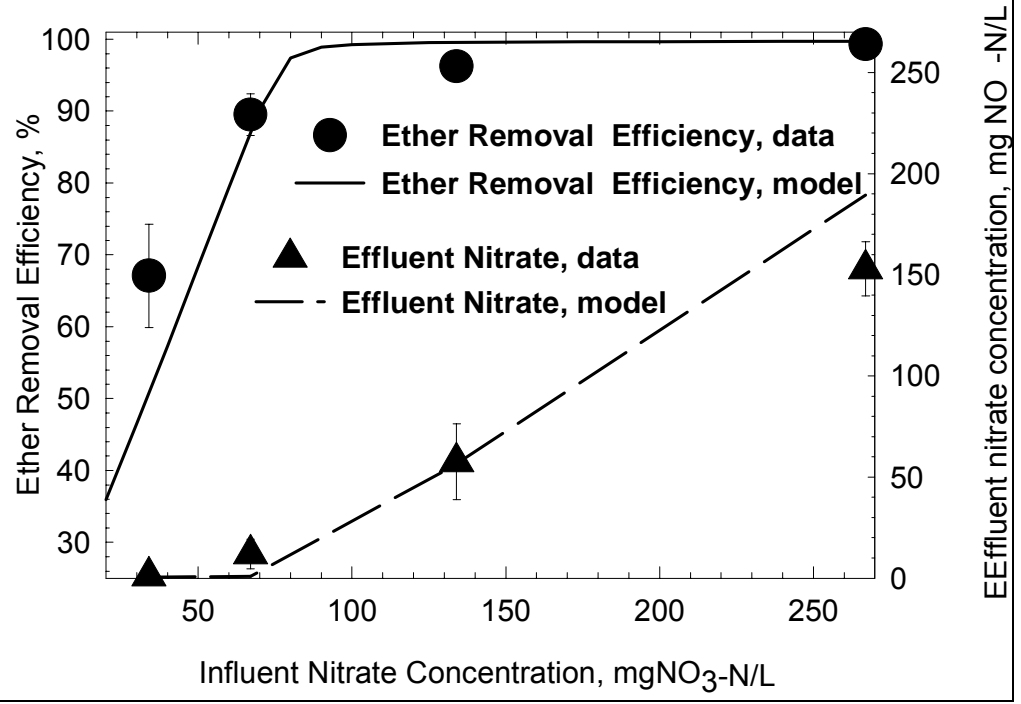

Figure 16. Model simulations of the effect of influent nitrate concentration. 


\section{Summary}

Transfer of oxygen was not rate limiting under the conditions of this experiment. On the other hand, diffusion of nitrate was found to be rate limiting for ether removal in the biofilters. The results appear to suggest that nitrate was rate limiting as a growth nutrient and not as an electron acceptor.

The optimum COD: $\mathrm{N}$ ratio is around 30:1 based on this experiment. This finding suggests that biofilter performance can be improved by manipulating the concentration of nitrate in the nutrient feed. Excess nitrate in the effluent will not be a concern in practice because it will typically be recycled within the system.

The oxygen limitation did not occur as expected based on theoretical estimation, which could be attributed to the unsaturated structure of the biofilms in gasphase biofilters. The mass transfer phenomena in gas-phase biotrickling filters still require further investigation. 


\section{Influence of Liquid Phase in Biotrickling Filters}

Liquid phase plays a critical role in both mass transfer processes and biological reactions in biotrickling filters. Particularly, the importance of the nonsaturation feature of the biofilms in gas-phase biotrickling filters has been evidenced by the previous study described in Chapter 5 and Zhu et al. (1996a,b). This chapter presents a study that further investigated the effect of liquid phase on VOC removal in the biofiltration processes. The study was conducted in two phases. In the first phase, the effect of draining after backwashing and flooding on VOC removal was studied. The fully saturated situation in biofilters was considered here. The second phase of the study examined the effect of liquid flow rate. The results obtained in this phase mainly reflected the influence of liquid phase for nonsaturated situations in biotrickling filters.

\section{Effect of Draining After Backwashing and Flooding}

One of the major features in the biofilter operation was that periodic backwash was used to remove extra biomass and maintain stable performance. This study on the impact of backwash showed an initial drop in biofilter contaminant removal efficiency after backwashing the reactors before a return to optimal performance. The drop in performance after backwashing can be attributed to both biological effects (e.g., loss of active biomass and the adaptation period required for bacteria under new conditions) and physical effect (e.g., increases in mass transfer resistance due to higher water content within biofilters after backwash).

To investigate the effect of water content on biofilter performance after backwash, a series of experiments was conducted. The first experiment involved evaluating the effect of draining after backwashing. Four identical biofilters were backwashed with liquid nutrient for 1 hour. After the backwash, one of the biofilters was started up by introducing ether immediately. The other biofilters were allowed to drain for different periods of time before introducing ether. The biofilter performance reflected both biological and physical effects. The second test studied the draining effect after flooding the biofilters. After the biofilter performance was stabilized, usually 24 hours after backwashing, the four biofilters were 
flooded with nutrient feed for 1 hour. One of the biofilters was once again started up by introducing ether immediately. The other biofilters were allowed to drain for different periods of time before introducing ether. Little biomass was lost during the flooding, so the performance reflected mainly a physical effect. Other complicating effects, such as absence of ether substrate, were also examined.

Figure 17 shows the overall performance of the four biofilters with respect to ether removal, and Table 9 summarizes the major operating conditions for this study. All biofilters were started at influent ether concentrations of $200 \mathrm{ppmv}$, gas flow rates of $6 \mathrm{~L} / \mathrm{min}$ or $8.64 \mathrm{~m}^{3} /$ day, and an EBRT of $25 \mathrm{sec}$, resulting in ether loadings of $5.3 \mathrm{~kg} \mathrm{COD} / \mathrm{m}^{3} /$ day. Each biofilter received $1 \mathrm{~L} /$ day of nutrient feed with nitrate concentrations of $1,067 \mathrm{mg} \mathrm{NO}-\mathrm{N} / \mathrm{L}$ and phosphorus concentrations of $13.2 \mathrm{mg} / \mathrm{L}$. Under these conditions, no nutrient limitation would occur based on the previous studies (See Chapter 5 and Zhu et al. 1997 and 1996b). The biofilters were backwashed once a week initially. Ether removal efficiencies in all the columns reached 90 percent within 10 days of start-up. During the first 2 weeks of operation, stability and reproducibility of performance of the four columns were examined. The similarity in ether removal efficiencies and profiles along the media depth among these biofilters indicate that all the columns operated and performed in a similar manner, which established a basic reference to properly evaluate and compare variations in operation in the later experiments.

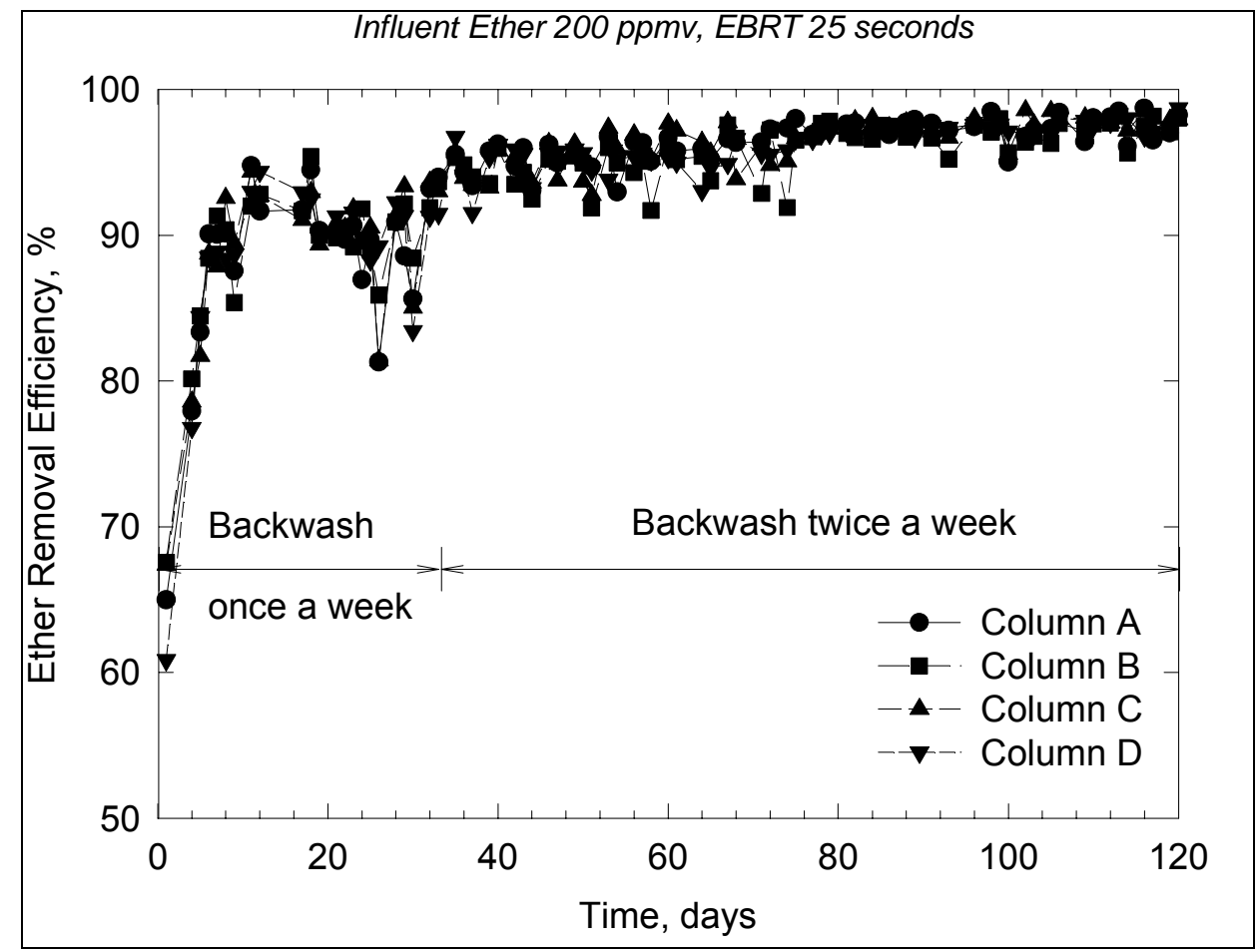

Figure 17. Overall biofilter performance with respect to ether removal during the study on draining effect after backwashing. 
Table 9. Major operating conditions in the study on draining effect after backwashing and flooding.

\begin{tabular}{ll}
\hline Influent Ether Concentrations, ppmv & 200 \\
Empty Bed Retention Time, sec & 25 \\
COD Loading Rate, $\mathrm{kg} \mathrm{COD/m}$ /day & 5.3 \\
Influent Nitrate Concentration, mg N/L & 1068 \\
Influent Air Flow Rate, $\mathrm{m}^{3} /$ day & 8.64 \\
Nutrient Liquid Flow Rate, L/day & 1.0 \\
Backwash Frequency, 1/week & $1-2$ \\
Drainage duration after backwashing or flooding, hour & $0-48$ \\
\hline
\end{tabular}

\section{Effect of Draining After Backwashing}

Between days 11 and 31 of operation, the biofilters were backwashed once a week. Biofilter performance was relatively stable with ether removal efficiency of around 90 percent for all the biofilters. The effect of draining after backwash was studied by introducing ether at $0,4,8$, and 12 hours after backwash. The results showed that biofilter performance recovered faster with an increase in draining time. Within 8 hours, ether removal efficiency increased from 50 to 70 percent for the column without extra draining and increased from 60 to 85 percent for the biofilter with 12 hours draining. All the biofilters reached about 90 percent ether removal within 24 hours.

Based on previous study, biofilter performance may be improved by increasing backwash frequency. To further study the mass transfer resistance in the liquid phase under more stable conditions, biofilters were backwashed twice a week after day 32 of operation. Biofilter performance improved immediately with more consistent removal and an increase of average ether removal efficiency from 89.6 percent to more than 95 percent. The same experiment on the effect of draining or wetting was conducted four times during this period. The sequence of draining among the four reactors was switched each time to reduce systematic error. Figure 18 illustrates the results with draining duration varying from 0 to 48 hours. It can be seen again that biofilter performance improved significantly after draining from 0 to 12 hours. Immediately after the backwash, the biofilm was fully saturated or completely covered with liquid. The media became dryer or partially wet with continued draining. This observation indicated that mass transfer resistance in the liquid phase was significant in the biotrickling filters. Biofilter performance can be improved by reducing water content in the media. Further increasing draining or drying time from 12 to 24 hours did not lead to improved performance. Draining for 48 hours even led to slower recovery of the performance because biological effects, such as the absence of ether substrate, started to dominate, which was proven in a later study. The results also indicate 
that the recovery process improved with the increase of backwash frequency. Ether removal efficiency at 1 hour after the start-up increased from 50 to 60 percent with once-a-week backwash; 70 to 90 percent with twice-a-week backwash. The physical effect, however, was also complicated in this experiment with biological effects such as loss of biomass.

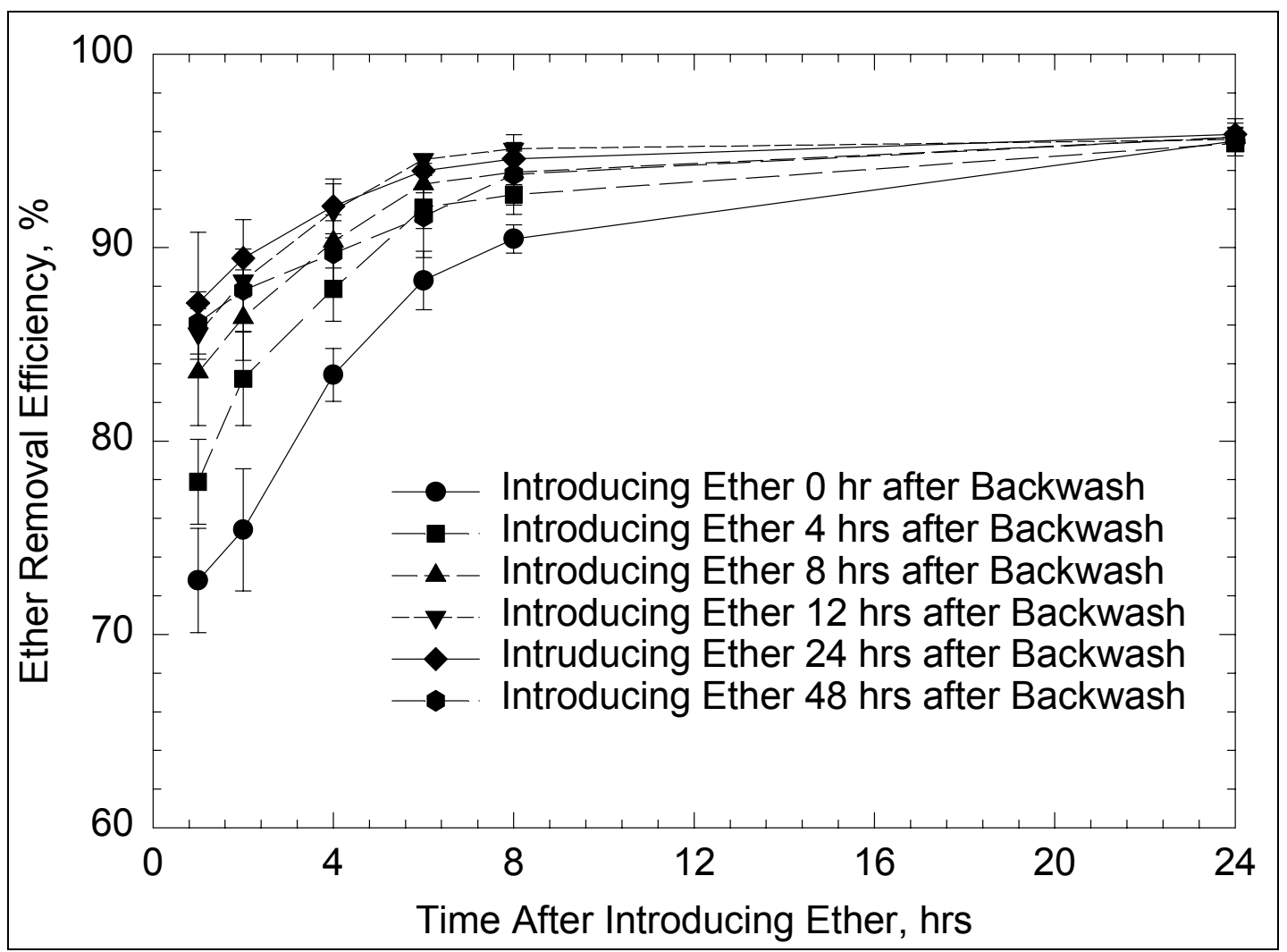

Figure 18. Effect on ether removal of draining after backwashing.

\section{Effect of Draining After Flooding}

A second test was conducted to study the draining effect after flooding, which mainly reflected the impact of water content. As Figure 19 shows, biofilter performance improved significantly with an increase in draining time, although the initial drop in performance was much less dramatic compared with that shown after backwashing (Figure 18). Ether removal efficiency initially dropped from 98 percent to about 92 percent when biofilters were started immediately after the flooding. Performance dropped very little after 4 hours of draining. To further understand this phenomenon, a liquid balance was conducted. Influent, effluent liquid flow rate, and evaporation rate were measured during draining. Table 10 shows the average results of liquid balance during this study. The results showed that the draining rate and liquid loss were higher than liquid supply during the first 2 hours. After that, an equilibrium seemed to exist between 
the influent and effluent. In other words, most of the water retained in the system during flooding or backwashing was drained in 2 hours. Figure 20 shows the relationship between the effluent liquid flow rate and ether removal after the flooding. It can be seen that the ether removal improvement corresponds to the loss of water within the column, indicating again that the physical effect plays an important role in the biofilters.

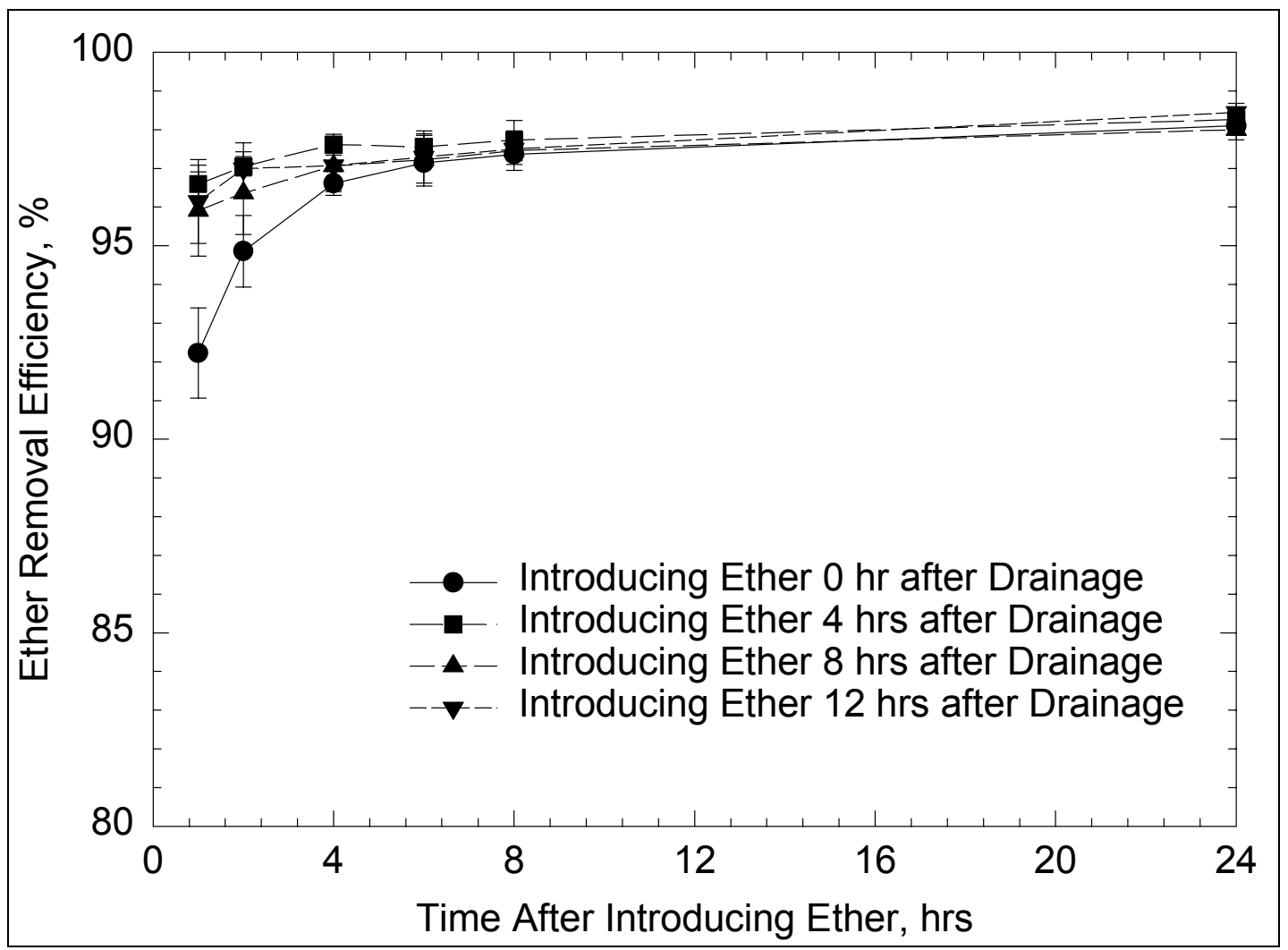

Figure 19. Effect of draining after flooding on ether removal.

Table 10. Liquid balance during draining process.

\begin{tabular}{ccccc}
\hline $\begin{array}{c}\text { Time After } \\
\text { Flooding } \\
(\mathbf{h r})\end{array}$ & $\begin{array}{c}\text { Influent Liquid } \\
\text { Flow Rate } \\
(\mathbf{m l} / \mathbf{h r})\end{array}$ & $\begin{array}{c}\text { Effluent Liquid } \\
\text { Flow Rate } \\
(\mathbf{m l} / \mathbf{h r})\end{array}$ & $\begin{array}{c}\text { Evaporation } \\
\text { Rate } \\
(\mathbf{m l} / \mathbf{h r})\end{array}$ & $\begin{array}{c}\text { Total Liquid Loss } \\
\mathbf{m l} / \mathbf{h r}\end{array}$ \\
\hline $0-1$ & 44.0 & 55.0 & 9.0 & 64.0 \\
$1-2$ & 44.0 & 36.9 & 9.0 & 45.9 \\
$2-3$ & 44.0 & 35.5 & 9.0 & 44.5 \\
$3-4$ & 44.0 & 35.1 & 9.0 & 44.1 \\
$4-8$ & 44.0 & 35.2 & 9.0 & 44.2 \\
$8-24$ & 43.9 & 34.9 & 9.0 & 43.9 \\
$24-48$ & 43.5 & 34.1 & 9.0 & 43.1 \\
\hline
\end{tabular}




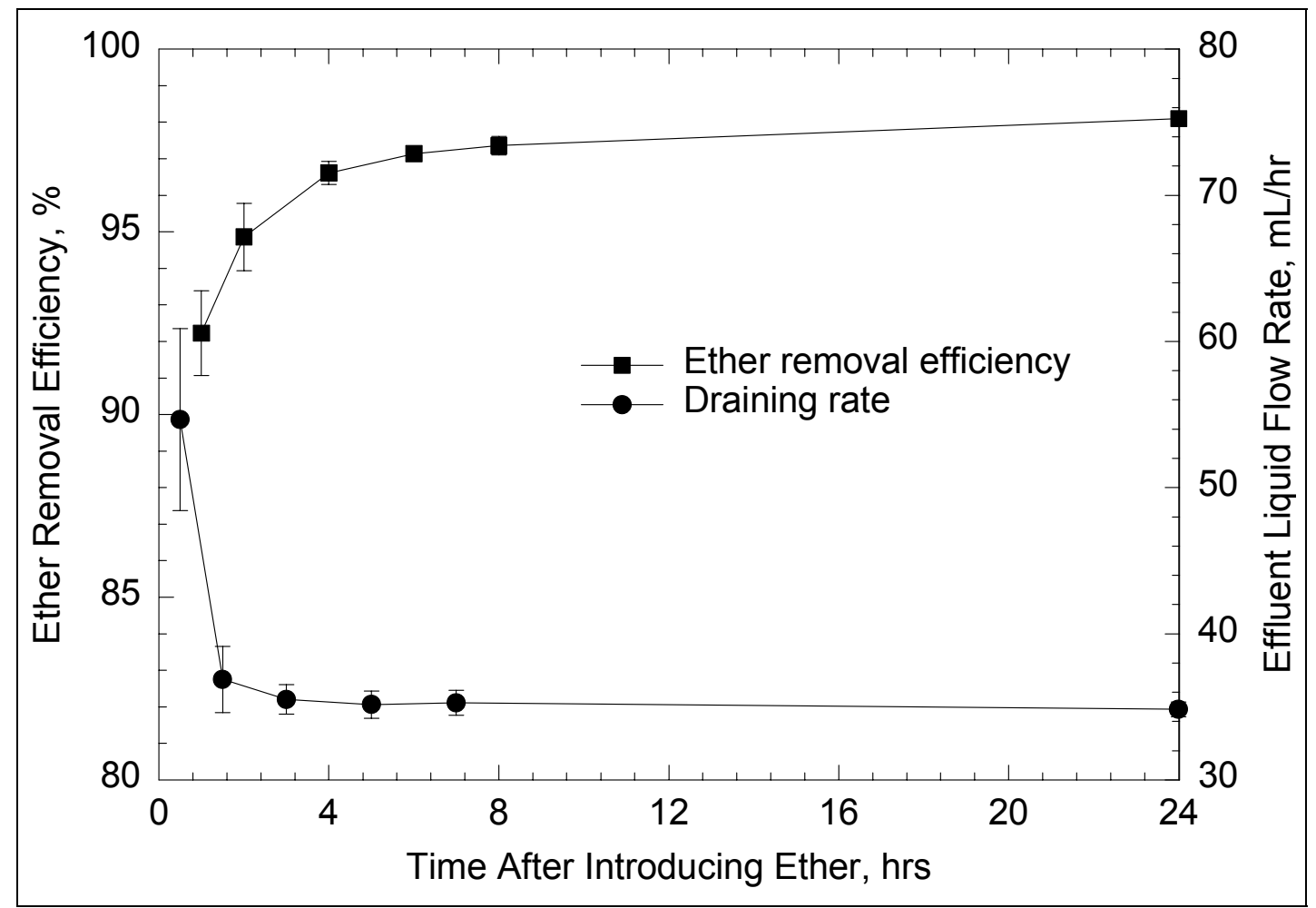

Figure 20. Effect on ether removal of liquid draining rate after flooding.

\section{Other Complicating Effects}

This study also examined other possible complicating factors for biofilter performance. An experiment was carried out to determine if stopping ether feed during the draining period had any effect on biofilter performance (Figure 21). After biofilter performance was stabilized, ether feed was stopped for 1 to 48 hours among the four biofilters before being restarted. The results showed that biofilter performance was not affected until ether was absent for more than 24 hours, which indicates that the draining effect after flooding was not complicated by the absence of ether.

To investigate whether the drop in performance related to limited oxygen content during backwashing and flooding, a study was also conducted that involved backwashing the biofilter with water high in dissolved oxygen (DO) and aerated with pure oxygen. The result indicated that different DO concentrations in backwash water had no effect on biofilter performance during this study (Figure 22).

Finally, the backwash effect and the flooding effect on ether removal are compared in Figure 23. The performance after backwashing reflects both biological and physical effects, and the performance after flooding reflects mainly physical effects. The difference between these two lines may represent mainly biological effects. It is obvious from the figure that, although biological effects seem more 
important, both biological and physical effects play significant roles in the improvement of biofilter performance after backwashing.

To better understand the biological effects, the viable biomass distribution within the biofilms was examined using an SCLM during this period. Figure 24 shows an image of a biofilm cross-section under the SCLM. Using a fluorescence stain, the live cells appear as bright spots. Most of the active biomass is seen at the surface of the biofilm, which indicates that the loss of active biomass was the major cause leading to the drop in performance immediately after backwashing.

\section{Effect of Liquid Flow Rates}

The study of the draining effect after backwashing and flooding showed that high water content in biotrickling filters might cause mass transfer limitation in the bed. Under normal operating conditions, however, the water content in biotrickling filters is much lower than that present after flooding. Water content in biotrickling filters is controlled by manipulating liquid flow rates. Since existing studies have not well explained how liquid flow affects biofilter performance, the main purpose of this phase of the study was to investigate both physical and biological effects in biotrickling filters.

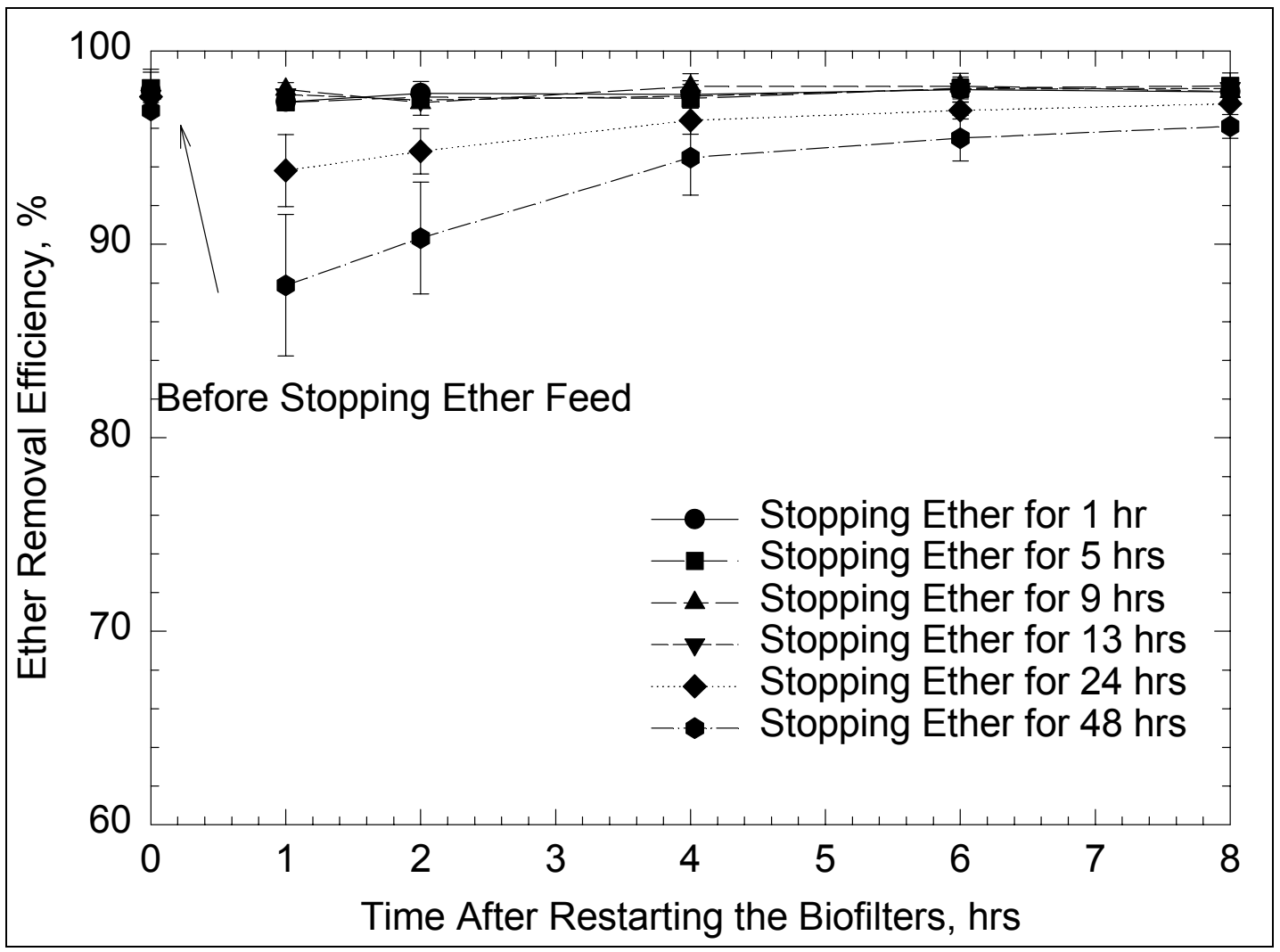

Figure 21. Influence on biofilter performance of stopping ether feed. 


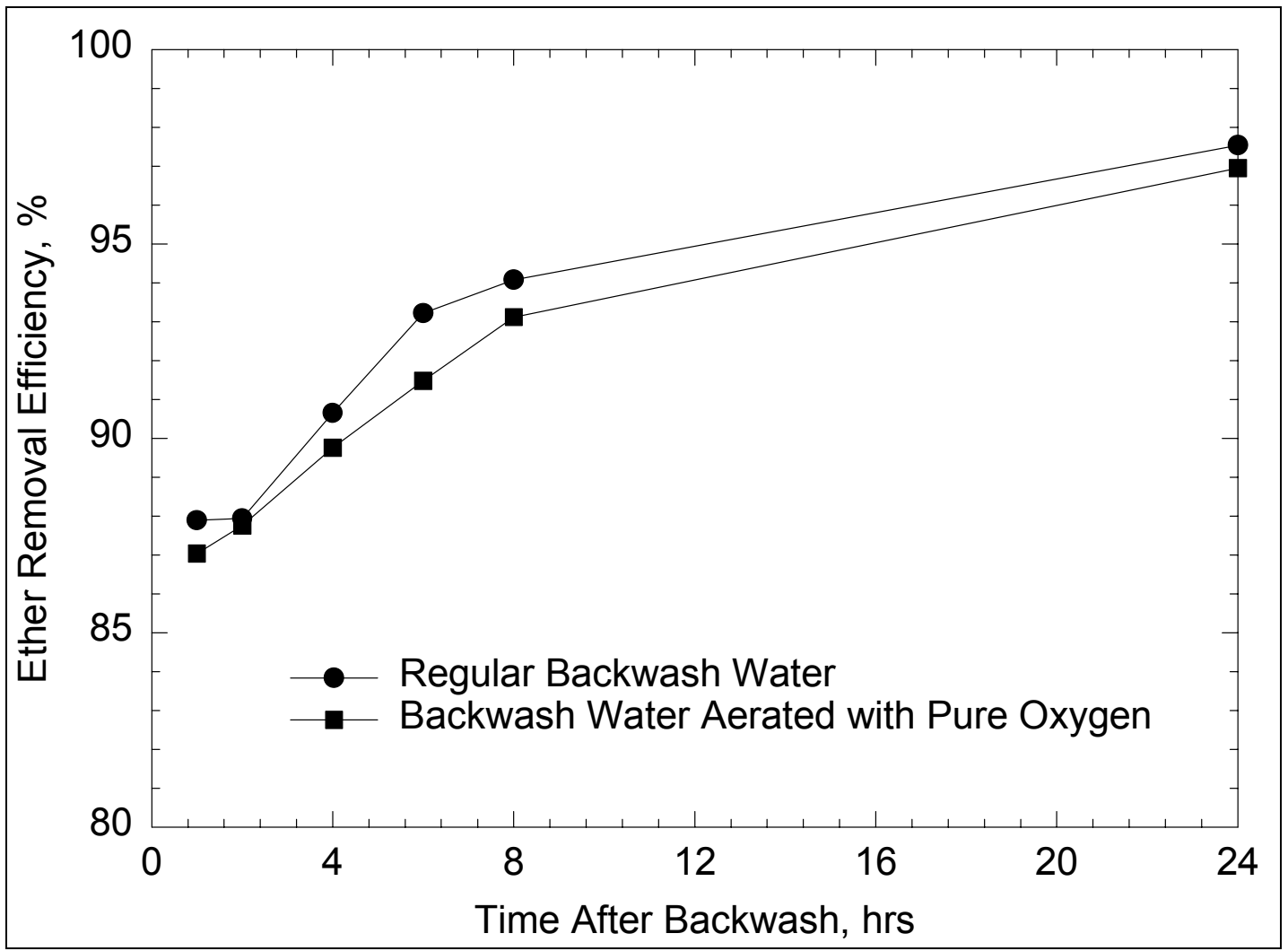

Figure 22. Influence of oxygen concentration during backwash.

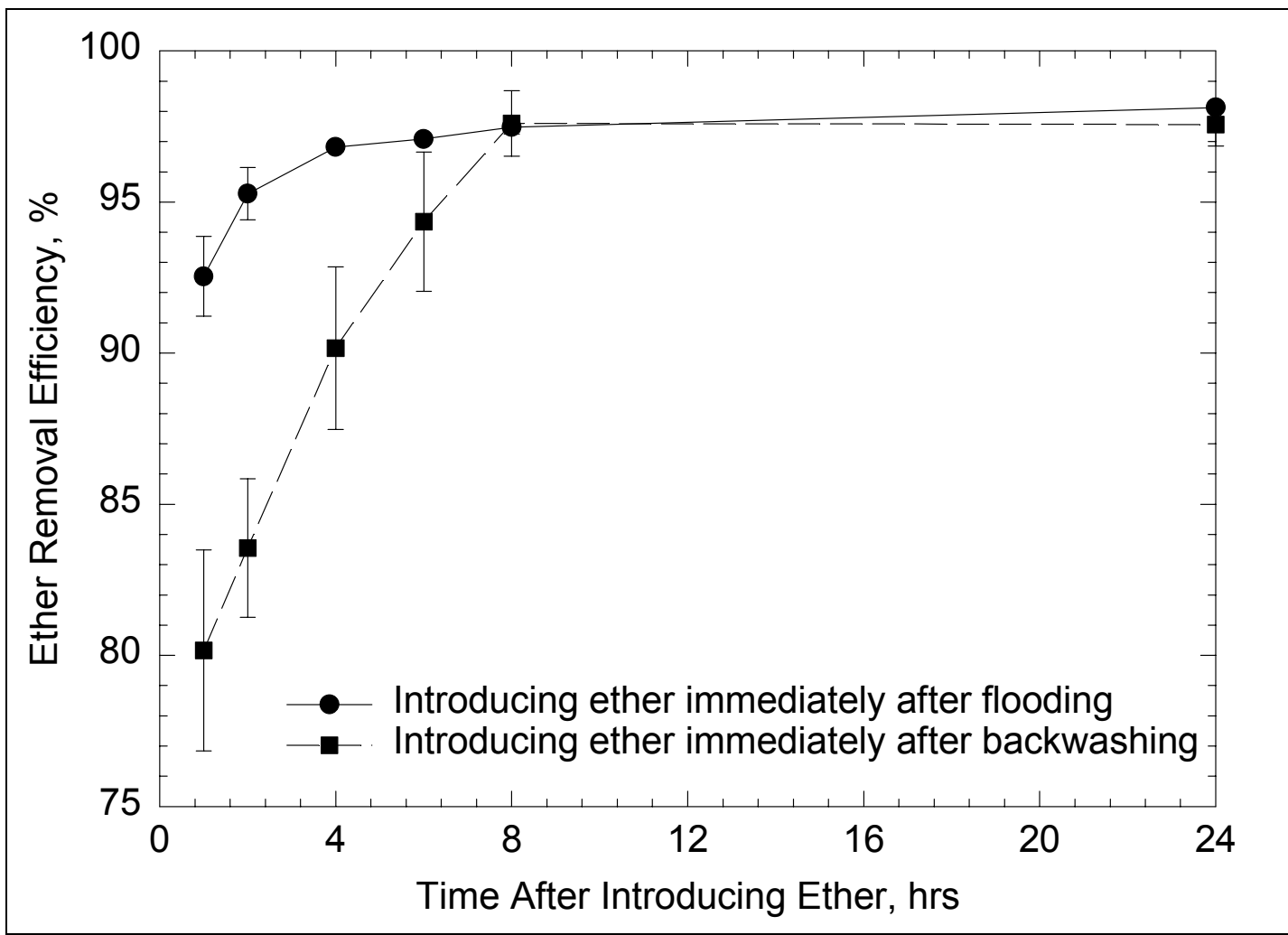

Figure 23. Comparison of the effect of flooding and backwashing on ether removal. 


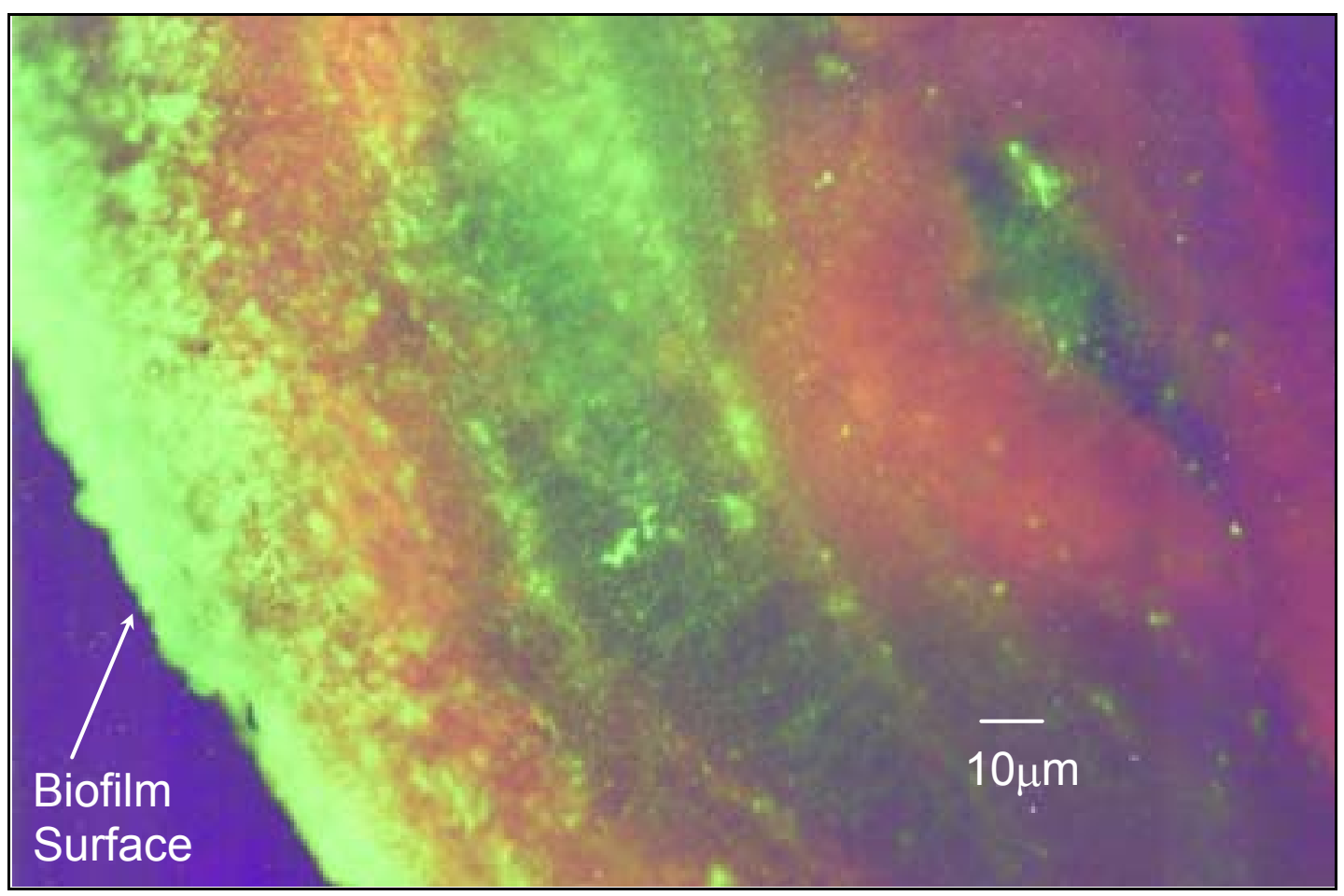

Figure 24. A biofilm cross section under a scanning confocal laser microscope.

Table 11 summarizes major operating conditions in the study of the effect of liquid flow rate. Two identical biofilters were used in this test. Both biofilters were operated at influent ether concentrations of 333 ppmv. The EBRT was kept at $25 \mathrm{sec}$ throughout the experiment, which resulted in ether loading at $7.1 \mathrm{~kg}$ $\mathrm{COD} / \mathrm{m}^{3} /$ day. The effect was studied at nutrient liquid flow rates of 1 and 20 L/day. Influent nitrate concentration was maintained at $1,067 \mathrm{mgN} / \mathrm{day}$, and backwash frequency was twice a week.

The two identical biotrickling filters were started at the nutrient liquid flow rate of $1 \mathrm{~L} /$ day. Ether removal efficiencies in both columns reached 90 percent within 2 weeks of start-up. The similarity of biofilter performance between the two columns during start-up indicates that Columns A and B operated and performed in a similar manner. Figure 25 shows the overall performance of the two biofilters with respect to ether removal.

Table 11. Major operating conditions in the study on the effect of liquid flow rate.

\begin{tabular}{lc}
\hline Influent Ether Concentrations, ppmv & 333 \\
Empty Bed Retention Time, sec & 25 \\
COD Loading Rate, kg COD/m³/day & 7.1 \\
Nutrient Liquid Flow Rate, L/day & 1 and 20 \\
Influent Air Flow Rate, $\mathrm{m}^{3}$ /day & 8.64 \\
Influent Nitrate Concentration, mg N/L & 1068 \\
Backwash Frequency & 2 \\
\hline
\end{tabular}




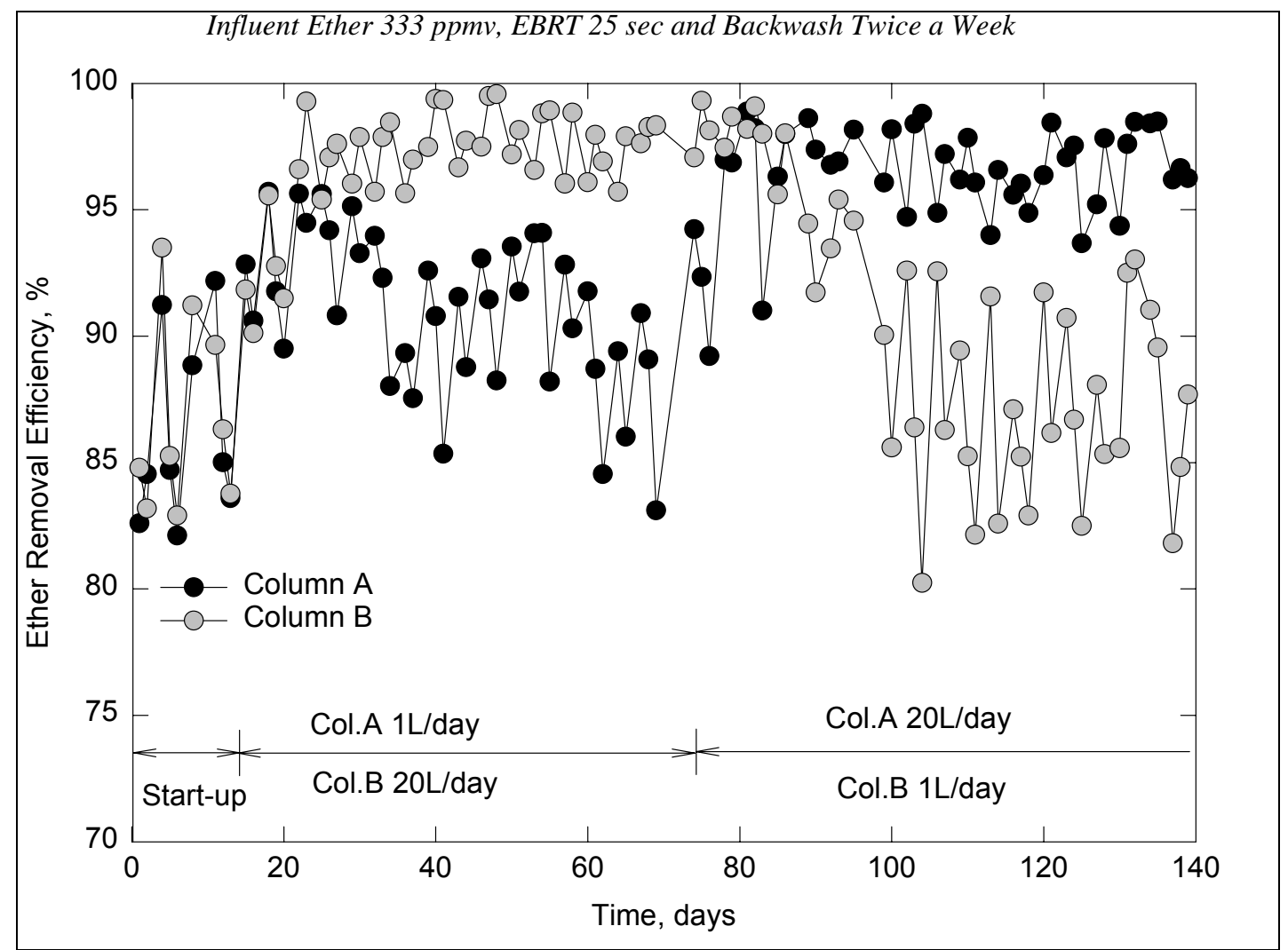

Figure 25. Effect of liquid flow rate on biofilter performance.

On day 14 of operation, the liquid flow to Column B was increased to $20 \mathrm{~L} /$ day and the liquid flow to Column A remained at $1 \mathrm{~L} /$ day. As can be seen in Figure 25 , liquid flow rates did not have a significant effect on ether removal for about a week. Ether removal efficiencies for both reactors were 92 percent on average. After a week, ether removal improved significantly in Column B. Between days 22 and 69 of operation, the average ether removal efficiency was 98 percent in Column B and 91 percent in Column A. Biofilter performance did not change immediately after the liquid flow rate was increased from $1 \mathrm{~L} /$ day to $20 \mathrm{~L} /$ day, suggesting mass transfer resistance through liquid phase for ether or oxygen was negligible.

Biomass growth analysis showed that the biofilter with a higher liquid flow rate had the higher biomass growth rate. The biomass yield was $0.093 \mathrm{gVSS} / \mathrm{gCOD}$ removed in Column A and $0.132 \mathrm{gVSS} / \mathrm{gCOD}$ in Column B. Figure 26 shows the results of phospholipid analysis, which represents the amounts of viable cells and biological activities. It can be seen that there was more viable biomass within the biofilm in the column with the higher liquid flow rate. This biomass was probably why Column B had better ether removal than Column A. Biofilm samples were also taken for water content analysis. The results showed that the biofilm water content in Column B was 93.6 percent on average; much higher 
than that in Column A, which was 85.5 percent (Figure 27). Higher water content in biofilm may also have resulted in higher biological activity. Microscopic observation of microorganisms showed that the microbial communities between the two columns were very different. In the biofilter with the higher liquid flow rate, many more filamentous organisms were observed. These results indicate that a higher liquid flow rate leads to improved biofilter performance through changes in biofilm formation and the improvement of biological activities. The results also confirmed the previous findings that biofilms in biotrickling filters are not completely covered by water. The mass transfer of substrates in the gas phase may not be limited by the liquid phase because direct mass transfer to a non-wetted biofilm may occur. That explains why no immediate effect was seen after the increase of the liquid flow rate. However, substrates in the liquid phase, like nutrients, can be transported into the biofilm only through wet areas. Increasing liquid flow may enhance their mass transfer into the biofilm, resulting in more active biomass.

To investigate whether this biological change under different liquid flow rates is repeatable and reversible, the liquid flow rates in the two biofilters were switched on day 73 of operation. The nutrient liquid flow rate was increased from $1 \mathrm{~L}$ /day to $20 \mathrm{~L}$ /day in Column $\mathrm{A}$ and decreased from $20 \mathrm{~L} /$ day to $1 \mathrm{~L}$ /day in Column B. Again, the biofilter performance did not exhibit significant change initially. About 1 week after the switch of the liquid flow rate, ether removal started to increase in Column A and decrease in Column B. Between days 82 and 139 of operation, the average ether removal efficiency was 97 percent in Column A, similar to the biofilter performance of Column B under the same conditions. The average ether removal efficiency dropped to 88 percent in Column $\mathrm{B}$, also similar to the performance of Column $\mathrm{A}$ at the same liquid flow rate during the previous stage (Figure 25). The biological properties also changed in the two biofilters. During this period, the biomass yield increased to $0.097 \mathrm{gVSS} / \mathrm{gCOD}$ in Column A and decreased to $0.062 \mathrm{gVSS} / \mathrm{gCOD}$ in Column B. It can be seen from Figures 26 and 27 that both water content and phospholipid content in biofilms increased in Column A after the increase of liquid flow rate. Although the biofilm water content did not have much change in Column $\mathrm{B}$, the phospholipid content dropped from $80 \mathrm{nmol} / \mathrm{mgVSS}$ to $60 \mathrm{nmol} / \mathrm{mgVSS}$ after the decrease in liquid flow rate. These results indicated that the change of biofilm properties and biofilter performance indeed resulted from the change in the nutrient liquid flow rate. 


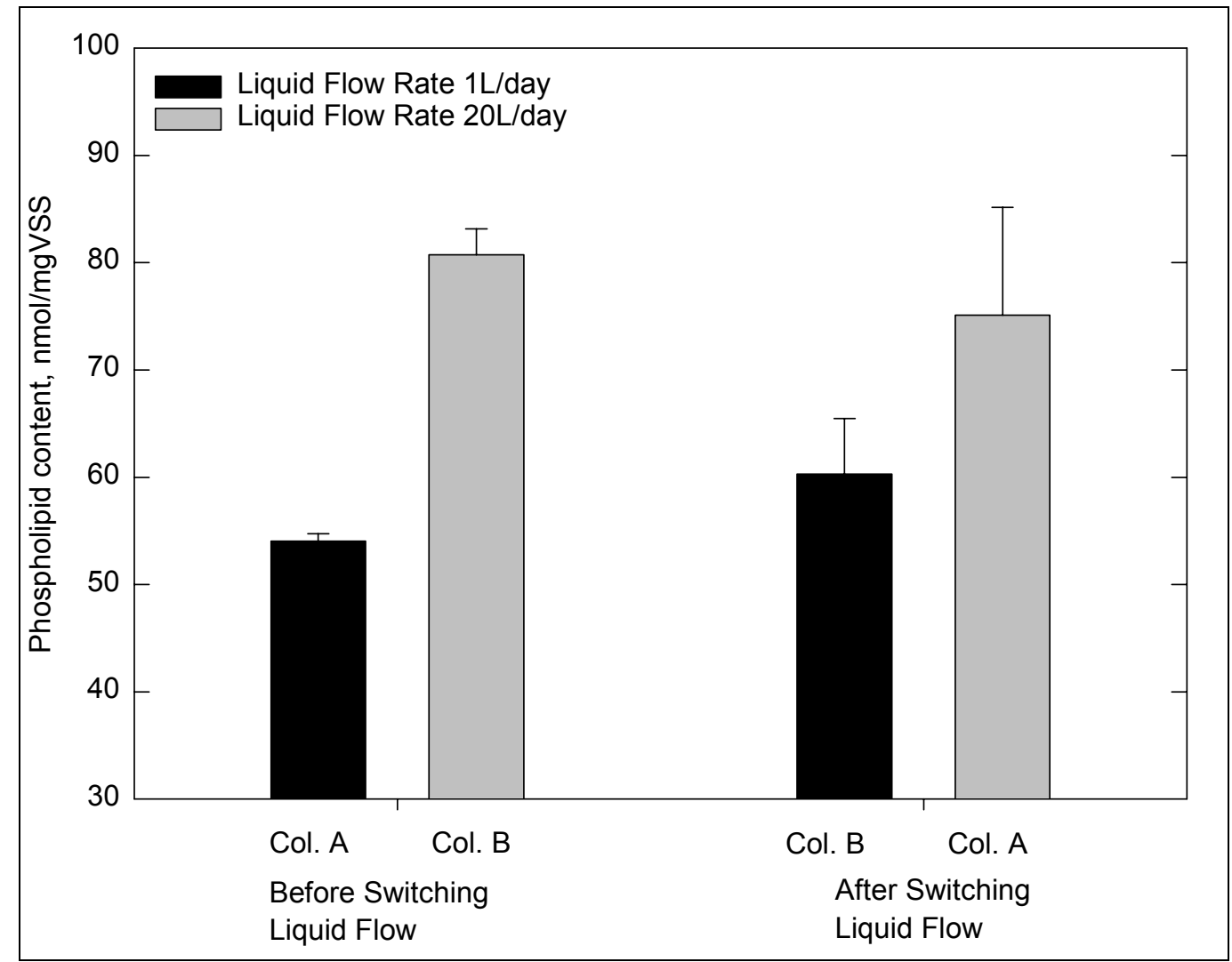

Figure 26. Effect of liquid flow on phospholipid content in biofilm.

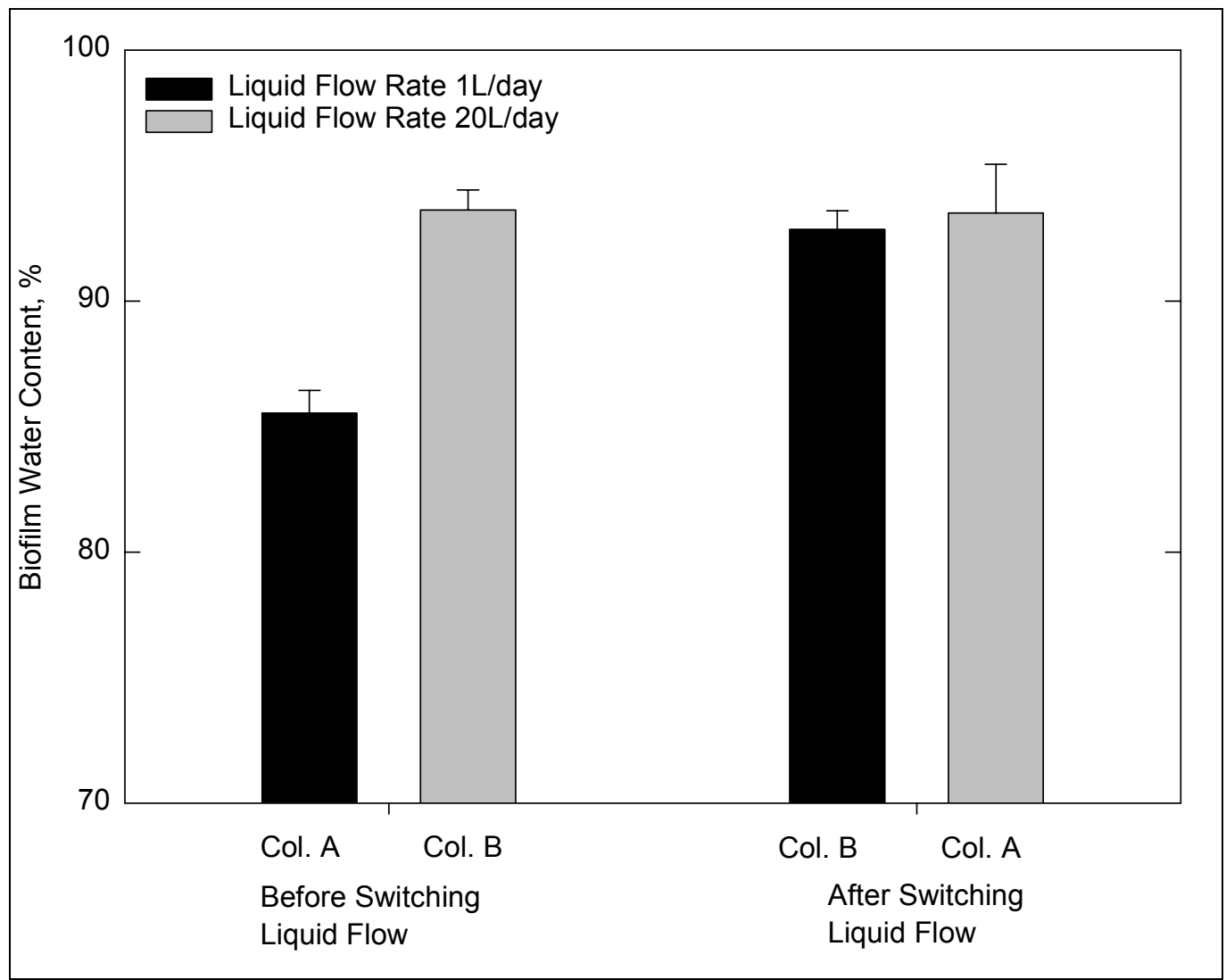

Figure 27. Effect of liquid flow rate on biofilm water content. 


\section{Summary}

Liquid phase plays a critical role in both mass transfer processes and biological reactions in biotrickling filters. This study was conducted in two phases to investigate the influence of liquid phase on VOC removal in the biofiltration processes. The effect of draining after backwashing and flooding was studied in the first phase. The results showed that both biological effect (loss of active biomass and adaptation effect) and physical effect (change in biofilm diffusivities and mass transfer resistance) play important roles in the improvement of biofilter performance after backwashing. Low water content improved the diffusivity of the VOC in the biofilm and reduced the mass transfer resistance within the biofilters.

Investigation of the effect of liquid flow rates in the second phase showed that the change of liquid flow rate has little immediate effect on biofilter performance, suggesting that mass transfer resistance through the liquid phase for ether or oxygen was negligible. A higher liquid flow rate, however, gradually leads to improved biofilter performance through changes in biofilm formation and the improvement of biological activity. The results can be attributed to the nonsaturated feature of the biofilms in gas-phase biotrickling filters. 


\section{Biofilm Structure and Oxygen Transfer Within Biofilms in Biotrickling Filters}

The importance of the nonsaturation feature of the biofilms in gas-phase biofilters has been discussed in previous chapters. The earlier studies, however, were all based on observations of the response of the biofilter to operating conditions. The internal structure of the biofilm in a gas-phase biofilter and how it affects the mass transfer of VOC, oxygen, and nitrate remains unclear. To further investigate, microelectrode techniques were used to analyze the mass transfer of oxygen within the biofilm.

\section{Experimental Set-up}

\section{Oxygen Microelectrode}

The solid-state oxygen electrode used is suitable for amperometric measurement of DO concentrations in aqueous solutions. The fabrication of this oxygen microelectrode was based on the method developed and modified by Dowben and Rose (1953), Whalen, Rilay, and Nair (1967), Linsenmeier and Yancey (1987), and Fu (1993). This oxygen microelectrode was made from a low melting-point bismuth alloy, consisting of bismuth (44.7 percent), lead (22.6 percent), indium (19.1 percent), tin (8.3 percent), and cadmium (5.3 percent). The alloy was melted and filled into the tip of a glass micropipette. Gold was electrochemically plated on the surface of the alloy tip. The tip diameter of this oxygen microelectrode was $10 \mu \mathrm{m}$.

The oxygen microelectrode was first polarized at $-750 \mathrm{mV}$ with respect to a silver / silver chloride $(\mathrm{Ag} / \mathrm{AgCl})$ reference electrode. It was then calibrated in an aqueous solution bubbled, in turn, with air (21 percent $\mathrm{O}_{2}$ ), a special gas containing 10 percent oxygen balanced with nitrogen $\left(10\right.$ percent $\left.\mathrm{O}_{2}\right)$, another special gas containing 5 percent oxygen balanced with nitrogen ( 5 percent $\mathrm{O}_{2}$ ), and pure nitrogen gas $\left(0\right.$ percent $\left.\mathrm{O}_{2}\right)$. The calibration curve of this oxygen microelectrode is illustrated in Figure 28, which shows a stable linear relationship between the electrode response and DO concentration based on duplicate sets of data obtained at the beginning and the end of the test. 


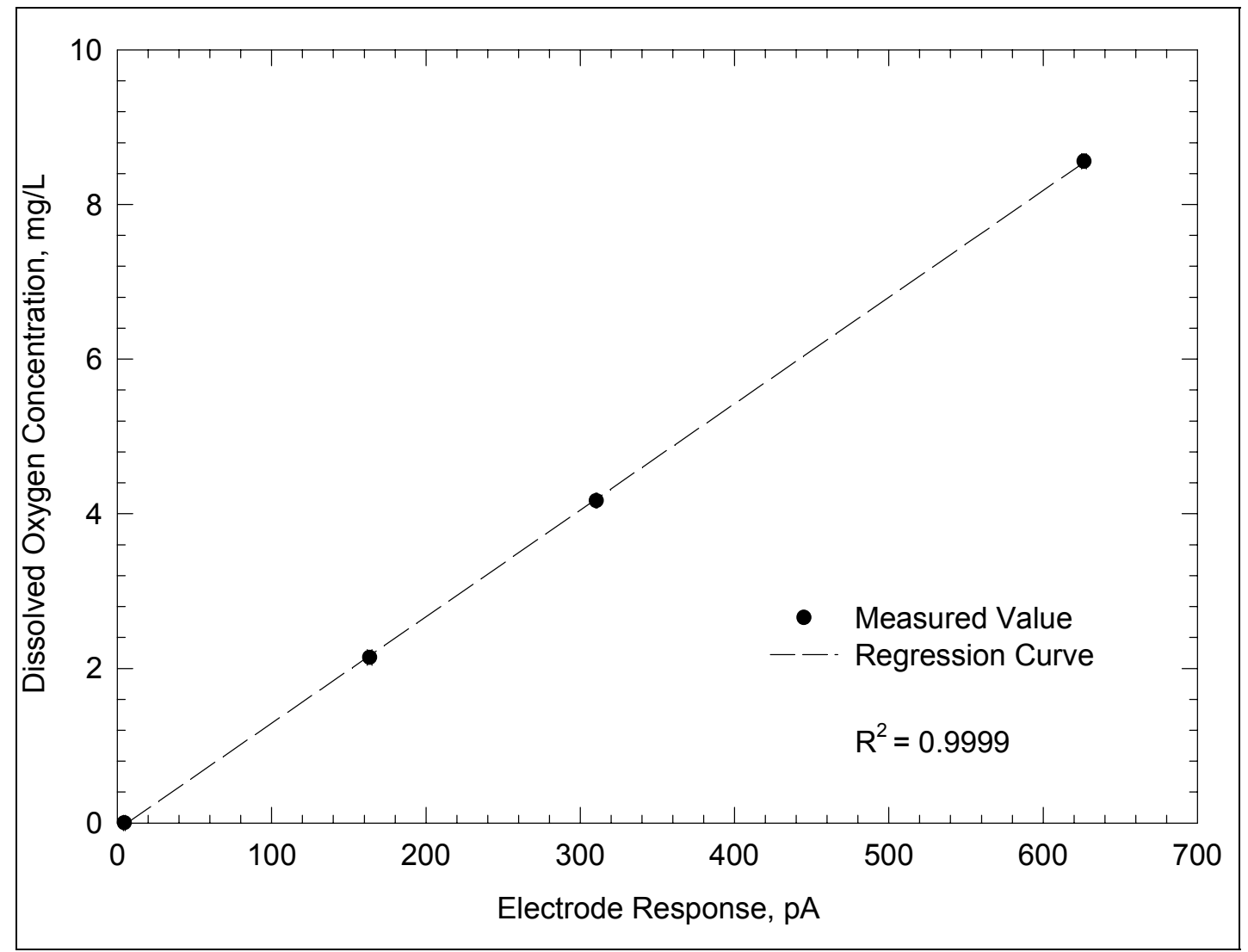

Figure 28. Calibration curve of the oxygen microelectrode.

The reference microelectrode was an $\mathrm{Ag} / \mathrm{AgCl}$ reference electrode. It was a glass micropipette filled with $3 \mathrm{M}$ of potassium chloride ( $\mathrm{KCl}$ ) solution and an $\mathrm{Ag}$ wire coated with $\mathrm{Ag} / \mathrm{AgCl}$. The tip diameter of this microelectrode was $5 \mu \mathrm{m}$.

\section{Biofilm Sample Measurements}

Figure 29 is a picture of the microelectrode measurement system. Biofilm samples grown on the ceramic pellets were taken from the biofilters and held on a small diamond holder. The diamond holder was tightly fixed at the center of a plexiglass tray. The sample and tray were placed under a Nikon SMZ-2T microscope for observation. A fiber optic light source (Dolan-Jenner Industries, 190-1) was used to illuminate the measurement area.

The oxygen microelectrode and the reference microelectrode were each fastened to a micromanipulator (World Precision, M3301). Using the micromanipulator, the tip of the reference microelectrode was placed inside the biofilm sample. The tip of the oxygen microelectrode was first positioned on the surface of the biofilm and then advanced in increments of 50 or $100 \mu \mathrm{m}$ into the biofilm sample to measure the DO concentration along the depth of the biofilm. Both microelectrodes were connected to a picoammeter for taking readings. A Faraday cage 
shielded the measurement system from possible electromagnetic interference (Yu and Bishop 1997). Biofilm samples were also observed using the Nikon SMZ-2T microscope to examine biofilm structures.

\section{Biofilm Structure and Oxygen Profiles Within Biofilms}

This experiment was conducted during the study of liquid flow rates (page 56). The biofilm samples were taken randomly from the biofilter operated at the high liquid flow rate $(20 \mathrm{~L} /$ day). Sampling locations were at the top, middle, and bottom of the column. Oxygen concentration distributions along the depth of the biofilms were measured immediately using the oxygen microelectrode.

Figure 30 profiles the oxygen concentration within a thick biofilm taken from the top of the biofilter. This biofilm was approximately 2.2-mm thick. Four profiles were obtained from the same pellet and the four analysis points were at least 1 $\mathrm{mm}$ apart to minimize interference. As the figure shows, the DO concentration at the surface of the biofilm was close to the saturation concentration of 8.5 $\mathrm{mg} / \mathrm{L}$. The DO concentrations decreased rapidly along the depth of the biofilm to between 0.1 and $0.9 \mathrm{mg} / \mathrm{L}$ at the interface of biofilm and the support pellet (the substratum). It is interesting to note two types of DO profiles within the biofilm. In one pattern (points 1 and 4), oxygen concentration decreased continuously and then stabilized after $1,000 \mu \mathrm{m}$ into the biofilm surface. The second pattern (points 2 and 3) shows that the oxygen concentration fluctuated in the deeper section of the biofilm. These patterns indicate that there are some high DO zones inside the biofilm, which suggest that certain passages for oxygen transfer into the deeper sections of the biofilm may exist in a gas-phase biotrickling filter. The latter type of profile also had a higher DO concentration at the substratum. Similar results were obtained from analysis of a few more pellets. It should be pointed out that the fluctuation in DO concentration within the biofilm was not likely caused by analytical errors. The analytical standard deviation for the microelectrode is much smaller than the range of the observed DO fluctuation.

Biofilm samples were observed with a microscope to further examine the biofilm structure. Figure 31 shows an image of a thick biofilm cross-section under the microscope. It was found that the biofilms had a layered structure with void spaces between the layers. The existence of high DO zones within the biofilm, as evidenced using the microelectrode measurements, may be attributed to this special biofilm structure. It is still unclear, however, how this layered structure was formed. 


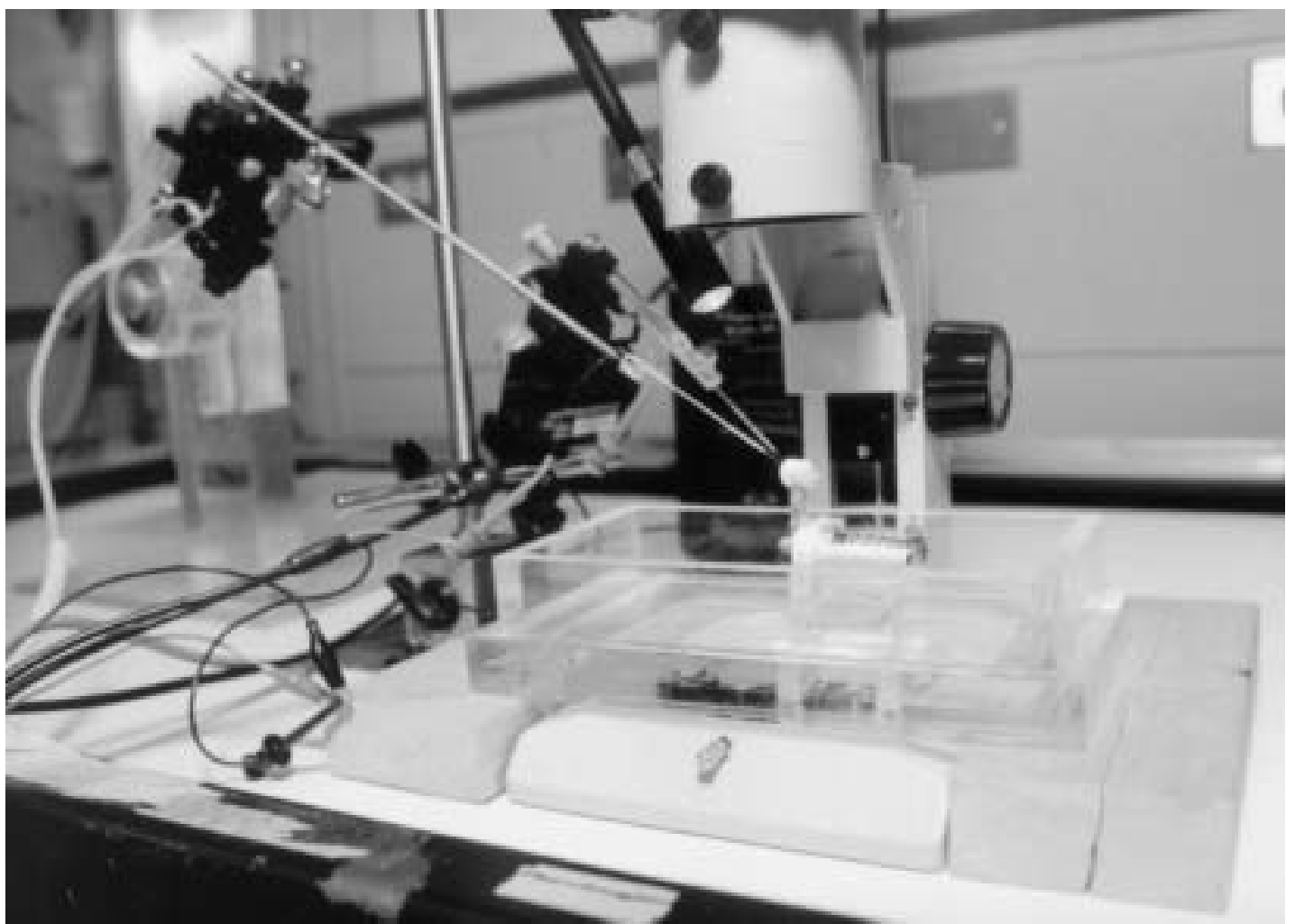

Figure 29. Microelectrode system with a biofilm pellet mounted on a diamond holder.

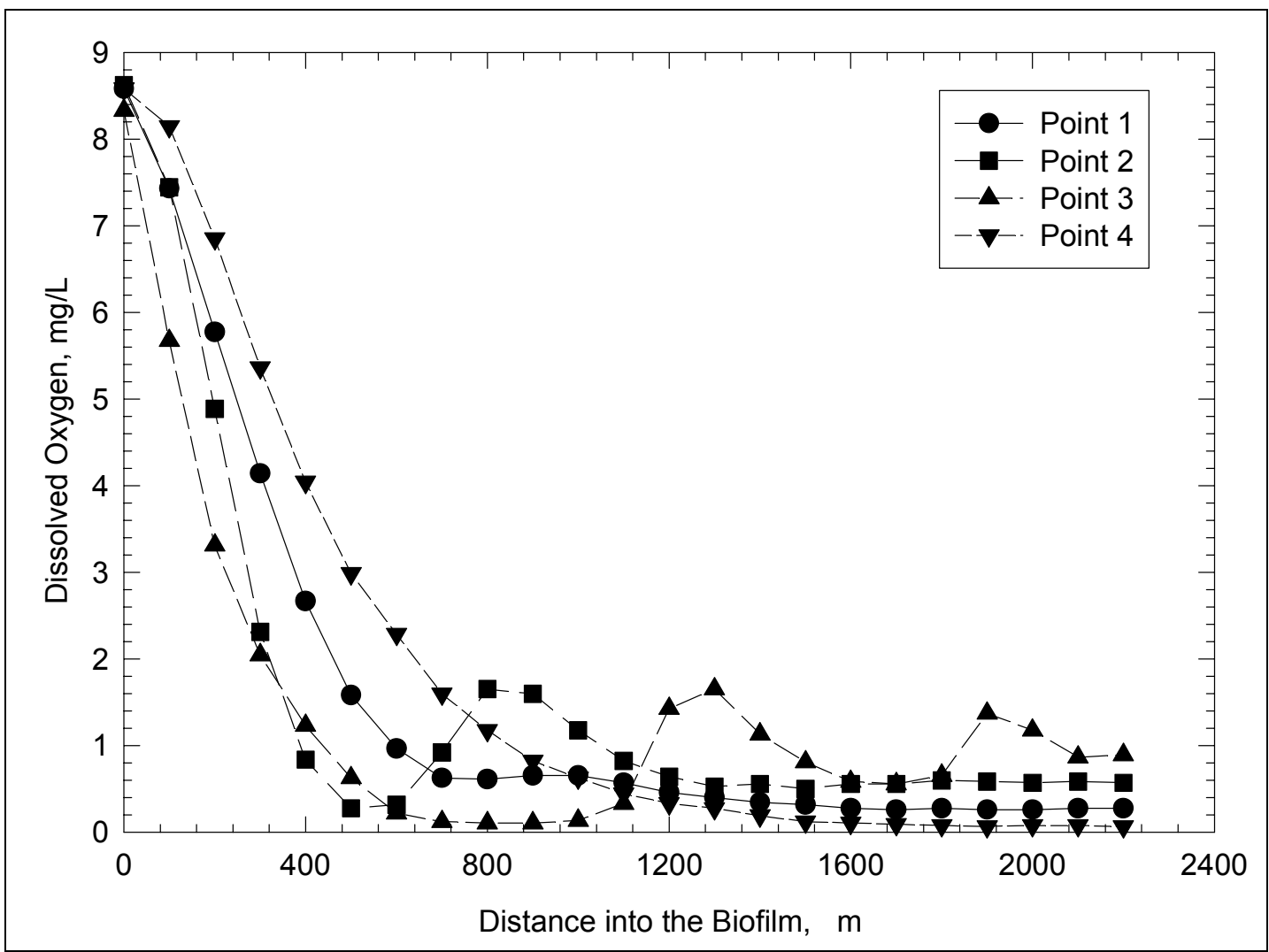

Figure 30. Profiles of oxygen concentrations within a thick biofilm taken from the top of the biofilter. 


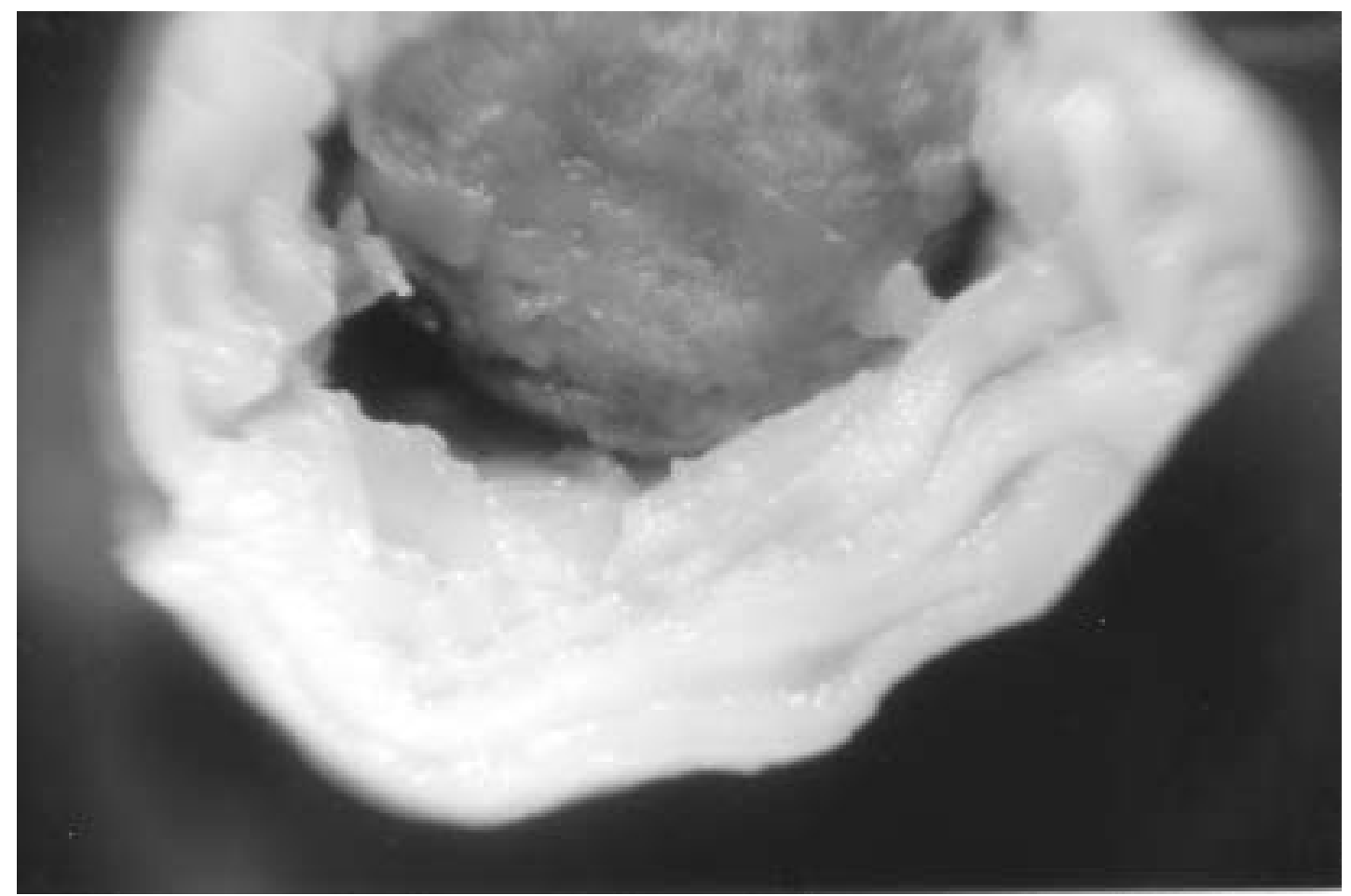

Figure 31. A cross-section of the biofilm used in this study.

\section{Mass Transfer Resistance in the Liquid Phase}

To determine the external mass transfer resistance, a test of the effect of nutrient flow application on oxygen penetration was conducted. First, a fresh biofilm sample was taken from the middle of the column and profiles of oxygen concentration within the biofilm were measured. A DO-saturated nutrient solution was then applied on the same biofilm sample at a rate similar to that applied in the biotrickling filter, and new oxygen profiles were measured immediately. The result shows that adding a small amount of water has little effect on oxygen penetration within the biofilm (Figure 32). Actually, a local increase in oxygen concentration from one profile still occurred even after the wetting of the biofilm. This result indicated that gas-liquid mass transfer resistance can be negligible in this biofilter system.

To better understand the effect of the liquid phase in the mass transfer process in a gas-phase biofilter, oxygen penetration in a biofilm submerged in a DOsaturated nutrient solution was examined and compared with the DO profiles for the same biofilm pellet when it was open to the air. As Figure 33 shows, there was a diffusion layer outside the biofilm surface when the biofilm was submerged in water. The oxygen concentration dropped dramatically before reaching the biofilm surface, which demonstrates why oxygen limitation is a much 
more serious problem for wastewater biofilm systems than gas-phase biofilm systems. The DO concentration did not continue to drop inside the biofilm when the pellet was submerged in water, probably because oxygen analysis was conducted immediately after the biofilm was submerged into the water. The DO content inside the biofilm was still very high. DO concentration dropped slightly with time among the three measurements.

Oxygen penetration along the depth of the biofilter was also investigated (Figure 34). The oxygen concentration within the biofilm increased along the medium depth from top to bottom of the biofilter. DO concentrations at the surface of all these biofilms were around the saturation concentration and decreased at the biofilm substratum to $0.5 \mathrm{mg} / \mathrm{L}, 0.9 \mathrm{mg} / \mathrm{L}$, and $4.9 \mathrm{mg} / \mathrm{L}$ for the biofilm sampled from the top, middle, and bottom of the column, respectively. This is because the biofilm became thinner and was subject to less ether substrate or less oxygen consumption from the top to the bottom of the biofilter. Unlike most wastewater biofilms in which oxygen is often depleted within a shallow layer, usually less than $0.5 \mathrm{~mm}$ into the surface ( $\mathrm{Fu} 1993)$, the biofilms as high as 2.2-mm thick still had full penetration of oxygen. This can be attributed to both the negligible gasliquid mass transfer resistance and the internal structure, which may have certain passages to facilitate oxygen transfer.

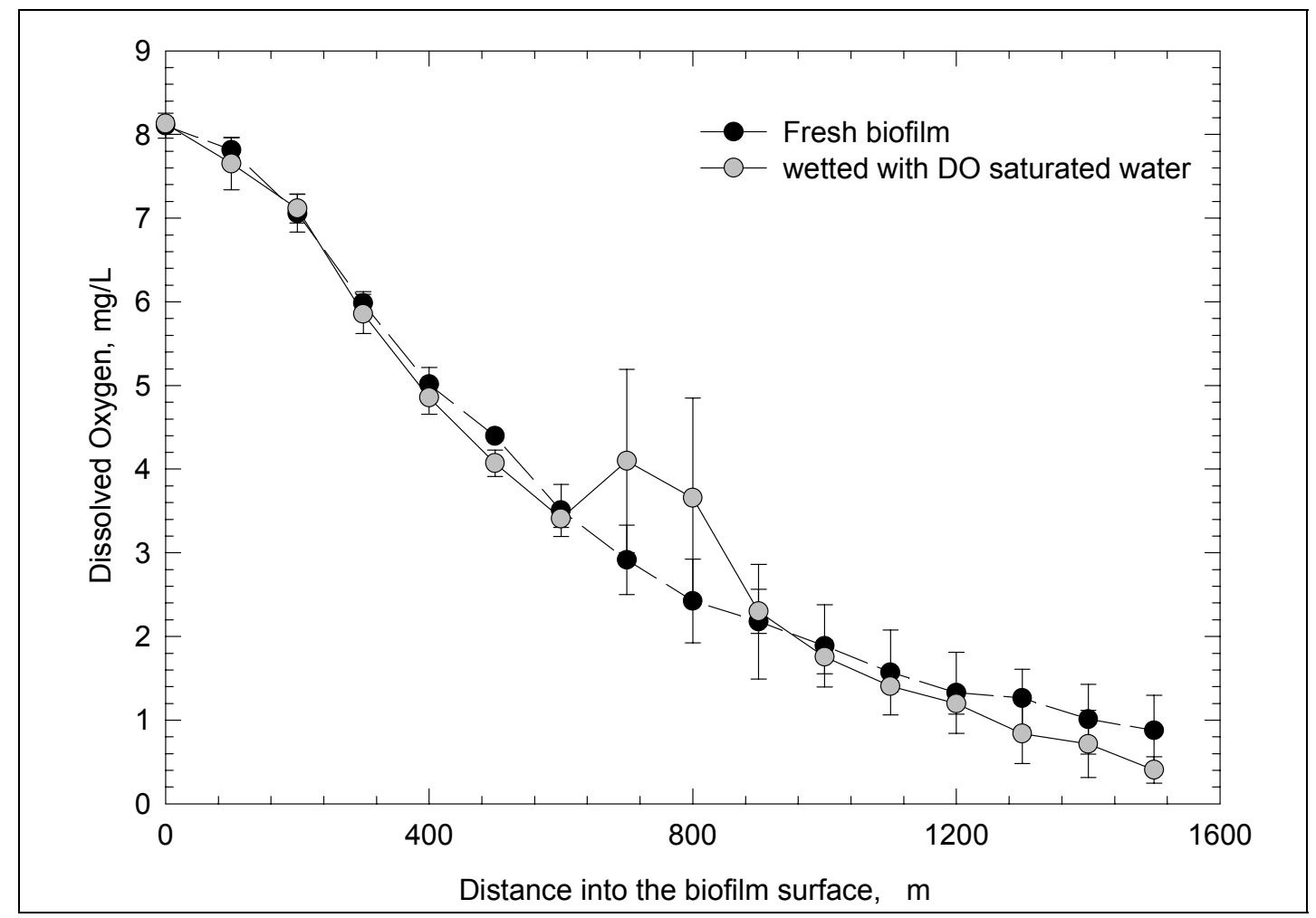

Figure 32. Effect of dropping DO-saturated water on biofilm. 


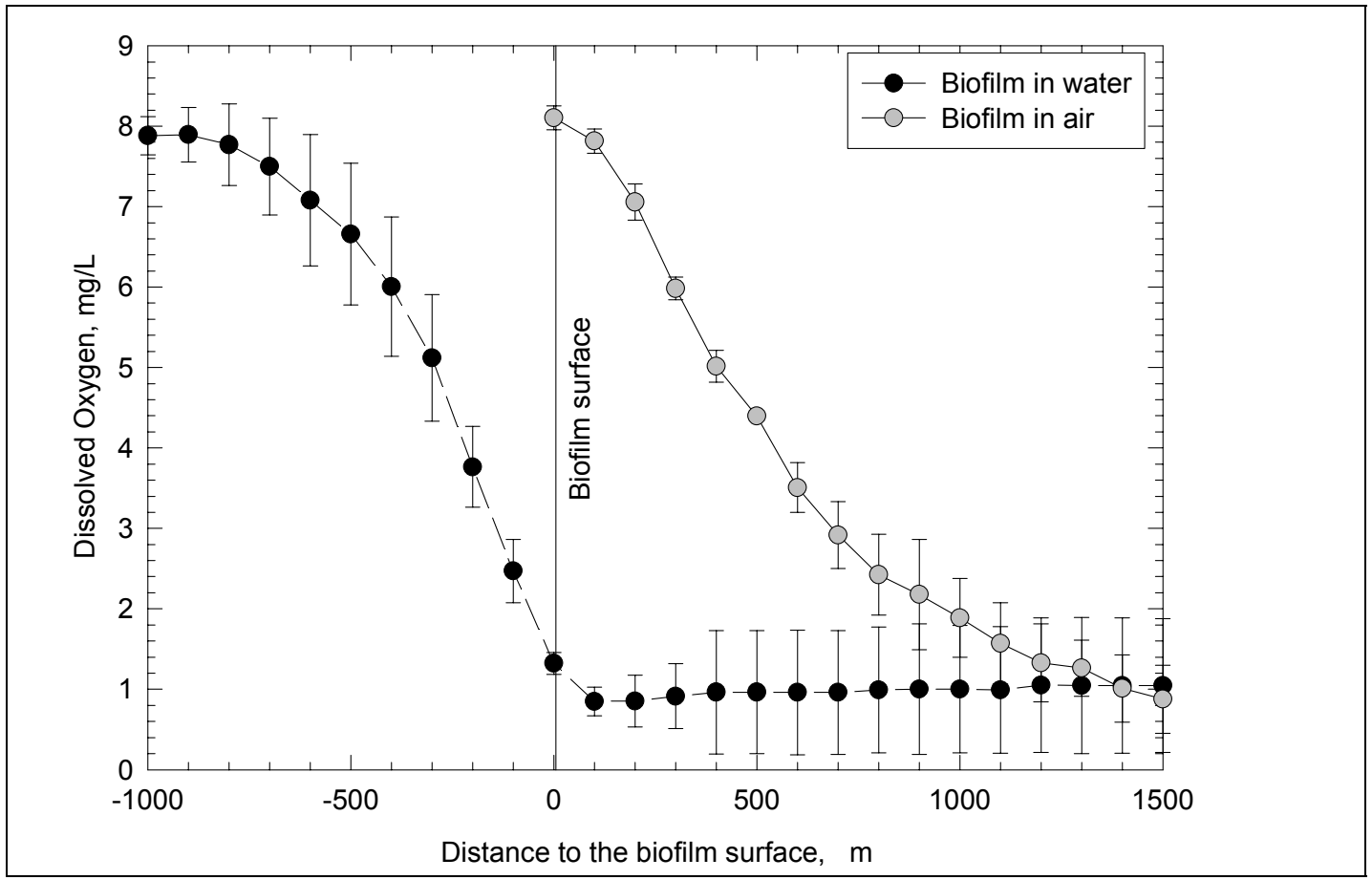

Figure 33. Comparison of oxygen profiles with biofilm in water and in air.

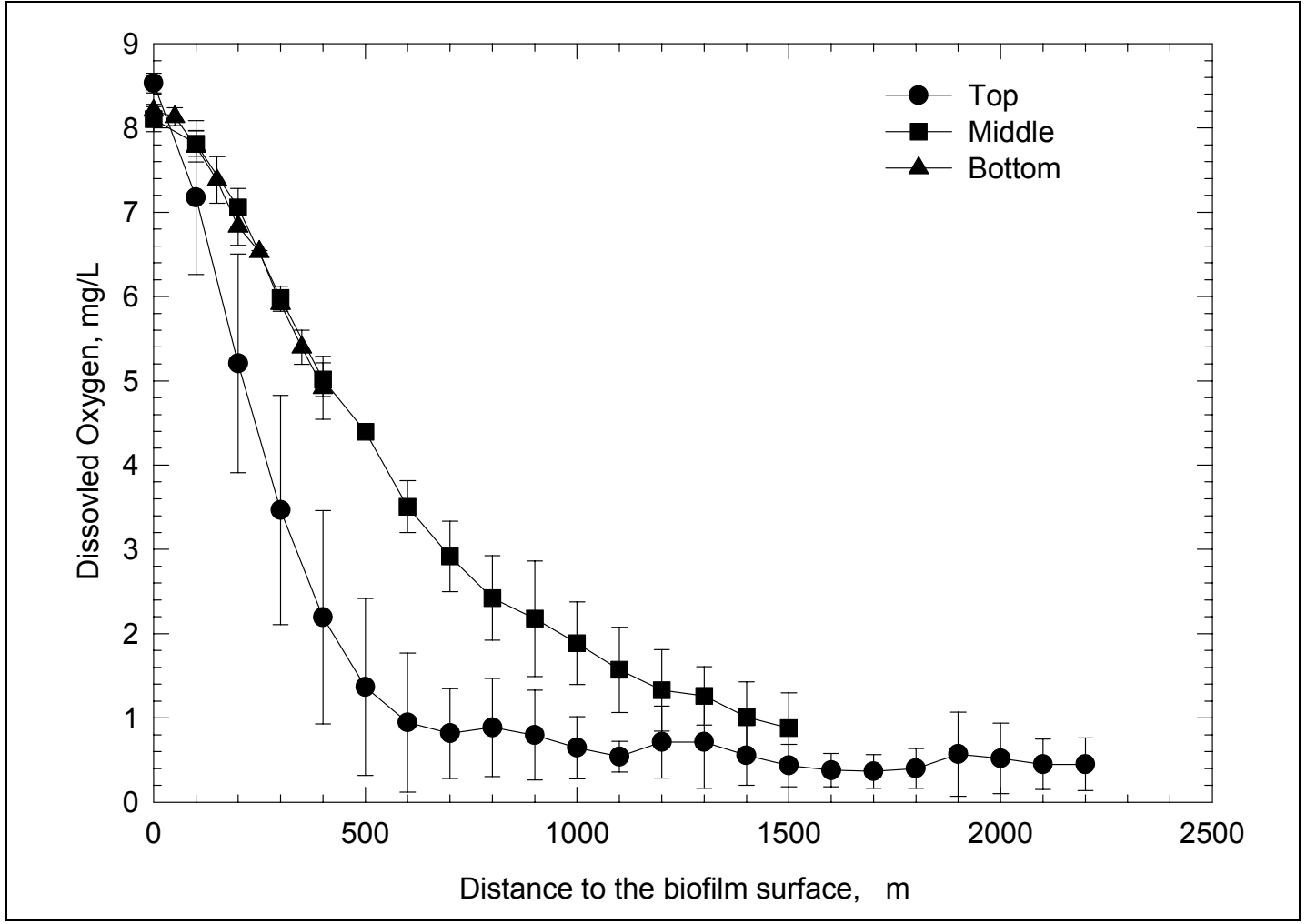

Figure 34. Oxygen profiles within biofilms along the medium depth. 


\section{Summary}

Microelectrode techniques were used, for the first time, to analyze the mass transfer of oxygen within the biofilm from a gas-phase biofilter. Results showed that, unlike most wastewater biofilms in which oxygen is often depleted within a shallow layer, biofilms as high as 2.2-mm thick still have full penetration of oxygen in a gas-phase biotrickling filter. Results also indicate that some high DO zones exist inside the biofilm, which suggests the presence of passages for oxygen transfer into the deeper section of the biofilm. The gas-liquid mass transfer resistance was also found negligible in the biotrickling filter system based on the microelectrode measurement.

Microscopic observations show that the biofilm has a layered structure with void spaces. The existence of high DO zones within the biofilm may be attributed to this special biofilm structure. Both the low gas-liquid mass transfer resistance and the special internal structure contribute to the high oxygen penetration within the biofilms in gas-phase biotrickling filters.

This study further indicated that biofilters for waste gas treatment are not completely saturated with water. Consequently, the small nutrient flow may not form a distinguishable liquid layer outside the biofilm. For gas-phase biofilters, the mass transfer of substrates in the gas phase (such as ether and oxygen) may not be limited by the aqueous phase as reported for wastewater biofilm systems, because gaseous compounds can be transported into the biofilm through nonwetted areas. On the other hand, for substrates that are present only in the liquid phase, such as nitrate, mass transfer limitations become more serious. 


\section{Effect of Henry's Constant on Biofilter Performance}

So far, all the studies presented in this report have been conducted using ether as a VOC substrate. To see a bigger picture, a study was then conducted to investigate biofilter performance in treating VOCs with a wide range of Henry's constants. As mentioned earlier, a key aspect of biofiltration is the transport of VOCs from the gas phase into the liquid phase. This process is frequently assumed to be related by vapor/liquid partition coefficients or Henry's constants. Generally, it is accepted that biofilters are only suitable to remove VOCs with moderate to low Henry's constants (De Header et al. 1994; Johnson and Deshusses 1996; Severin, Shi, and Hayes 1993). Little information has been reported, however, on how Henry's constant affects mass transfer, such as oxygen limitation and kinetics in gas-phase biofilters. The study reported in this chapter addresses these issues through both experimental investigation and theoretical analysis.

\section{Experimental Study}

\section{Model VOCs}

In this study, four model VOCs were selected to examine the effect of Henry's constant (Table 12). The selection criteria included:

1. Henry's constants vary in a wide range of magnitudes

2. Their diffusivities are not significantly different

3. All these compounds are readily biodegradable.

Since enough data have been collected for ether treatment from previous studies, the experiment conducted in the study only examined the performance of three other compounds (butanol, toluene, and hexane). Therefore, three parallel biotrickling filters were used in this experiment that are designated as Column A (butanol column), Column B (toluene column), and Column C (hexane column). The biofilters were seeded with mixed liquor taken from a local wastewater treatment plant. 
Table 12. Henry's constants and some other properties for selected VOCs.

\begin{tabular}{|c|c|c|c|c|}
\hline VOCs & $\begin{array}{c}\text { Boiling Point } \\
\left({ }^{\circ} \mathrm{C}\right)\end{array}$ & $\begin{array}{c}\text { Vapor Pressure } \\
\left(\mathrm{mmHg} \text {, at } 20^{\circ} \mathrm{C}\right)\end{array}$ & $\begin{array}{c}\text { Solubility } \\
\left(\mathrm{g} / \mathrm{L}, \text { at } 20^{\circ} \mathrm{C}\right)\end{array}$ & $\begin{array}{c}\text { Henry's Constant } \\
\left(\text { at } 25^{\circ} \mathrm{C}\right)\end{array}$ \\
\hline Iso-Butanol & 107.9 & 10 & 95 & 0.0005 \\
\hline Di-Ethyl Ether & 35.0 & 442 & 69 & 0.034 \\
\hline Toluene & 110.8 & 22 & 0.52 & 0.29 \\
\hline n-Hexanes & 68.7 & 120 & 0.013 & 53 \\
\hline
\end{tabular}

Source: Yaws 1999; Verschueren 1999.

\section{Effect of Henry's Constant}

The effect of Henry's constant was examined using a series of organic loading rates. Table 13 summarizes the major operating parameters in this study. The experimental results are shown in Figure 35 and Table 14. The three biotrickling filters were started up co-currently at an EBRT of $25 \mathrm{sec}$, inlet gas flow rates of $6 \mathrm{~L} / \mathrm{min}$, nutrient liquid flow rates of $1 \mathrm{~L} /$ day, influent nitrate concentrations of $500 \mathrm{mgN} / \mathrm{L}$, and a VOC injection rate of $0.1 \mathrm{~mL} / \mathrm{hr}$, resulting in VOC loading rates of about $2 \mathrm{~kg} \mathrm{COD} / \mathrm{m}^{3} /$ day. The results showed that the VOC elimination capacities increased with the decrease of the Henry's constants or the increase of the gas-liquid partition (Figure 35). The average removal efficiencies for treating butanol, toluene, and hexane were $99.8,86.5$, and 38.4 percent, respectively. On day 130 of this experiment, the VOC injection rate was doubled to $0.2 \mathrm{~mL} / \mathrm{hr}$ (VOC loading rates increased to about $4 \mathrm{~kg} \mathrm{COD} / \mathrm{m}^{3} /$ day), and influent nitrate concentration was also increased to $1,000 \mathrm{mg} / \mathrm{L}$. It can be seen that, with the increased influent loadings, the VOC elimination capacity also doubled for the butanol column, increased about 30 percent for the toluene column, and had little change for the hexane column, suggesting that the mass transfer between vapor and liquid or between vapor and biofilm was a rate-determining step for toluene and hexane treatment but not for butanol and ether (based on previous data) under these conditions. It was also noticed during this period that nitrate consumption was much higher than needed for biomass growth in the butanol column, suggesting that denitrification may have occurred in this reactor.

Table 13. Major operating conditions in the study of Henry's constant effect.

\begin{tabular}{ll}
\hline Influent VOC Injection Rate, $\mathrm{ml} / \mathrm{hr}$ & $0.1-0.4$ \\
Influent COD Loading Rate for Butanol Column, $\mathrm{kg} \mathrm{COD} / \mathrm{m}^{3} / \mathrm{day}$ & $2.0-8.1$ \\
Influent COD Loading Rate for Toluene Column, $\mathrm{kg} \mathrm{COD} / \mathrm{m}^{3} / \mathrm{day}$ & $2.3-9.2$ \\
Influent COD Loading Rate for Hexane Column, $\mathrm{kg} \mathrm{COD} / \mathrm{m}^{3} / \mathrm{day}$ & $2.25-9.0$ \\
Influent Nitrate Concentrations, $\mathrm{mg} \mathrm{NO} \mathrm{H}_{3} \mathrm{~N} / \mathrm{L}$ & $500-4000$ \\
Empty Bed Retention Time, sec & 25 \\
Influent Air Flow Rate, $\mathrm{m}^{3} / \mathrm{day}$ & 8.64 \\
Nutrient Liquid Flow Rate, L/day & 1.0 \\
Backwash Frequency, 1/week & $0.5-2$ \\
\hline
\end{tabular}




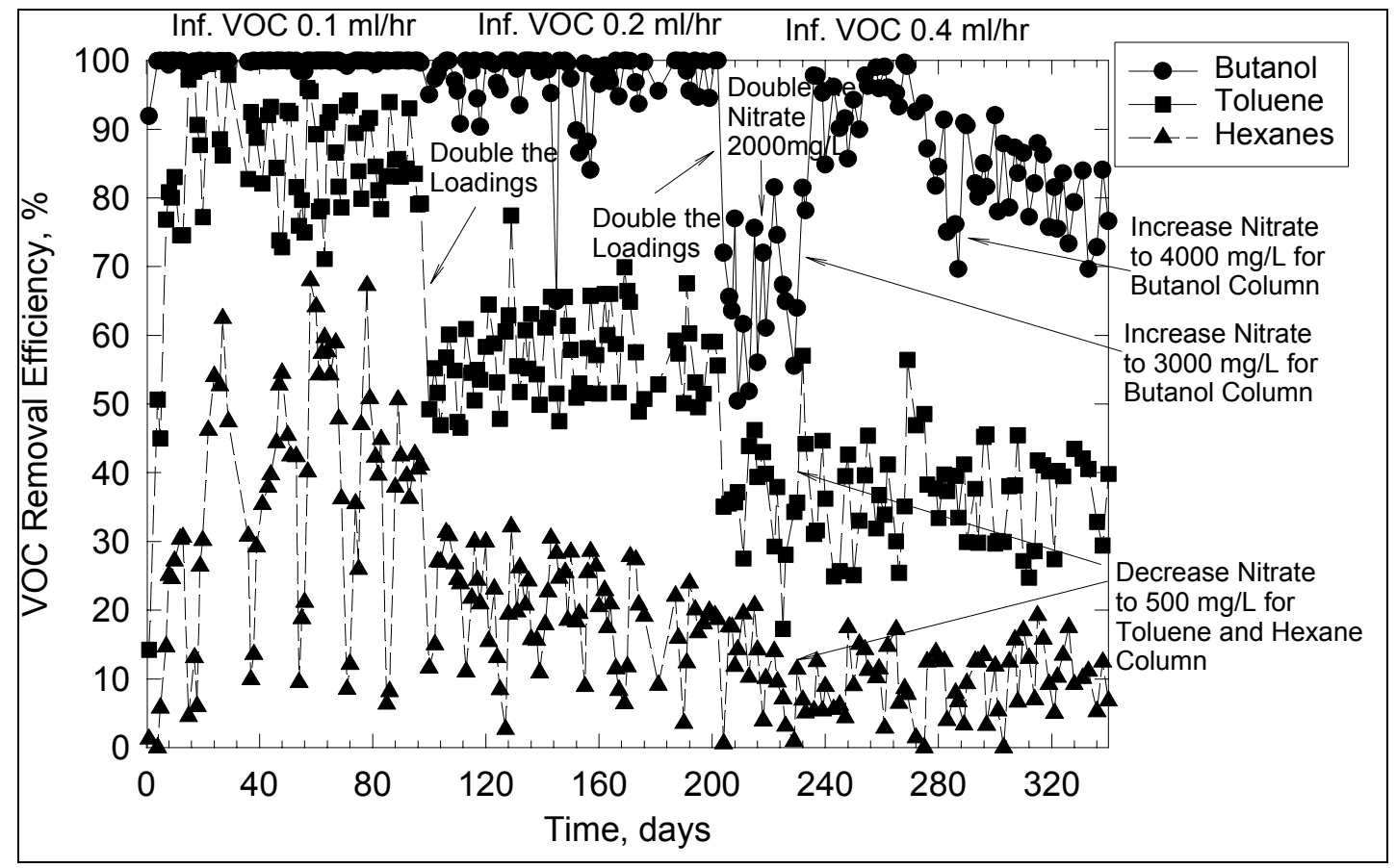

Figure 35. Effect of Henry's constant on biofilter performance.

Table 14. Effect of Henry's constants on biofilter performance during the variations of VOC and nitrate loadings.

\begin{tabular}{|c|c|c|c|c|c|c|c|c|}
\hline \multirow{2}{*}{$\begin{array}{l}\text { Time } \\
\text { Period }\end{array}$} & \multirow{2}{*}{$\begin{array}{l}\text { Average VOC } \\
\text { Loading } \\
\left(\mathrm{kg} \mathrm{COD} / \mathrm{m}^{3} \mathrm{~d}\right)\end{array}$} & \multirow{2}{*}{$\begin{array}{l}\text { Influent } \\
\text { Nitrate } \\
(\mathrm{mgN} / \mathrm{L})\end{array}$} & \multicolumn{3}{|c|}{$\begin{array}{c}\text { Average Effluent Nitrate } \\
(\mathrm{mgN} / \mathrm{L})\end{array}$} & \multicolumn{3}{|c|}{$\begin{array}{c}\text { Average VOC Removal } \\
(\%)\end{array}$} \\
\hline & & & Col. A & Col. B & Col. C & Col. A & Col. B & Col. C \\
\hline $1-99$ & 2 & 529.4 & 182.1 & 520.9 & 551.6 & 99.8 & 86.5 & 38.4 \\
\hline $100-202$ & 4 & 1028 & 83.8 & 1057 & 1115 & 97.5 & 57.0 & 19.7 \\
\hline 203-216 & 8 & 1053 & 0.73 & 1061 & 1129 & 63.7 & 37.4 & 14.4 \\
\hline $217-230$ & 8 & 1977 & 59.3 & 1680 & 2105 & 70.2 & 32.6 & 7.96 \\
\hline $231-270$ & 8 & $3046 / 536^{*}$ & 289 & 502 & 552 & 94.7 & 36.9 & 9.29 \\
\hline $288-340$ & 8 & $3849 / 497^{*}$ & 474 & 475 & 539 & 81.9 & 36.4 & 10.0 \\
\hline
\end{tabular}

* Col. A, Col. B, and Col. C represent butanol, toluene, and hexane columns, respectively. During day 231 to 326 of the operation, influent nitrate was 3,000 to $4,000 \mathrm{mgN} / \mathrm{L}$ for Col. A and $500 \mathrm{mgN} / \mathrm{L}$ for Col. $B$ and $C$.

The results also indicated that removal of excess biomass or periodical backwash is necessary to maintain long-term performance. The optimal backwash frequency of biomass removal, however, is related to Henry's constants of the VOCs. It can be seen from Figure 36 that the biofilter treating a less soluble compound took longer to recover to optimal performance, thus requiring less frequent backwash. At the two lower loadings, backwash frequencies were chosen at once a week for both the butanol and toluene columns, and once very two weeks for the hexane column. 


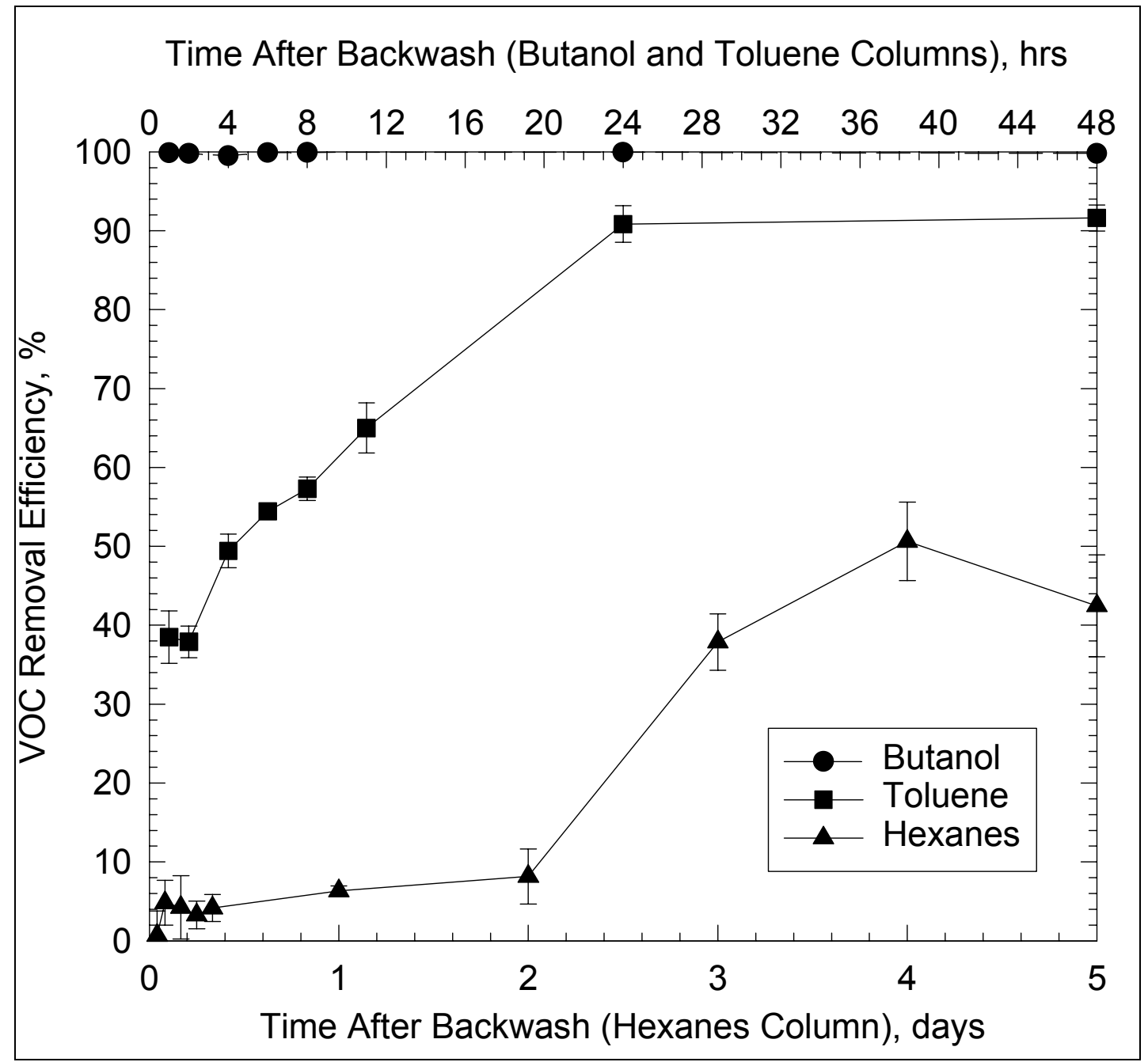

Figure 36. Influence of backwash on different VOC removal at VOC loading of $2 \mathrm{~kg} / \mathrm{m}^{3} / \mathrm{day}$.

On day 203 of the operation, the VOC loading rate was further increased to about $8 \mathrm{~kg} \mathrm{COD} / \mathrm{m}^{3} /$ day. Based on the previous results, backwash frequencies during this period were chosen to be twice a week for the butanol column, once a week for the toluene column, and once every 2 weeks for the hexane column. The results showed once again that the VOC elimination capacities increased with the decrease of the Henry's constants. However, a dramatic drop in butanol removal from 98 to 64 percent was observed after the increase of VOC loading. The drop in performance was a result of the nitrate limitation caused by denitrification occurring in the butanol column. The expected nitrate consumption for biomass growth was about $110 \mathrm{mgN} / \mathrm{L}$ based on the biomass yield of 0.042 gVSS/gCOD during this period and assuming 14 percent nitrogen in the biomass. However, the effluent nitrate concentration was below $1 \mathrm{mgN} / \mathrm{L}$ with an influent nitrate concentration of $1000 \mathrm{mgN} / \mathrm{L}$. To eliminate nitrate limitation, the nitrate concentration in nutrient feed was further increased to $2,000 \mathrm{mg} / \mathrm{L}$ on day 216 of the operation. Butanol removal efficiency did increase from 64 to 70 percent, but 
the effluent nitrate concentration still dropped to only $59 \mathrm{mg} / \mathrm{L}$ on average. Further increase of nitrate concentration became necessary. At the same time, VOC removal decreased in the toluene and hexane columns when the influent nitrate was raised to $2,000 \mathrm{mg} / \mathrm{L}$, suggesting that inhibition may have occurred at this high nitrate concentration. On day 231, two nutrient feed systems were used to provide optimal nutrient solution for the butanol column and the other two columns. The influent nitrate concentration was further increased to $3,000 \mathrm{mgN} / \mathrm{L}$ for the butanol-fed column and decreased to $500 \mathrm{mgN} / \mathrm{L}$ for the toluene and hexane-fed columns. It can be seen from Figure 35 and Table 14 that the butanol removal efficiency increased immediately from 70 percent to over 90 percent after the increase of influent nitrate. The effluent nitrate concentration in this reactor was $289 \mathrm{mgN} / \mathrm{L}$ on average, suggesting the increase of influent nitrate was necessary to provide sufficient nitrate as both a nutrient and an electron acceptor. At the same time, after the influent nitrate concentrations were reduced to $500 \mathrm{mgN} / \mathrm{L}$, the performance in toluene and hexane columns were stabilized or recovered. After day 270, however, the butanol removal gradually decreased and the trend did not stop even after the influent nitrate concentrated was further increased to $4,000 \mathrm{mgN} / \mathrm{L}$ on day 288 , suggesting that there was a culture change and denitrifiers were accumulating during this period. It was estimated through a mass balance that about 40 percent of the butanol removed was degraded through denitrification at influent nitrate of $4,000 \mathrm{mgN} / \mathrm{L}$.

That denitrification occurred in the butanol column can be attributed to the extremely low Henry's constant of butanol, which led to a high butanol concentration in the aqueous and biofilm phases, and resulted in oxygen limitation in the biofilter. This study also demonstrated that long-term investigation on the effect of Henry's constant is necessary because oxygen limitation may not be observed in a short-term study like the one conducted by Johnson and Deshusses (1996).

\section{Theoretical Analysis}

\section{Model Simulation}

The purpose of the model simulation here is not to achieve a best fit of the experimental data or to conduct parameter estimation. Rather, it is to achieve better understanding of the experimental results and effect of Henry's constant in general. The comparison of experimental results and model simulation will also provide more insights for future model improvement. The simplified version of the model described in Chapter 3 was used to simulate the effect of Henry's constant. The mathematical model considers a dynamic three-phase system (gas, water, and biofilm), non-uniform biomass distribution, and one limiting 
substrate (VOC). The basic simulation parameters are shown in Table 15. These parameters were obtained through a parameter estimation study using ether as a substrate (Alonso et al. 2000).

The comparison of experimental results and model simulation under various influent VOC loadings is shown in Table 16 and Figure 37. The results of model simulation were based on the calculated VOC removal after three backwash cycles or after the dynamic removal reached a quasi steady state. The experimental data for ether removal is from the study presented in Chapters 4 and 5, and based on the results under the condition of no nitrate limitation. It can be seen that, although the general trend showed that VOC removal increased with the decrease of the Henry's constants, the model did not fit the data well except for the case of ether removal. For butanol treatment, the model overestimated the removal because the model did not consider oxygen limitation and denitrification. For toluene removal, only one point fits well, but the trend for toluene removal under various VOC loadings did not agree between the model simulation and experimental results. This problem may be resolved by using appropriate parameters for toluene treatment. For hexane removal, however, the model greatly underestimated the removal. Hexane removal varied from 10 to 40 percent during the experimental study, but model simulation could never reach more than 1 percent removal efficiency. This underestimation may have resulted from the use of incorrect parameters and may also be attributed to the fact that the model did not consider the special biofilm structure in this reactor. Unlike the biofilters treating the other three compounds in this study, there was no visible biofilm grown around the media pellets in the hexane-fed column. The effect of the internal pores of this porous media may not be negligible in this case. By considering a porous media, the surface area will be greatly increased and better simulation results could be achieved.

Table 15. Basic simulation parameters.

\begin{tabular}{|c|c|}
\hline Parameters & Value \\
\hline Monod constant, $\mathrm{K}_{\mathrm{s}}$ & $0.1 \mathrm{mg} \mathrm{COD} / \mathrm{L}$ \\
\hline Biomass yield coefficient, $Y$ & $0.19 \mathrm{~g} \mathrm{COD}$ biomass/g COD substrate \\
\hline Maximum growth rate, $\square \mu_{\mathrm{m}}$ & 0.4 day $^{-1}$ \\
\hline Biomass maintenance rate, $b$ & 0.1 day $^{-1}$ \\
\hline Decay rate coefficient, $k_{d}$ & 0.035 day $^{-1}$ \\
\hline Detachment coefficient, $\mathrm{C}_{\mathrm{det}}$ & 0.06 day $^{-1}$ \\
\hline Active biomass concentration, $\mathrm{X}$ & $45000 \mathrm{~g} \mathrm{COD} / \mathrm{m}^{3}$ \\
\hline Biofilm/water diffusivity ratio, $r_{d}=D_{f s} / D_{w s}$ & 0.2 \\
\hline VOC diffusivity in water & $9.0 \times 10^{-6} \mathrm{~cm}^{2} / \mathrm{s}$ \\
\hline Initial biofilm thickness, $\mathrm{L}_{\mathrm{f} 0}$ & $0.01 \mathrm{~cm}$ \\
\hline Initial fraction of active biomass & 0.8 \\
\hline
\end{tabular}


Table 16. Effect of Henry's constant on biofilter performance: model simulation and experimental data.

\begin{tabular}{|c|c|c|c|c|c|c|c|c|c|c|c|}
\hline \multicolumn{3}{|c|}{ Butanol } & \multicolumn{3}{|c|}{ Ether } & \multicolumn{3}{|c|}{ Toluene } & \multicolumn{3}{|c|}{ Hexane } \\
\hline \multirow[b]{2}{*}{ Load } & \multicolumn{2}{|c|}{ Removal, \% } & \multirow[b]{2}{*}{ Load } & \multicolumn{2}{|c|}{ Removal, \% } & \multirow[b]{2}{*}{ Load } & \multicolumn{2}{|c|}{ Removal, \% } & \multirow[b]{2}{*}{ Load } & \multicolumn{2}{|c|}{ Removal, \% } \\
\hline & Model & Data & & Model & Data & & Model & Data & & Model & Data \\
\hline 2.02 & 100 & 99.8 & 1.78 & 100 & 99.9 & 2.31 & 67.0 & 86.5 & 2.25 & 0.73 & 38.4 \\
\hline 4.04 & 100 & 97.5 & 3.56 & 99.9 & 99.0 & 4.62 & 56.2 & 57.0 & 4.5 & 0.75 & 19.7 \\
\hline 8.08 & 100 & $94.7^{*}$ & 7.12 & 97.5 & 97.7 & 9.24 & 45.2 & 36.9 & 9 & 0.72 & 9.38 \\
\hline
\end{tabular}

*Based on results during the stable period at influent nitrate concentration of $3,000 \mathrm{mg} / \mathrm{L}$

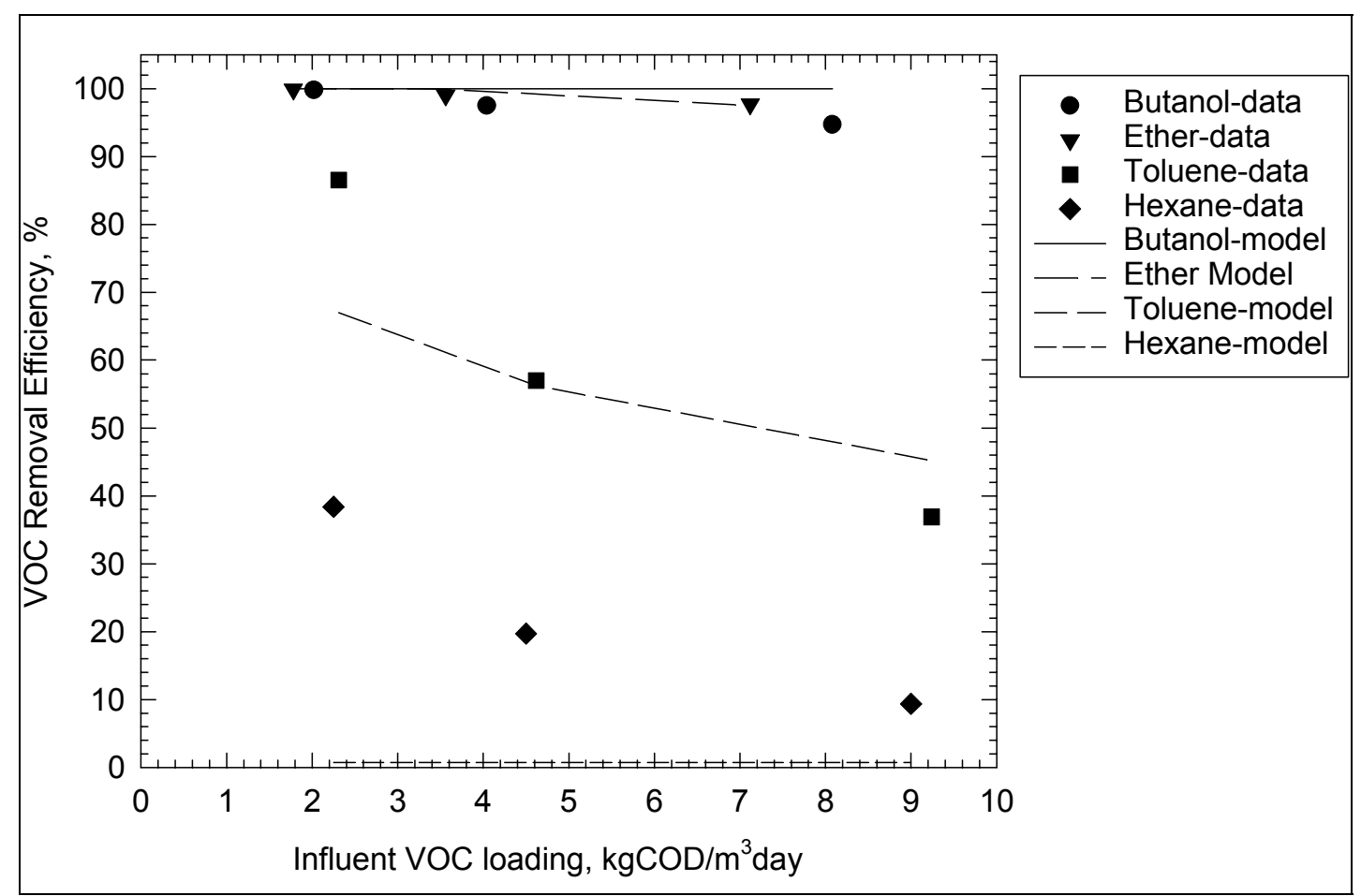

Figure 37. Effect of Henry's constant: data and model simulation.

Since different VOCs with different kinetic and mass transfer properties were used in this study to investigate the effect of Henry's constant, one fundamental question that should be addressed is how these factors affected or complicated the effect of Henry's constant on biofilter performance. To answer this question, the effect of two major kinetic parameters (Monod constant and maximum growth rate) and substrate diffusivity in biofilm were simulated under a wide range of Henry's constants $\left(10^{-4}\right.$ to 100$)$, using the fundamental model and the parameters listed in Table 15 (unless indicated otherwise). The influent gasphaseVOC concentration of $1.17 \mathrm{mgCOD} / \mathrm{L}$ was used in the simulation, which corresponds to an influent COD loading rate of $4 \mathrm{~kg} / \mathrm{m}^{3} /$ day in our biofilter system. 


\section{Effect of Monod Constant}

Figure 38 shows that effect of the Monod constant, $\mathrm{K}_{\mathrm{s}}$, on VOC removal under a wide range of Henry's constant. It can be seen that, with the increase in Henry's constant or the decrease in available substrate in the biofilms, the VOC removal efficiency decreases. At the same time, as the Monod constant is increased from $10^{-6}$ to $100 \mathrm{mg} / \mathrm{L}$, the VOC removal efficiency decreases significantly for VOC with Henry's constant between 0.02 and 1. However, when Henry's constant is less than approximately 0.01 (such as for butanol) or greater than 10 (such as for hexanes), the Monod constant is no longer a limiting factor.

\section{Effect of Maximum Growth Rate}

A similar trend can be seen for the effect of the maximum growth rate, $\mu \mathrm{m}$, on VOC removal (Figure 39). As the maximum growth rate increases from 0.2 to 4 day $^{-1}$, the VOC removal efficiency increases significantly when the Henry's constant value is between 0.1 and 10. However, when Henry's constant is less than approximately 0.01 (such as for butanol) or greater than 10 (such as for hexanes), maximum growth rate becomes unimportant.

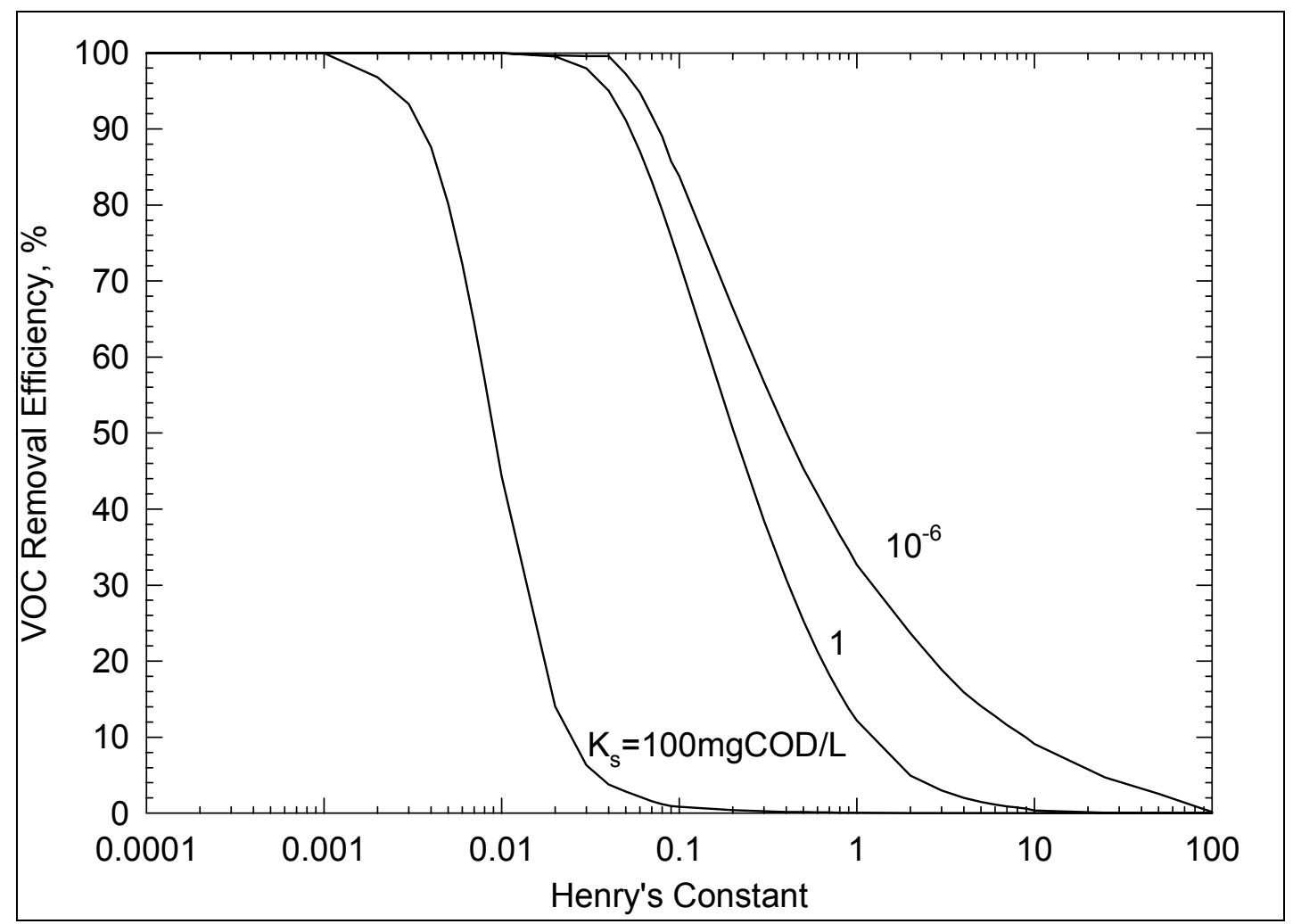

Figure 38. Effect of Monod constant vs effect of Henry's constant on VOC removal. 


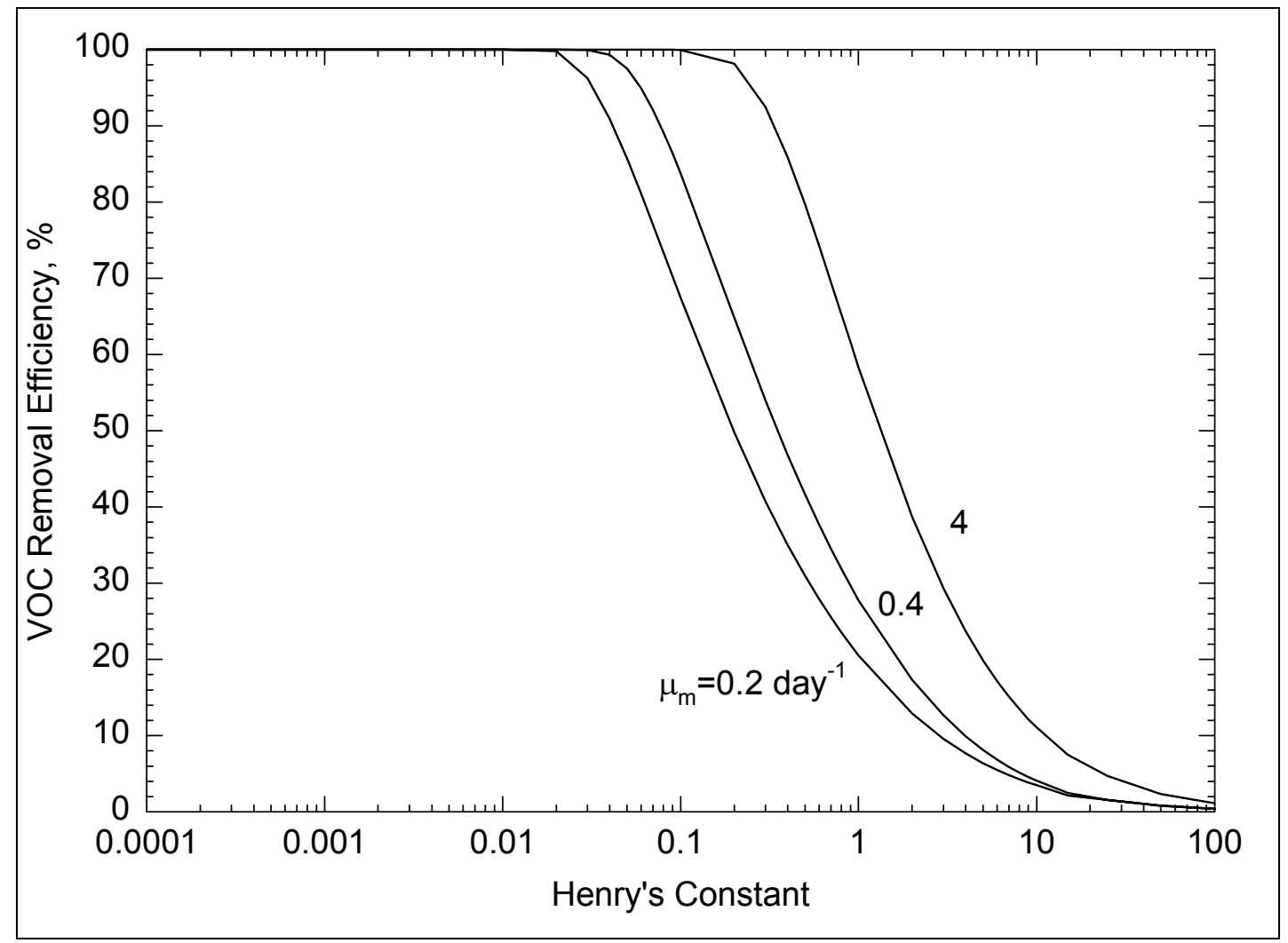

Figure 39. Effect of maximum growth rate vs effect of Henry's constant on VOC removal.

\section{Effect of Diffusivity}

Although diffusivity in water for most VOCs is around $10^{-5} \mathrm{~cm}^{2} / \mathrm{s}$, the diffusivity of VOCs in biofilms may vary significantly depending on the biofilm structure and VOC properties. Based on the studies on nitrate effect and biofilm structure presented in previous chapters, Alonso et al. (1997a,b) conducted a theoretical analysis and showed that diffusivity of VOCs in biofilms could be higher than in water for an unsaturated biofilm. The diffusivity in the biofilms is represented by biofilm/water diffusivity ratio. The effect of substrate diffusivity in the biofilm, $\mathrm{D}_{\mathrm{f}} / \mathrm{D}_{\mathrm{w}}$, on the VOC removal efficiency is shown in Figure 40. It can again be seen that, as the value of $\mathrm{D}_{\mathrm{f}} / \mathrm{D}_{\mathrm{w}}$ increases from 0.1 to 10 , the VOC removal efficiency increases significantly for VOC with Henry's constant between 0.1 and 10. When Henry's constant is less than approximately 0.01 (such as for butanol) or greater than 10 (such as for hexanes), VOC diffusivity in biofilm is not rate limiting.

Based on this analysis, a better picture can be seen regarding the causes for the poor performance of the model simulations for butanol, toluene, and hexane removal in this study (Figure 37). In the case of hexane with a Henry's constant value of 53, the severe underestimation by the model cannot be improved through varying kinetic parameters and the diffusivity in the biofilm. A more 
reasonable approach for improving the model, as discussed previously, is to consider the media as porous instead of solid. In the case of toluene with an $\mathrm{H}$ value of 0.29 , model simulations could be improved by selecting appropriate kinetic and mass transfer parameters. In the case of butanol with an $\mathrm{H}$ value of 0.0005 , varying kinetic parameters and the diffusivity in the biofilm for butanol will not improve the result of model simulation. Oxygen limitation and denitrification must be considered in the model for this case.

\section{Henry's Constant and Oxygen Limitation}

Equation 9 shows that the occurrence of oxygen limitation in a gas-phase biofilter is directly related to the Henry's constant of the VOC being treated. Using typical values of $D_{w s}$ at $1 \times 10^{-5} \mathrm{~cm}^{2} / \mathrm{sec}$ and $v_{0}$ at 8 , the relationship between Henry's constant and the critical VOC concentration in the gas phase at $27{ }^{\circ} \mathrm{C}$ is shown in Figure 41. Biofiltration technology is typically applied for treating VOCs at a concentration range of 50 to 500 ppmv. It can be seen that oxygen limitation will never occur for treating VOCs with $\mathrm{H}$ values greater than 0.3 . Oxygen will also always be flux limiting for treating VOCs with $\mathrm{H}$ values less than 0.03 . For VOCs with $\mathrm{H}$ values between 0.03 and 0.3 , whether oxygen limitation will occur depends on VOC concentration and other factors such as biofilm structure. In future modeling work, therefore, oxygen limitation and denitrification, if applicable, must be considered when dealing with VOCs of Henry's constants less then 0.01 .

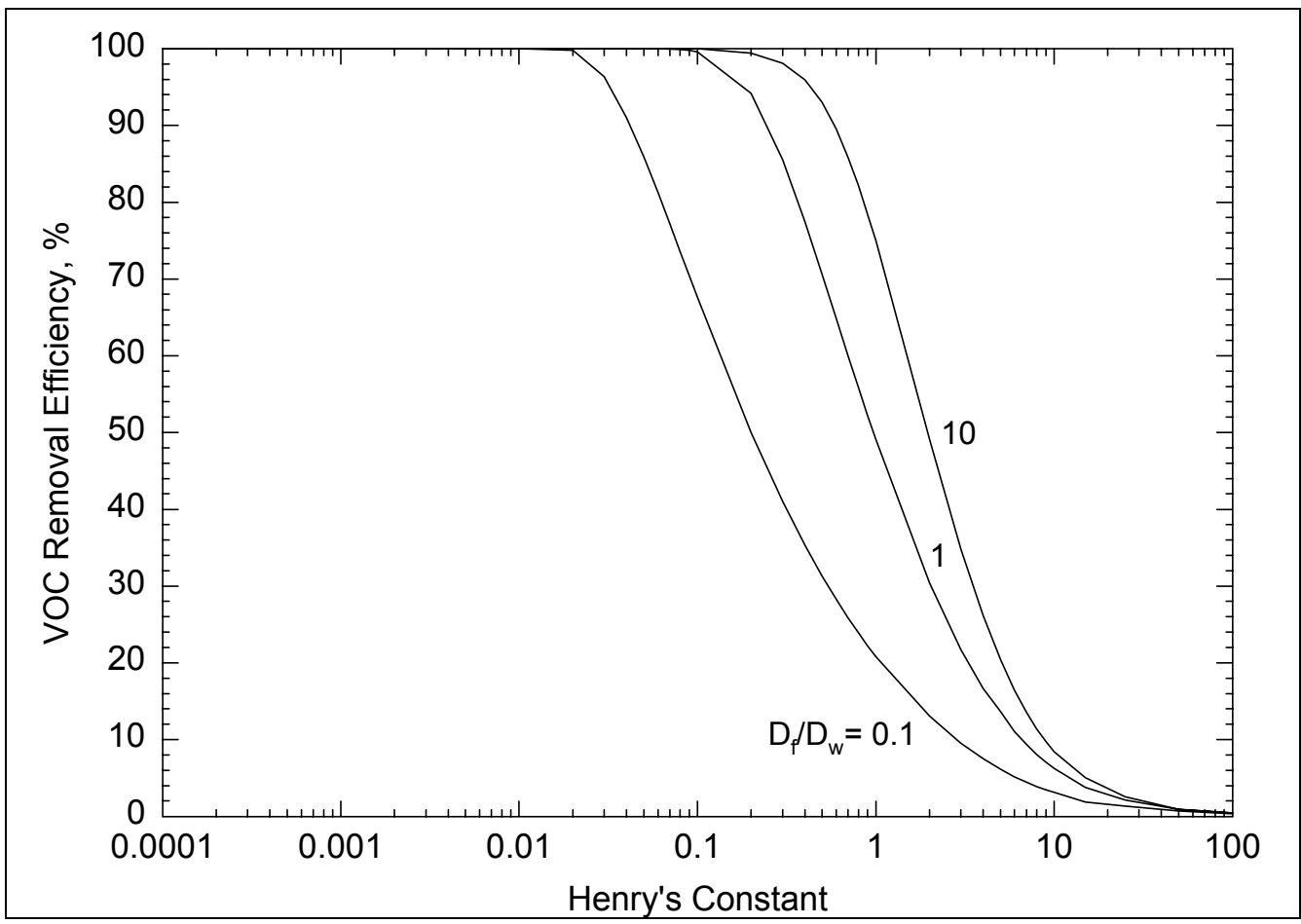

Figure 40. Effect of substrate diffusivity within biofilm vs effect of Henry's constant. 


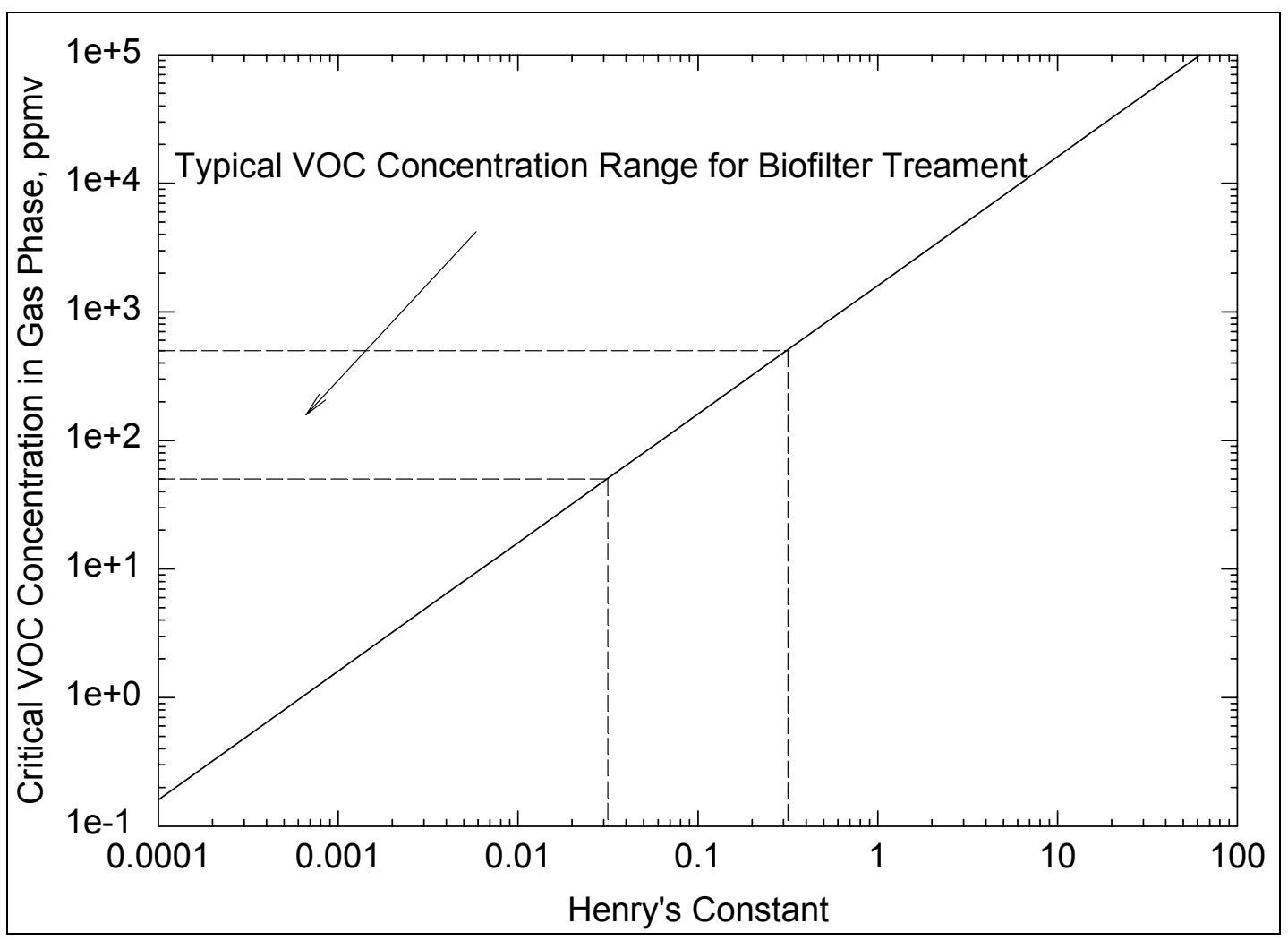

Figure 41. Effect of VOCs Henry's constant on oxygen limitation.

Table 17 shows the critical VOC concentrations for the four VOCs tested in this study. Since toluene and hexane partial pressures were never greater than 461 and 89,500 ppmv in this study, oxygen limitation was never a problem for treating these two compounds. However, the butanol concentration in the gas phase in this study was always much greater (two magnitudes) than $1.2 \mathrm{ppmv}$, which was why oxygen became a limiting factor in the butanol column. In the case of the treatment of ether, although the influent ether concentration was greater than $81 \mathrm{ppmv}$ in most of the study, little oxygen limitation was observed, which was attributed to the special biofilm structure or the existence of passages for oxygen transfer into the deeper section of the biofilm as described in Chapter 7.

Table 17. Determination of oxygen limitation: parameters and critical VOC concentrations.

\begin{tabular}{l|rrrr}
\hline & Butanol & Ether & Toluene & Hexanes \\
\hline $\mathrm{H}$ & 0.0005 & 0.034 & 0.29 & 53 \\
$\mathrm{D}_{\mathrm{w}, \mathrm{o}}, \mathrm{cm}^{2} / \mathrm{s}$ & $2.1 \mathrm{E}-5$ & $2.1 \mathrm{E}-5$ & $2.1 \mathrm{E}-5$ & $2.1 \mathrm{E}-5$ \\
$\mathrm{D}_{\mathrm{w}, \mathrm{s}}, \mathrm{cm}^{2} / \mathrm{s}$ & $9.0 \mathrm{E}-6$ & $9.0 \mathrm{E}-6$ & $1.0 \mathrm{E}-5$ & $8.0 \mathrm{E}-6$ \\
$v_{\mathrm{o}}$ & 6 & 6 & 8 & 9.5 \\
$v_{\mathrm{s}}$ & 1 & 1 & 1 & 1 \\
$\mathrm{C}_{\mathrm{w}, \mathrm{o}}\left(27^{\circ} \mathrm{C}\right)$ & 7.95 & 7.95 & 7.95 & 7.95 \\
\hline$p_{\mathrm{i}, \text { critical }}, \mathrm{ppmv}$ & 1.2 & 81 & 461 & 89500 \\
\hline
\end{tabular}




\section{Summary}

The long-term experimental study on the effect of Henry's constant indicated that the VOC removal efficiency generally increased with decreases in substrate's Henry's constant. The results also showed that, with the increase in influent VOC loading, VOC elimination capacity increased proportionally for the butanol column when oxygen limitation was not dominant. Also shown was that the VOC elimination capacity increased slightly for the toluene column and exhibited little change for the hexane column, suggesting that the mass transfer of VOC between vapor and liquid or between vapor and biofilm was a ratedetermining step for the treatment of VOCs with high Henry's constant such as toluene and hexane but not for VOCs with low Henry's constants such as butanol and ether. Denitrification was observed in the biofilter that treated the butanol. About 40 percent of the butanol removed was degraded through denitrification at an influent nitrate concentration of $4,000 \mathrm{mgN} / \mathrm{L}$. This finding was attributed to the extremely low Henry's constant for butanol, which leads to a high butanol concentration in the liquid biofilm phase and resulted in oxygen limitation in the biofilter.

Model simulations confirmed the experimental results and provided better understanding of the effect of Henry's constant. The theoretical analysis indicated that, when the VOC's Henry's constant is between 0.01 and 10, the biofiltration process is limited by Henry's constant, kinetic parameters, and the contaminant's diffusivity in the biofilm. However, when Henry's constant is less than approximately 0.01 or greater than 10 , the kinetic parameters and the diffusivity in the biofilm become unimportant. In the case of a Henry's constant of less than 0.01 , oxygen limitation becomes a determining factor. In future biofilter studies and modeling, more attention should be given to oxygen limitation and denitrification processes, particularly for treating VOCs with low Henry's constants. 


\section{Biomass Dynamics and Growth Control}

One of the major challenges for successfully operating a biotrickling filter is to control biomass growth. Excessive biomass accumulation in the biofilters will lead to bed clogging and poor VOC removal (Sorial et al. 1994a and 1995; Van Lith, David, and Marsh 1990). In these cases, a means of controlling biomass becomes necessary. An ideal situation with respect to biomass growth in a biofilter would be no net growth as a result of balancing biomass growth and decay. Maintaining biomass at a steady state may be achieved in low-loaded biofilters and when treating certain low-yield compounds. In many systems, however, particularly those treating high concentrations of readily degradable compounds, significant growth of biomass is anticipated.

In this chapter, major factors affecting biomass growth are identified and biomass distribution along the biofilters is examined. Two biomass control approaches were investigated. The first study was to evaluate the impact of backwashing and different backwash strategies on biofilter performance. The second study was to determine the feasibility of limiting nutrient phosphorus for biomass growth control in biotrickling filter.

\section{Biomass Accumulation and Distribution}

\section{Factors Affecting Biomass Growth}

Table 18 summarizes the effect of the major operating parameters on biomass growth. The observed biomass yield is correlated with organic loading, EBRT, liquid flow rate, and airflow direction. The observed biomass yield is seen to have increased with increases in organic loading, EBRT, and liquid flow rate. The biofilter under counter-current operation also showed slightly higher biomass growth than that under the co-current flow mode. In all these cases, the higher observed biomass yield is correlated with the high ether elimination capacity. 
Table 18. Effect of major operating conditions on biomass growth.

\begin{tabular}{|c|c|c|c|c|c|c|c|}
\hline \multicolumn{2}{|c|}{ Influent Loading(1) } & \multicolumn{2}{|c|}{$\mathrm{EBRT}^{(2)}$} & \multicolumn{2}{|c|}{ Liquid Flow Rate(3) } & \multicolumn{2}{|c|}{ Airflow Direction(4) } \\
\hline $\begin{array}{c}\text { Loading } \\
(\mathrm{kg} \\
\left.\text { COD } / \mathrm{m}^{3} / \text { day }\right)\end{array}$ & $\begin{array}{l}\text { Average Yield } \\
\text { (gVSS/gCOD) }\end{array}$ & $\begin{array}{r}\text { EBRT } \\
\text { (sec) } \\
\end{array}$ & $\begin{array}{l}\text { Average Yield } \\
\text { (gVSS/gCOD) }\end{array}$ & $\begin{array}{l}\text { Liquid Flow } \\
\text { Rate (L/day) } \\
\end{array}$ & $\begin{array}{l}\text { Average Yield } \\
\text { (gVSS/gCOD) }\end{array}$ & $\begin{array}{c}\text { Flow } \\
\text { Pattern } \\
\end{array}$ & $\begin{array}{l}\text { Average Yield } \\
\text { (gVSS/gCOD) }\end{array}$ \\
\hline 1.8 & 0.044 & & & & & & \\
\hline 3.6 & 0.039 & 8.3 & 0.037 & & & Co- & \\
\hline 5.3 & 0.072 & 12.5 & 0.036 & 1 & 0.078 & Current & 0.040 \\
\hline 7.1 & 0.066 & 25 & 0.065 & & & & \\
\hline 8.9 & 0.084 & 50 & 0.080 & & & Counter & \\
\hline 10.7 & 0.088 & 100 & 0.120 & 20 & 0.115 & Current & 0.046 \\
\hline
\end{tabular}

Notes: (1) EBRT at $25 \mathrm{sec}$, (2) Influent Loading at $8.9 \mathrm{~kg} \mathrm{COD} / \mathrm{m}^{3} / \mathrm{day}$, and (3) and (4) Influent Loading at $7.1 \mathrm{~kg} \mathrm{COD} / \mathrm{m}^{3} /$ day and EBRT at $25 \mathrm{sec}$.

\section{Biomass Distribution}

Visual observations throughout this study indicated an uneven biomass and biofilm thickness distribution along the medium depth with the majority of the biomass concentrated within the top sections of the columns. During the study, however, it was very difficult, if not impossible, to take biomass samples without disrupting the experiments. The biomass distribution was finally analyzed after the study on EBRT effect on day 683. The two biofilters were dismantled, and biofilm thickness and volatile solids were measured according to the methods described in Chapter 3. The total pellets in each section of the columns were also counted. The results of this study are summarized in Table 19, Figure 42, and Figure 43. After the analysis, the biofilm pellets were used to seed the four new biofilters in later studies.

Table 19. Results summary from biomass distribution study.

\begin{tabular}{l|ccccc}
\hline Column A & $\begin{array}{c}\text { Section } \\
\text { Volume } \\
\left(\mathbf{c m}^{\mathbf{3}}\right)\end{array}$ & $\begin{array}{c}\text { Biofilm } \\
\text { Pellets } \\
\text { (Count \#) }\end{array}$ & $\begin{array}{c}\text { Biofilm } \\
\text { Thickness } \\
(\mathbf{m m})\end{array}$ & $\begin{array}{c}\text { Biofilm } \\
\text { Volume } \\
\left(\mathbf{c m}^{\mathbf{3}}\right)\end{array}$ & $\begin{array}{c}\text { Biomass } \\
\text { Dry Weight } \\
(\mathbf{g V S})\end{array}$ \\
\hline Section 1 & 410 & 381 & 1.96 & 192 & 27.0 \\
Section 2 & 725 & 1,095 & 1.21 & 285 & 32.3 \\
Section 3 & 743 & 1,627 & 0.66 & 201 & 31.9 \\
Section 4 & 702 & 1,856 & 0.42 & 134 & 20.5 \\
Section 5 & 413 & 1,355 & 0.14 & 32 & 9.6 \\
\hline Column B & & & & & 26.5 \\
\hline Section 1 & 362 & 573 & 1.05 & 226 & 53.7 \\
Section 2 & 725 & 1,394 & 0.84 & 194 & 40.1 \\
Section 3 & 743 & 1,665 & 0.63 & 153 & 32.6 \\
Section 4 & 720 & 1,743 & 0.49 & 54 & 14.0 \\
Section 5 & 413 & 1,225 & 0.26 & & \\
\hline
\end{tabular}




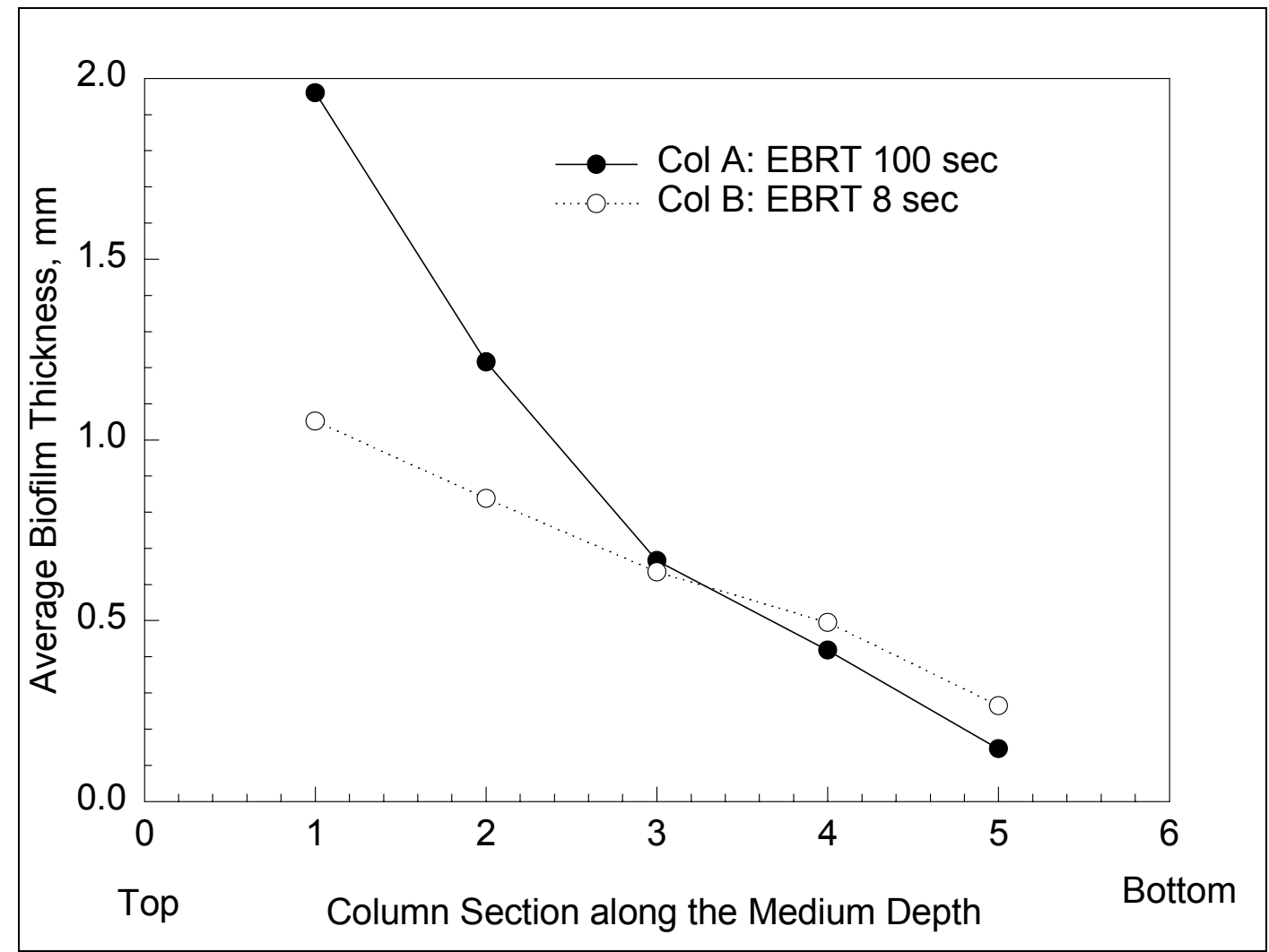

Figure 42. Biofilm thickness distribution at ether loading of $8.9 \mathrm{~kg} \mathrm{COD} / \mathrm{m}^{3} /$ day.

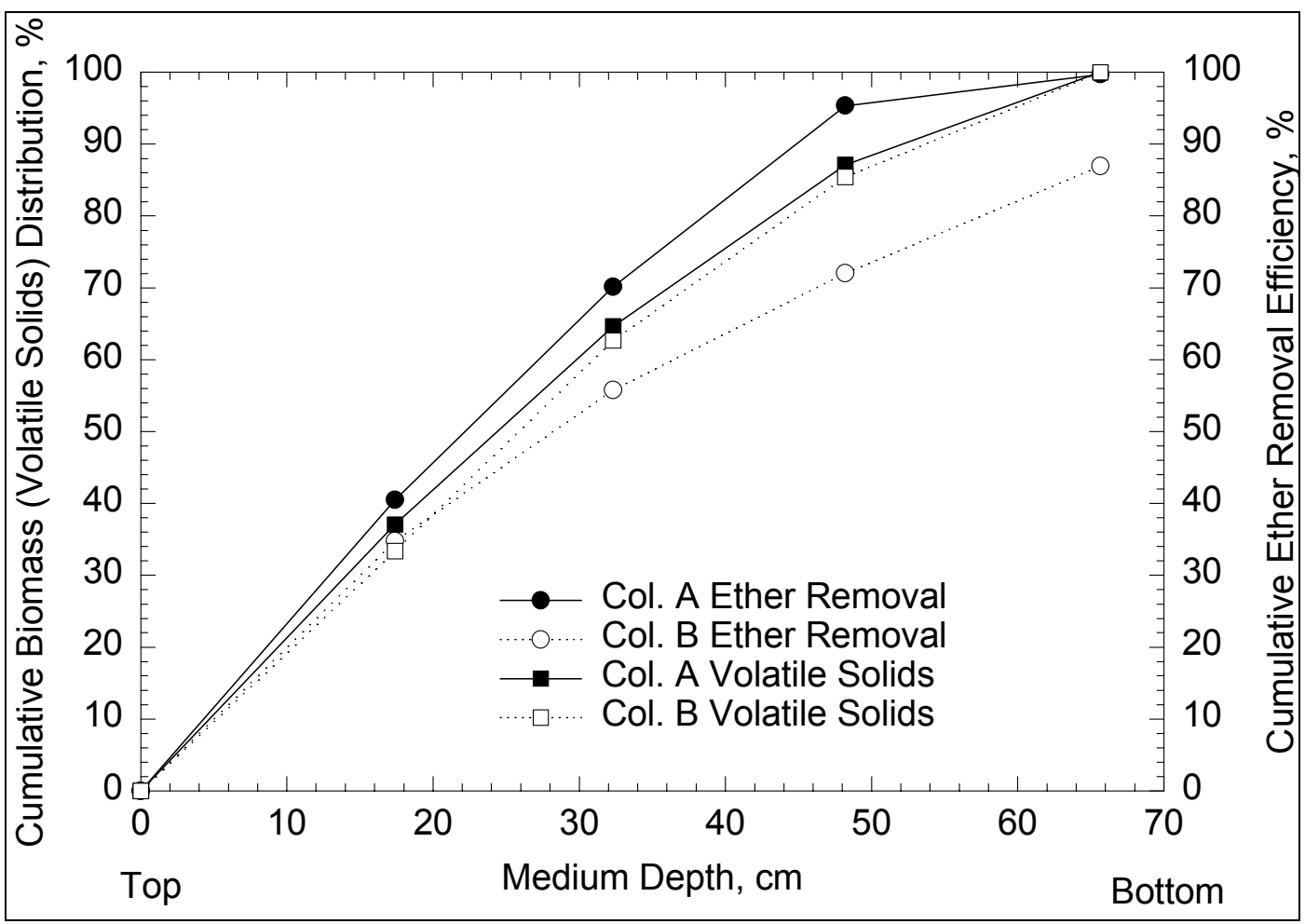

Col. A: EBRT $100 \mathrm{sec}$; Col. B: EBRT sec.

Figure 43. Biomass distribution and ether removal along the biofilters at ether loading rate of $8.9 \mathrm{~kg} \mathrm{COD} / \mathrm{m}^{3} /$ day. 
Before being dismantled, the two biofilters were operated at an ether loading rate of $8.9 \mathrm{~kg} \mathrm{COD} / \mathrm{m}^{3} /$ day with an EBRT of $100 \mathrm{sec}$ in Column A and $8 \mathrm{sec}$ in Column B. Figure 42 shows that the biofilm thickness varied from $2.0 \mathrm{~mm}$ at the top to $0.14 \mathrm{~mm}$ at the bottom in Column A and from $1.1 \mathrm{~mm}$ to $0.26 \mathrm{~mm}$ in Column B. The thicker biofilm at the top of Column A probably resulted from the higher mass transfer driving force, since Column A was operated at both higher EBRTs and influent ether concentrations. It can also be attributed to a better moisture condition with a lower dry airflow rate. Figure 43 shows the relationship between biomass distribution and ether removal along the medium depth in the two biofilters.

Figure 43 shows that the biofilter sections with more biomass contributed to more ether removal. In the top two sections where about 65 percent of the total biomass resided, 60 to 70 percent of the influent ether was degraded. It should be noted that these biomass profiles were some of the most uniform distributions throughout this study. Based on visual observations, the biofilm distributions along the columns were much more uneven when the biofilters were operated at lower organic loading rates.

Biomass distribution is also related to the compounds being treated and probably to the Henry's constants of the VOCs. Based on the observation during the study on the effect of Henry's constants, the profile of biofilm thickness along the butanol column was similar to that along the ether columns, with thick biofilms on top and thin biofilms at the bottom. For the biofilter treating toluene, however, the biofilm thickness was relatively thin and quite uniform along the column. As for the biofilter treating hexane, the least soluble compound studied, no visible biofilm was observed throughout the column. This result can be attributed to both the kinetics and the mass transfer properties, such as Henry's constants.

The general trend has shown that more biomass led to better VOC removal. When too much biomass growth occurs, however, biofilter performance will deteriorate. In this case, making biomass accessible by diffusing contaminants on the biofilm specific surface area may play a more important role, which leads to the next discussion on biofilter backwashing.

\section{Backwash Strategies}

Based on the findings by Sorial et al. (1994a, 1995) and Smith et al. (1994), periodic backwashing of the biofilters was selected as the approach for removing excess biomass for this study. More investigation was required to understand the effect of backwashing and to optimize the backwashing process, so studies were 
performed on the effect of major parameters related to the backwashing process, including backwash frequency and backwash duration.

\section{Backwash Frequency}

Backwash frequency is the most important parameter of the backwashing process. The effect of backwash frequency was investigated under various conditions using ether as a model VOC (Table 20). Two biofilters, designated Columns A and $\mathrm{B}$, were used for this study.

Initially, the effect of backwash frequency was examined at low organic loadings. Figure 44 shows the effect of backwashing on ether removal during day 95 to 145 of the operation. The influent ether concentration was $67 \mathrm{ppmv}$ to Column $\mathrm{A}$ and $133 \mathrm{ppmv}$ to Column $\mathrm{B}$, resulting in a loading of $1.8 \mathrm{~kg} \mathrm{COD} / \mathrm{m}^{3} /$ day for Column $\mathrm{A}$ and $3.6 \mathrm{~kg} \mathrm{COD} / \mathrm{m}^{3} /$ day for Column B. The two biofilters were backwashed once a week initially. The ether removal efficiency in Column A remained stable at 99.7 percent during this time. For Column B, however, there was a cyclical effect of backwashing on ether removal. The ether removal efficiency increased for 4 to 5 days after backwashing and then began to decrease. The biofilter performance recovered again with another backwash. Between days 123 and 143, the columns were not backwashed in order to observe the effect of biomass accumulation on performance. As Figure 44 shows, Column A maintained its performance during this time. Column B showed an initially steady removal efficiency, but it began to decrease rapidly around day 140 . This decrease indicated that a means of biomass removal is necessary to maintain performance and the optimum frequency of biomass removal will depend on operating conditions such as VOC loading.

Table 20. Major operating conditions in the study on backwash frequency.

\begin{tabular}{l|c|c}
\hline & Test $\mathbf{1}$ & Test 2 \\
\hline Influent Ether Concentrations, ppmv & $67-133$ & $333-400$ \\
Backwash Frequency, \#/week & $1 / 3$ and 1 & 1 and 2 \\
Empty Bed Retention Time, sec & 25 & 25 \\
Ether Loading Rate, $\mathrm{kg} \mathrm{COD/m} / \mathrm{day}$ & $1.8-3.6$ & $8.9-10.7$ \\
Influent Nitrate Concentration, mg N/L & 67 & 533 \\
Influent Air Flow Rate, $\mathrm{m}^{3} / \mathrm{day}$ & 8.64 & 8.64 \\
Nutrient Liquid Flow Rate, L/day & 1.0 & 1.0 \\
\hline
\end{tabular}




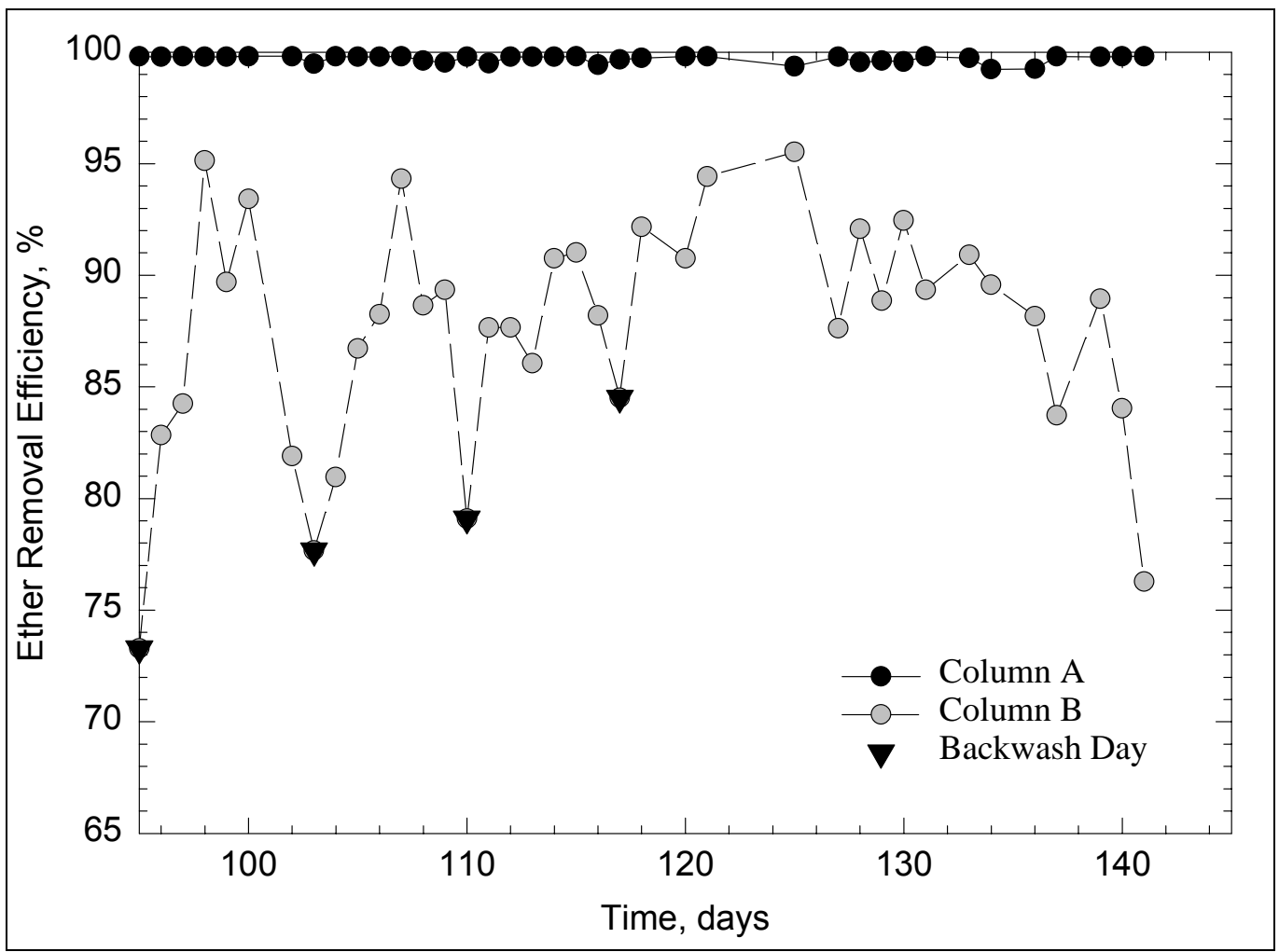

Figure 44. Removal efficiency with respect to backwash cycles at ether loading of 1.8 and $3.6 \mathrm{~kg} \mathrm{COD} / \mathrm{m}^{3} /$ day.

The effect of backwash frequency was further studied at higher ether loading rates. On day 403 of the operation, the influent ether concentration was increased to $333 \mathrm{ppmv}$ for Column A and $400 \mathrm{ppmv}$ for Column B, resulting in a loading of $8.9 \mathrm{~kg} \mathrm{COD} / \mathrm{m}^{3} /$ day for Column A and $10.7 \mathrm{~kg} \mathrm{COD} / \mathrm{m}^{3} /$ day for Column B. The two biofilters were also backwashed once a week initially. Figure 45 illustrates the biofilter performance during this period. At lower ether loading rates, backwashing once a week was sufficient to keep a steady ether removal. At these high ether loadings, however, steady removal could only be maintained for 3 or 4 days before decreasing rapidly. Weekly biofilter performance was also very unstable. The general trend showed a decrease in ether removal efficiency, especially in Column B.

After day 438 the backwash frequency was increased to twice a week for both columns. The ether removal efficiency was increased from an average of 86 to 94 percent for Column A, and from 85 to 90 percent for Column B. Ether removal performance was also more stable. The results show that the performance of biofilters with high loading rates can be improved by increasing backwash frequency. Based on this study, optimal backwash frequencies of once a week for influent COD loading from 1.8 to $7.1 \mathrm{~kg} / \mathrm{m}^{3} /$ day and twice a week for COD loading from 8.9 to $10.7 \mathrm{~kg} / \mathrm{m}^{3} /$ day are recommended. 


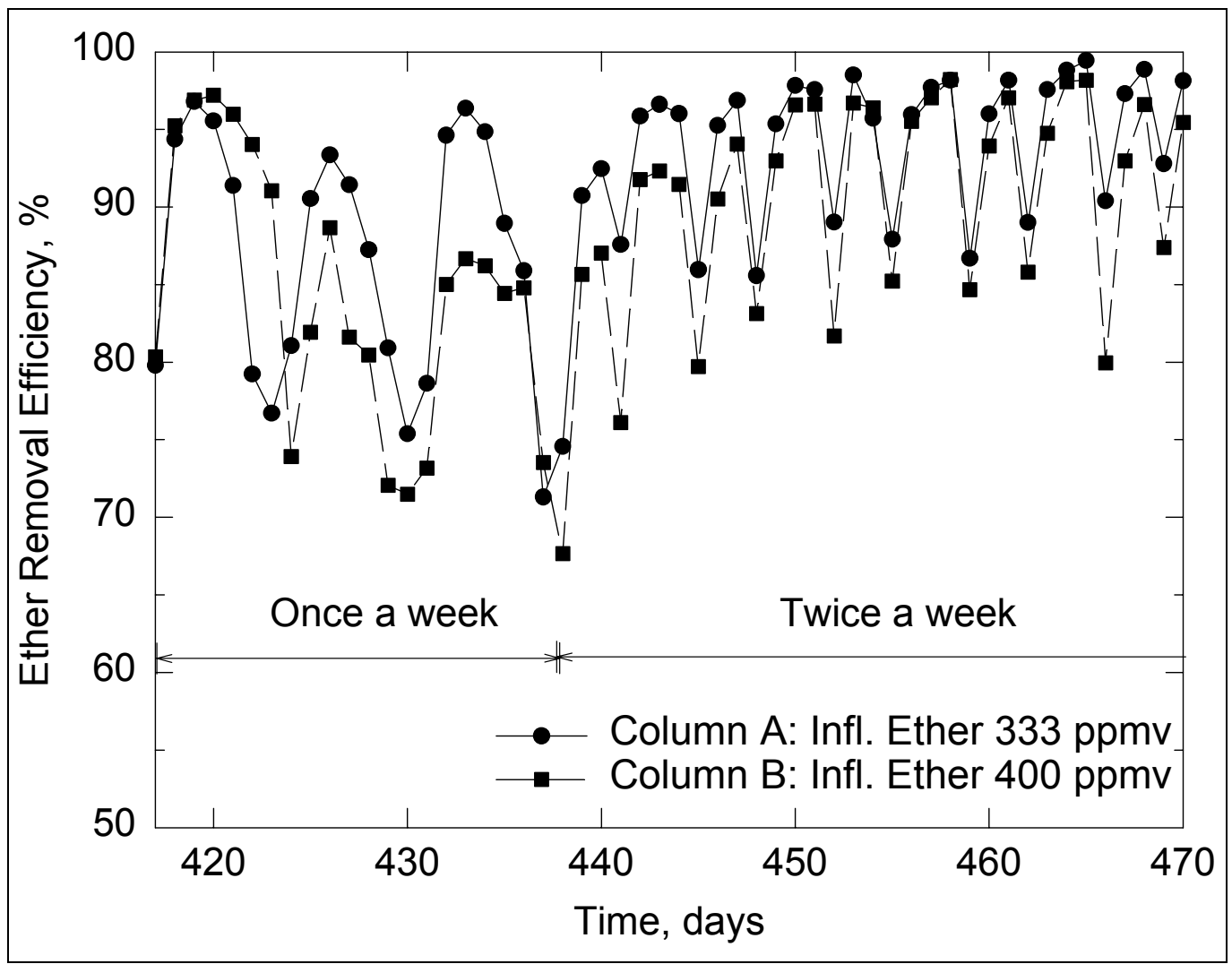

Figure 45. Effect of backwash frequency on ether removal at ether loading of 8.9 and $10.7 \mathrm{~kg}$ $\mathrm{COD} / \mathrm{m}^{3} /$ day.

Backwash frequency higher than twice a week is not recommended because it also takes some time, usually 24 hours after backwashing, for biofilters to recover to stable performance. This initial drop in performance was also strongly correlated with the influent ether loadings. Figure 46 shows that the effect of backwashing increases with increased influent ether loading rates.

In Chapter 8 it was shown that the optimal backwash frequency for biomass removal is also related to the compounds being treated and probably to the Henry's constants of the VOCs. The higher the Henry's constant of a VOC being treated, the less available substrate and slower growth for microorganisms within the biofilms. The results showed that the biofilter treating a less soluble compound took longer to recover to optimal performance, thus requiring less frequent backwash.

Throughout this study, the biofilters maintained a low backpressure that varied between 0.05 and 0.2 in. of water depending on operating conditions. The pressure drop normally did not increase with the drop in biofilter performance within a backwash cycle. Dramatic increase of backpressure only occurred a few times at the end of backwashing cycles when biofilters were operated at higher 
loadings. This finding confirmed a modeling simulation conducted by Alonso et al. (1997b) suggesting that the drop in performance was caused by a decrease in the specific surface area of the media as a result of biomass growth. This result indicates that backwashing should be conducted based on VOC removal performance and economic factors, and not based on pressure drop. Conducting backwash after significant backpressure increase and bed clogging is usually too late to maintain stable biofilter performance.

\section{Backwash Duration}

Another important parameter regarding the backwash strategies is the backwash duration or the water recirculating time during a backwash. The duration of the backwash period in all previous studies was 1 hour. Figure 47 shows typical suspended solids (SS) and VSS profiles with respect to recirculating time in an hour. The SS and VSS concentrations in the recirculating water have no significant change after 10 min of backwash, which means that most excess biomass was washed out within the first $10 \mathrm{~min}$.

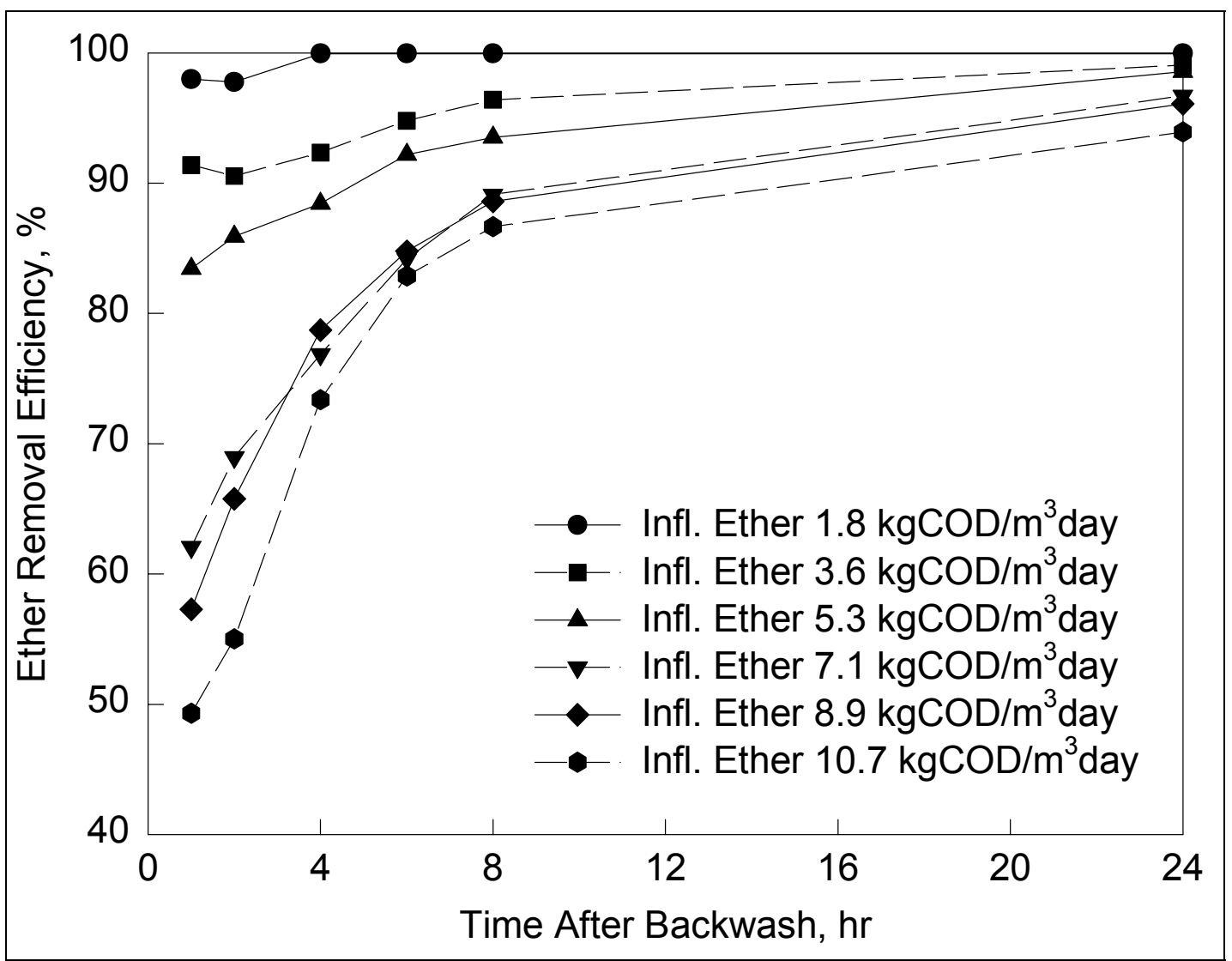

Figure 46. Impact of backwash on ether removal. 


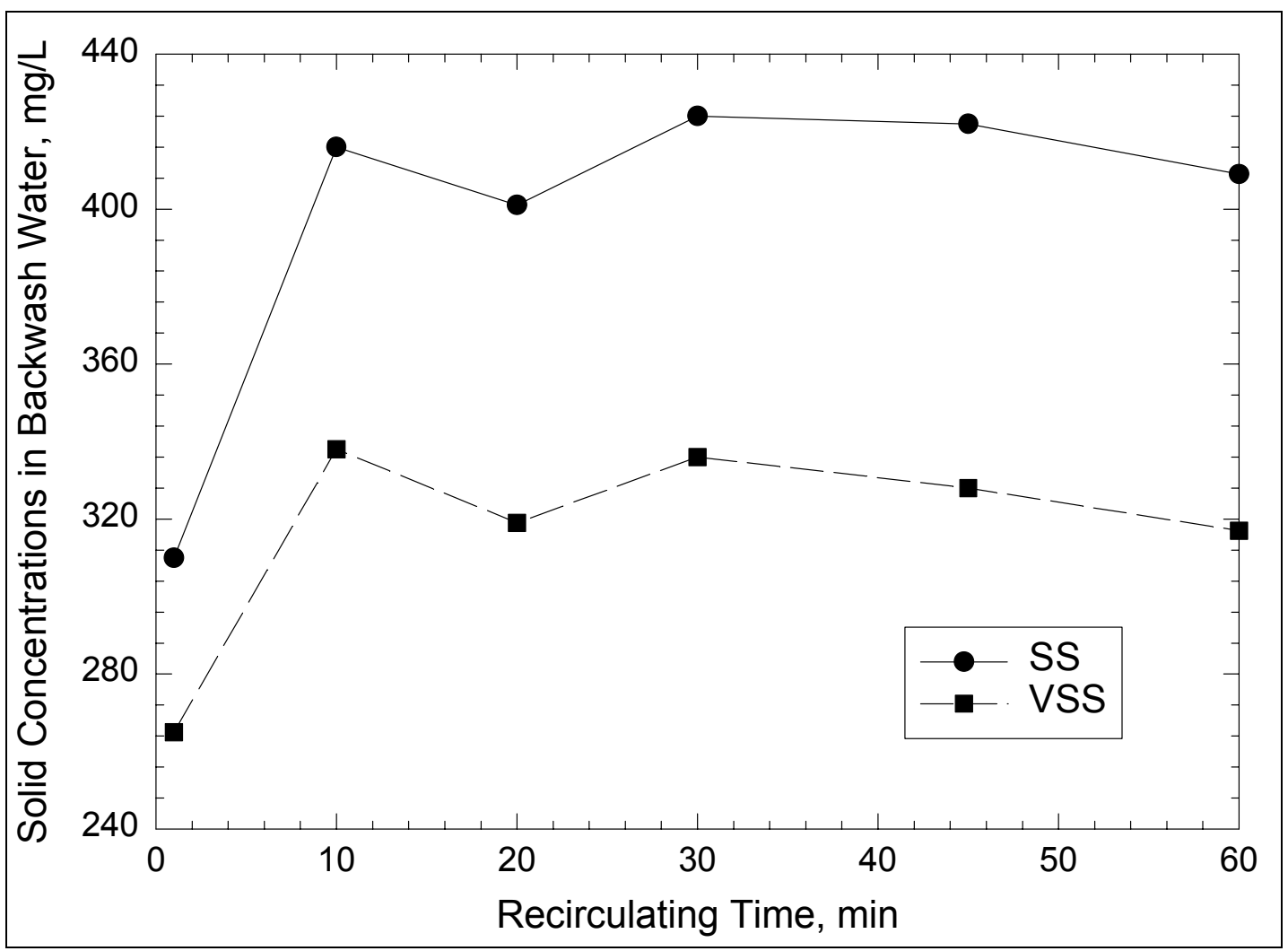

Figure 47. Effect of backwash duration with respect to SS and VSS concentrations in backwash water.

Between days 452 and 521 of operation, the biofilters were backwashed twice a week, and three recirculating durations (10, 30, and $60 \mathrm{~min})$ were used to investigate the effect on ether removal. Major operating parameters used in this test are listed in Table 21. The results (Figure 48) show that ether removal slightly increased with the increase of backwash duration and biofilter performance was also more stable using a 1-hr backwash duration. These results suggest that the longer backwash duration may not affect the total biomass washed out but may improve biomass distribution within the biofilters, which leads to better biofilter performance. According to this result, a backwash duration of 1 hour is recommended.

Table 21. Major experimental parameters used in backwash duration test.

\begin{tabular}{lc}
\hline Influent Ether Concentrations, ppmv & $333-400$ \\
Backwash Duration, min & $10-60$ \\
Backwash Frequency, \#/week & 2 \\
Influent Nitrate Concentration, $\mathrm{mg} \mathrm{NO}_{3}-\mathrm{N} / \mathrm{L}$ & 533 \\
Empty Bed Detention Time, sec & 25 \\
COD Loading Rate, $\mathrm{kg} \mathrm{COD} / \mathrm{m}^{3} / \mathrm{day}$ & $8.9-10.7$ \\
Influent Gas Flow Rate, $\mathrm{m}^{3} / \mathrm{day}$ & 8.64 \\
Nutrient Liquid Flow Rate, L/day & 1.0 \\
\hline
\end{tabular}




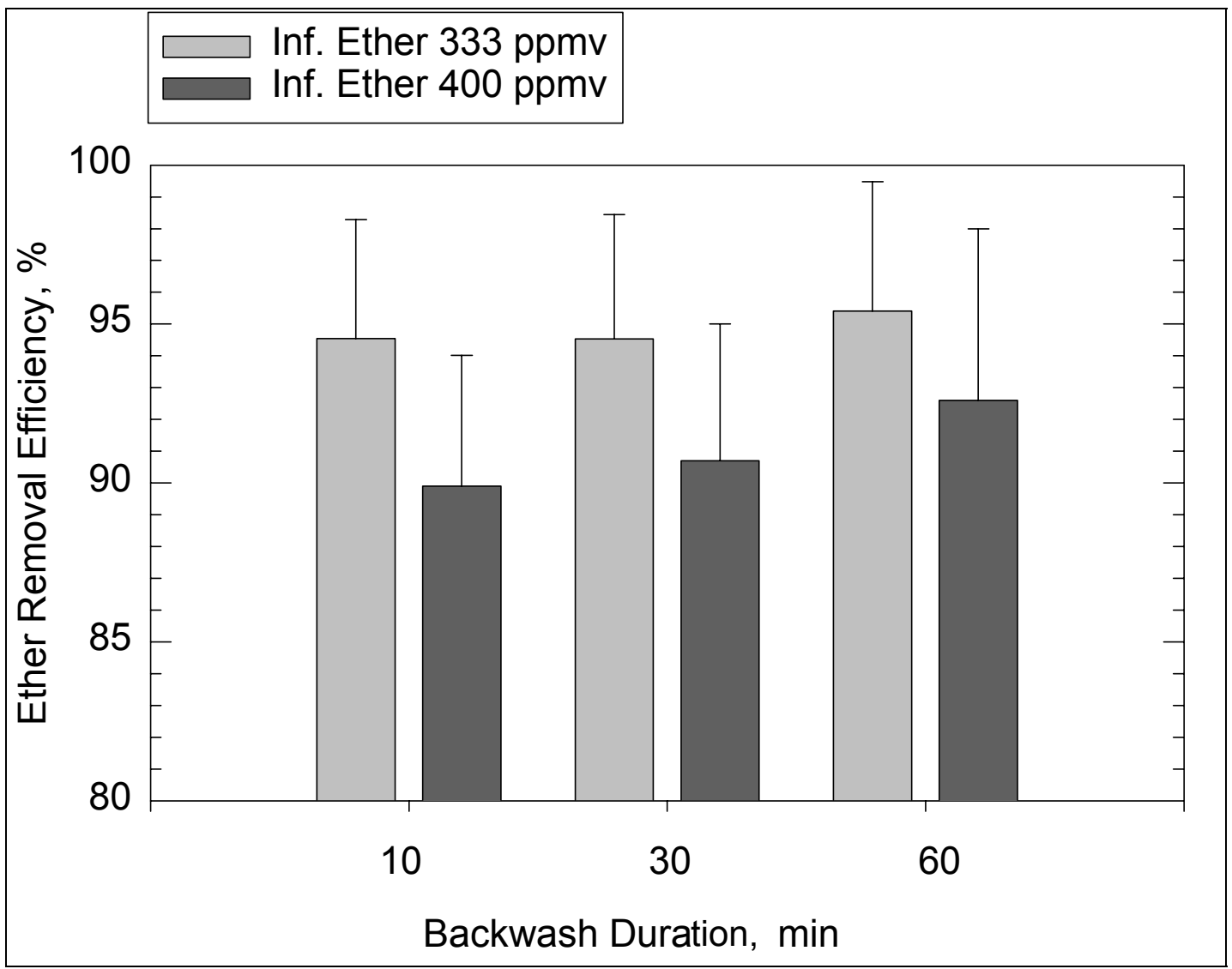

Figure 48. Effect of backwash duration with respect to ether removal.

\section{Effect of Phosphorus}

\section{Effect of Phosphorus Limitation on Biomass Control}

The influent phosphorus concentration to the biofilters in all previous studies was maintained at $13.2 \mathrm{mgP} / \mathrm{L}$. As described in earlier chapters, the effects of ether loading rate and nitrate concentration were investigated between days 72 and 521 of operation. The influent ether concentrations to Columns A and B were varied from 67 to $400 \mathrm{ppmv}$ resulting in COD volumetric loading rates ranging from 1.8 to $10.7 \mathrm{~kg} / \mathrm{m}^{3} /$ day. Table 22 summarizes the relationship between COD:P ratio and the corresponding ether removal efficiency during this period. The results show that, with an increase in ether concentration from 67 to 400 ppmv or COD: P ratio from 333 to 2,000, the ether removal efficiency only decreases from 99.9 to 90 percent. Phosphorus was not significantly limiting ether removal and biomass growth, although the P:COD ratio was much lower than usually suggested for biomass growth, which is 1:100 (Gaudy and Gaudy 1980). The biomass yield actually increased from 0.04 to $0.09 \mathrm{gVSS} / \mathrm{gCOD}$ during this period. The drop in efficiency with the increase of ether loading was 
more likely attributed to mass transfer or kinetics. The low demand for phosphorus in the biofilters suggests that microorganisms within the biofilm could have accumulated phosphorus or reused phosphorus released from biomass decay.

Since limiting phosphorus supply did not seem to significantly affect biofilter performance, a study was conducted to investigate the feasibility of using phosphorus-limiting conditions to control biomass growth in biofilters. Table 23 shows the major operating parameters. On day 529 of operation, an experiment was started to evaluate biofilter performance without nutrient-P in the nutrient feed. The influent ether concentration was 333 ppmv for Column A and 400 ppmv for Column B, respectively. The backwash frequency was maintained at once a week. Influent nitrate concentration was maintained at 1,068 mg/L. Based on results from a previous study, nitrate would not be a limiting factor at this high concentration (Chapter 5, Zhu et al. 1996a,b). The two biofilters were operated with 13.2-mgP/L nutrient feed for only one day after backwash, and then switched to phosphorus-free nutrient feed until the next backwash. Since microorganisms can uptake and accumulate phosphorus within cells, this type of operation should supply sufficient phosphorus initially and then hopefully control biomass growth by limiting phosphorus during each backwash cycle. Figure 49 shows the results comparing biofilter performance under regular nutrients (13.2mgP/L) with that under phosphorus limiting conditions for both columns. It can be seen that, although ether removal dropped faster at the end of the backwash cycle when phosphorus was absent, the average ether removal efficiency was not significantly different under the two conditions. The average ether removal efficiency was 88.1 percent with phosphorus and 88.4 percent without phosphorus for Column A, and 84.5 percent with phosphorus and 82.7 percent without phosphorus for Column B.

Table 22. Summary of the results during influent ether loading variations.

\begin{tabular}{|c|c|c|c|}
\hline $\begin{array}{c}\text { Influent Ether } \\
\text { Loading } \\
\text { (kg COD/M } / \text { day) } \\
\end{array}$ & $\begin{array}{c}\text { Influent COD:P } \\
\text { (Ratio) }\end{array}$ & $\begin{array}{l}\text { Average Yield } \\
\text { (gVSS/gCOD) }\end{array}$ & $\begin{array}{c}\text { Average Ether } \\
\text { Removal Efficiency at } \\
\text { Optimal Conditions* } \\
(\%) \\
\end{array}$ \\
\hline 1.8 & 333 & 0.044 & 99.9 \\
\hline 3.6 & 667 & 0.039 & 99.0 \\
\hline 5.3 & 1,000 & 0.072 & 98.9 \\
\hline 7.1 & 1,333 & 0.066 & 97.7 \\
\hline 8.9 & 1,667 & 0.084 & 94.0 \\
\hline 10.7 & 2,000 & 0.088 & 90.0 \\
\hline
\end{tabular}

* Optimal conditions: a) Influent COD:N = 30; b) backwashing once a week for COD loading from 1.8 to $7.1 \mathrm{~kg} / \mathrm{m}^{3} /$ day and twice a week for COD loading from 8.9 to 10.7 $\mathrm{kg} / \mathrm{m}^{3} /$ day. 
Table 23. Major operating conditions used in phosphorus limitation test.

\begin{tabular}{lc}
\hline Influent Ether Concentrations, ppmv & $100-400$ \\
Influent Phosphorus Concentrations, mg P/L & $0-13.2$ \\
Empty Bed Retention Time, sec & 25 \\
COD Loading Rate, kg COD/m³/day & $2.7-10.8$ \\
Influent Nitrate Concentration, mg N/L & 1068 \\
Influent Air Flow Rate, ${ }^{3} /$ day & 8.64 \\
Nutrient Liquid Flow Rate, L/day & 1.0 \\
\hline
\end{tabular}

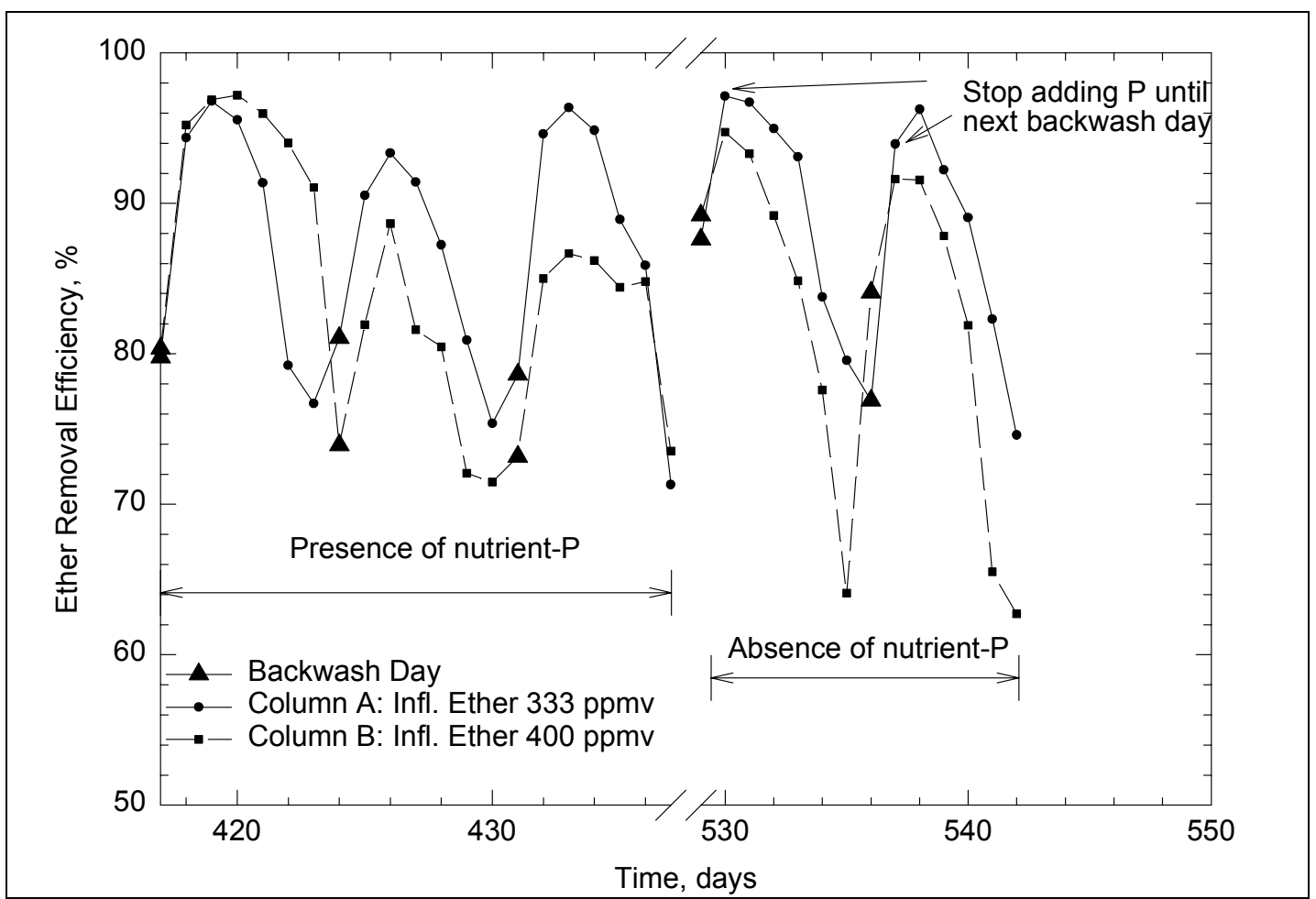

Figure 49. Comparison of biofilter performance with and without phosphorous in nutrient feed.

To further investigate the role of phosphorus on biomass control, on day 543 of operation, the influent ether concentrations were decreased to $100 \mathrm{ppmv}$ for Column A and 200 ppmv for Column B. The same phosphorus addition cycle was used, but backwash frequency was reduced from once a week to once every 2 weeks. A comparison of biofilter performance with and without phosphorus limitation is shown in Figure 50. During the first two backwash cycles, ether removal was fairly stable and similar to the performance when nutrient phosphorus was present. The profiles of the ether concentration along the medium depth during the second backwash cycle are illustrated in Figure 51. Although the final ether removal efficiencies were similar, it can be seen that ether removal decreased in the top section of the bed with time, while greater removal was achieved in the lower sections of the media. This is probably because phosphorus was depleted on the top portion with time and transferred to the lower 
portions through biomass decay. During the third backwashing cycle, however, the ether removal efficiency decreased from about 99 to 96 percent in Column A and to 62 percent in Column B. The steady decrease in performance and the color change in the media indicated the biofilters were approaching failure. The drop in performance occurred after about 2 months of limiting phosphorus, suggesting that, although limiting nutrient-P may not affect biofilter performance significantly and could reduce backwash frequency over the short term, stable operation at high removal efficiency cannot be sustained long term without the addition of nutrient-P.

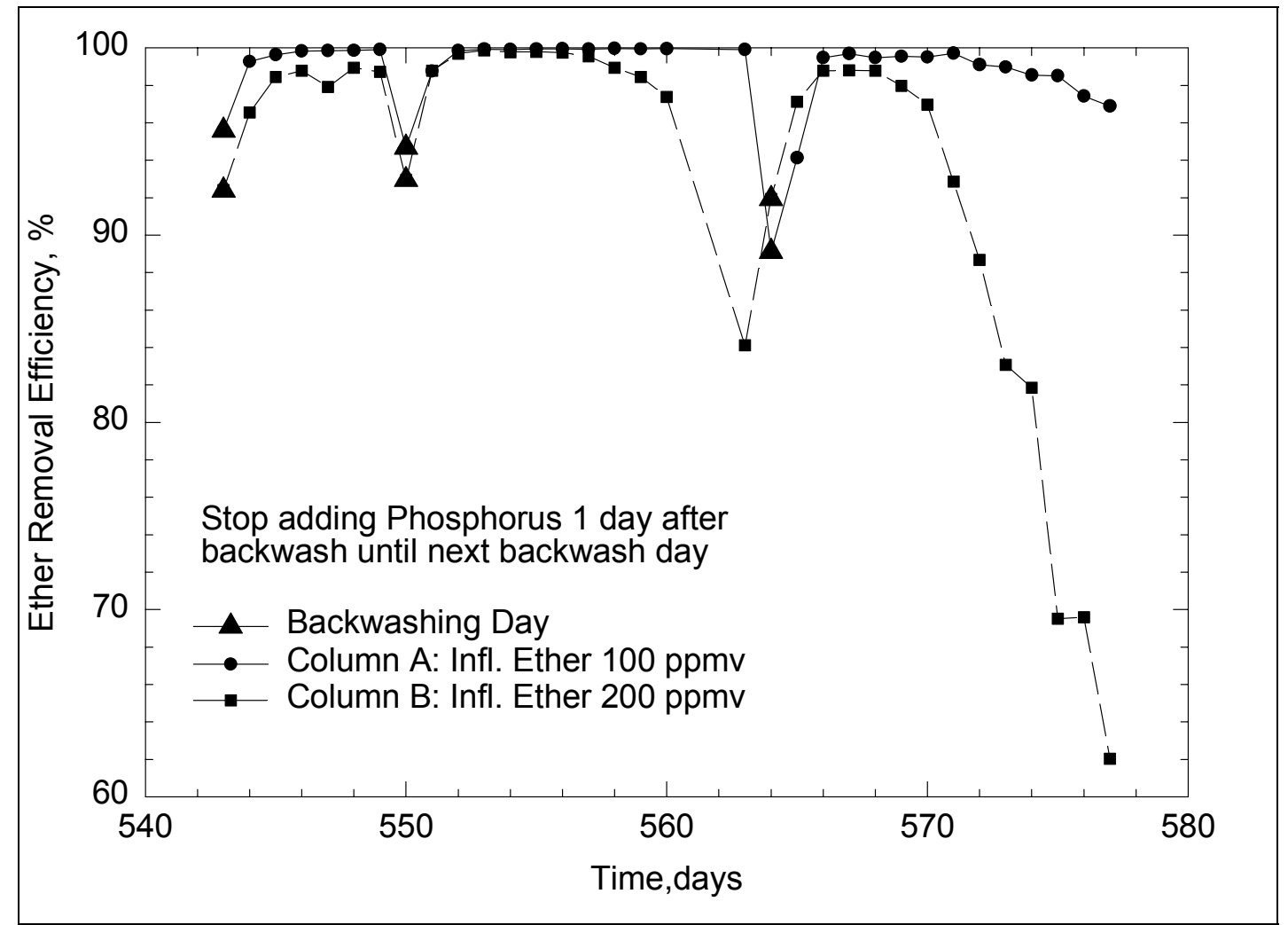

Figure 50. Biofilter performance under the condition of phosphorous absence at influent ether of 100 and 200 ppmv.

\section{Phosphorus Requirement}

The effect of the influent phosphorus concentration and phosphorus requirement for biotrickling filters was further investigated by varying the influent phosphorus concentrations at identical organic loading rates. Two more biotrickling filters were set up, identical to the two used in previous studies. Fresh media were well mixed with the biologically active media from the two existing biofilters and were evenly packed into the four identical biofilters. One more nutrient supply system was established so that nutrient feed with two different compositions can be delivered at the same time. Table 24 summarizes the major operating 
parameters. The four biofilters were started up at influent ether concentrations of 333 ppmv. The initial phosphorus concentration was maintained at 13.2 mgP/L. After the biofilter performance was stabilized, the effect of phosphorus was examined by varying the influent concentration of phosphorus at identical organic loading rates of $8.9 \mathrm{~kg} \mathrm{COD} / \mathrm{m}^{3} /$ day. Four influent phosphorus concentrations were studied at two different EBRT. The results are summarized in Figure 52 and Table 25.

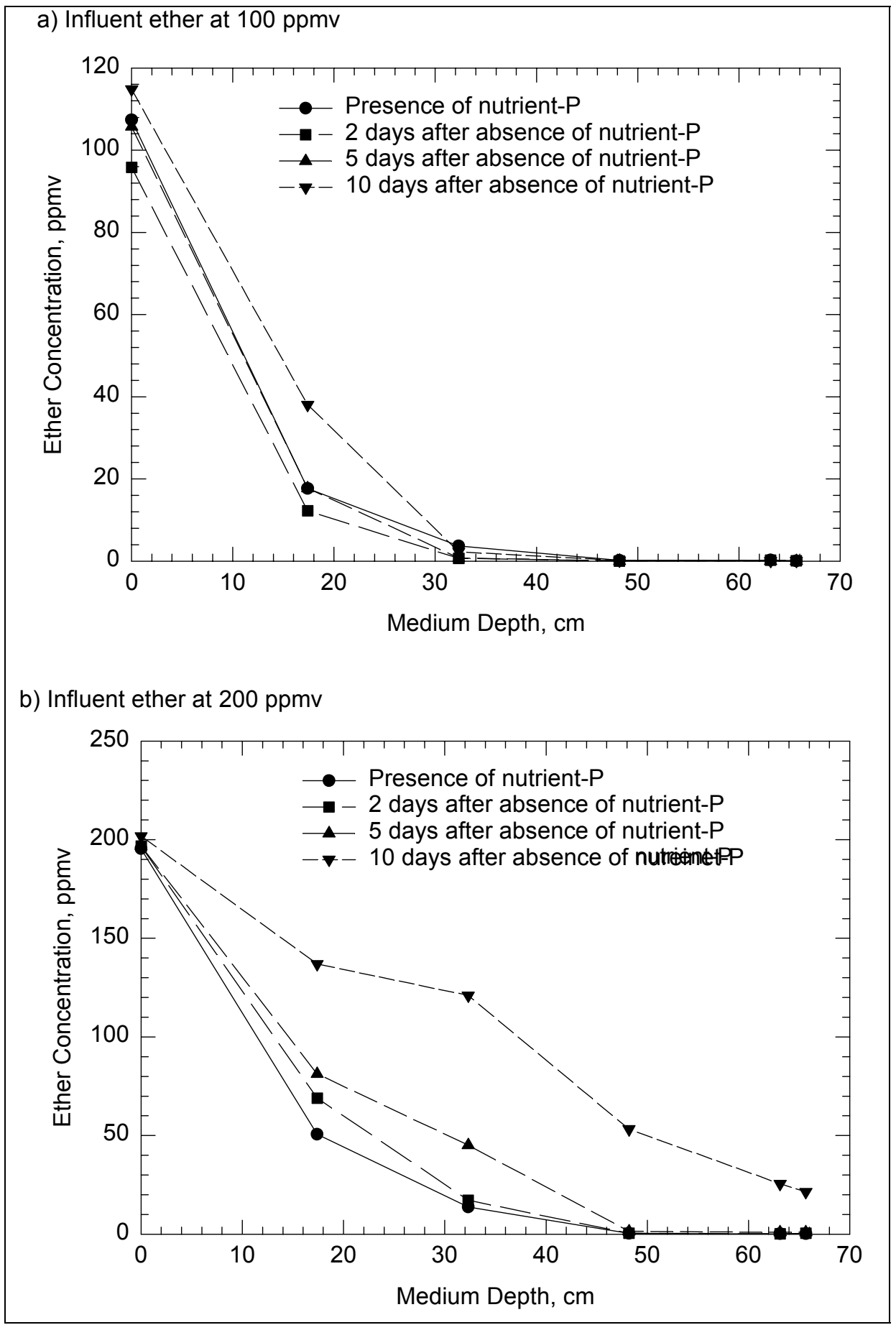

Figure 51. Effect of phosphorous absence on ether profiles along the medium depth. 
Table 24. Major operating conditions used in phosphorus requirement test.

\begin{tabular}{lc}
\hline COD Loading Rate, $\mathrm{Kg} \mathrm{COD} / \mathrm{m}^{3}$-day & 8.9 \\
Influent Phosphorus Concentrations, mg P/L & $3.3-52.8$ \\
Empty Bed Retention Time, sec & $12.5 \& 25$ \\
Influent Ether Concentrations, ppmv & $167 \& 333$ \\
Influent Nitrate Concentration, mg N/L & 1068 \\
Influent Air Flow Rate, $\mathrm{m}^{3}$ /day & 8.64 \\
Nutrient Liquid Flow Rate, L/day & 1.0 \\
\hline
\end{tabular}

a) EBRT at $25 \mathrm{sec}$

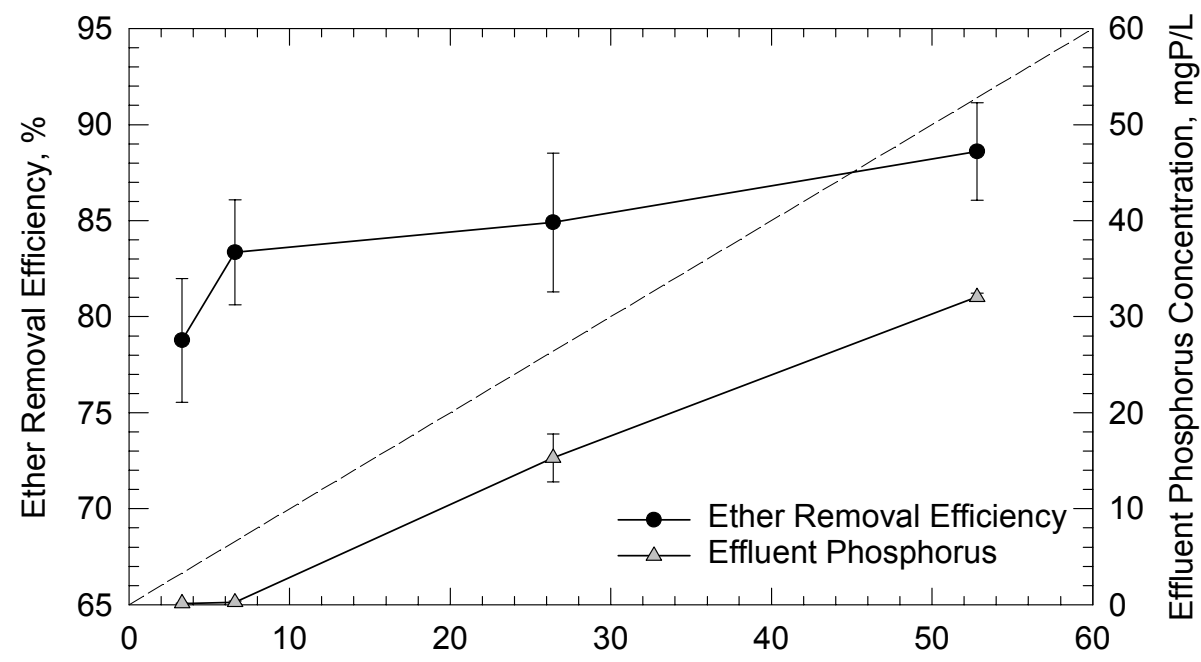

Influent Phosphorus Concentration, mgP/L

b) EBRT at $12.5 \mathrm{sec}$

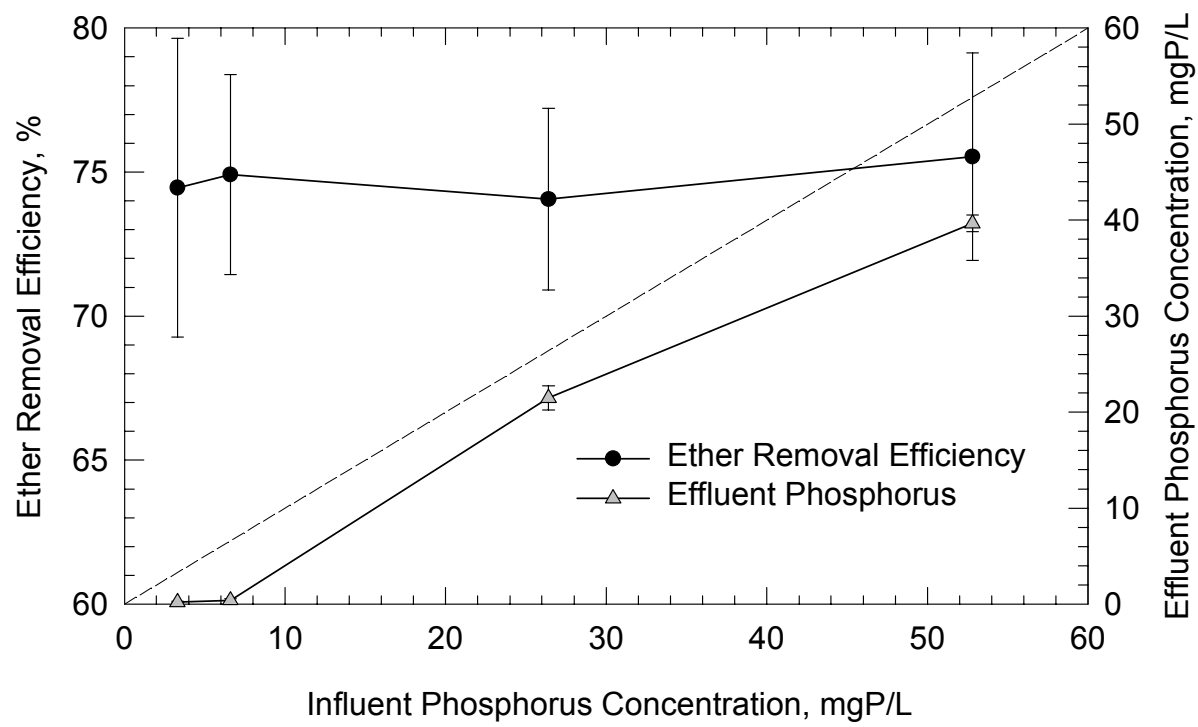

Figure 52. Effect of influent phosphorous concentrations on ether removal at an ether loading rate of $8.9 \mathrm{~kg} \mathrm{COD} / \mathrm{m}^{3} /$ day. 
Table 25. Summary of the results during the variations of the influent phosphorus concentrations.

\begin{tabular}{|c|c|c|c|c|c|c|c|}
\hline \multirow[b]{2}{*}{$\begin{array}{c}\text { Influent P } \\
(\mathrm{mgP} / \mathrm{L})\end{array}$} & \multirow[b]{2}{*}{$\begin{array}{l}\text { Influent } \\
\text { (COD:P) }\end{array}$} & \multicolumn{2}{|c|}{$\begin{array}{c}\text { Average Ether } \\
\text { Removal Efficiency } \\
(\%)\end{array}$} & \multicolumn{2}{|c|}{$\begin{array}{c}\text { Average COD:P } \\
\text { Uptake ratio }\end{array}$} & \multicolumn{2}{|c|}{$\begin{array}{l}\text { Average Yield } \\
\text { (gVSS/gCOD) }\end{array}$} \\
\hline & & $\begin{array}{c}\text { EBRT } \\
25 \mathrm{~s}\end{array}$ & $\begin{array}{l}\text { EBRT } \\
12.5 \mathrm{~s}\end{array}$ & $\begin{array}{c}\text { EBRT } \\
25 \mathrm{~s}\end{array}$ & $\begin{array}{l}\text { EBRT } \\
12.5 \mathrm{~s}\end{array}$ & $\begin{array}{c}\text { EBRT } \\
25 \mathrm{~s}\end{array}$ & $\begin{array}{l}\text { EBRT } \\
12.5 \mathrm{~s}\end{array}$ \\
\hline 3.3 & $6667: 1$ & 78.8 & 74.8 & $5580: 1$ & $5242: 1$ & 0.0704 & 0.0318 \\
\hline 6.6 & 3333:1 & 83.4 & 74.9 & 2930:1 & 2863:1 & 0.0712 & 0.0417 \\
\hline 26.4 & $833: 1$ & 84.9 & 74.1 & $2038: 1$ & $3046: 1$ & 0.0655 & 0.0394 \\
\hline 52.8 & $417: 1$ & 88.6 & 75.5 & $961: 1$ & $1278: 1$ & 0.0733 & 0.0426 \\
\hline
\end{tabular}

On day 66 of operation, the influent concentration of phosphorus to Columns A and $\mathrm{B}$ was reduced from $13.2 \mathrm{mgP} / \mathrm{L}$ to $6.6 \mathrm{mgP} / \mathrm{L}$, and the influent concentration of phosphorus to Columns $\mathrm{C}$ and $\mathrm{D}$ was doubled to $26.4 \mathrm{mgP} / \mathrm{L}$. The airflow rate to Columns $\mathrm{A}$ and $\mathrm{C}$ was maintained at $6 \mathrm{~L} / \mathrm{hr}$, resulting in an influent ether concentration of $333 \mathrm{ppmv}$ and an EBRT of $25 \mathrm{sec}$. The airflow rate to Columns $\mathrm{B}$ and $\mathrm{D}$ was increased to $12 \mathrm{~L} / \mathrm{hr}$, resulting in an influent ether concentration of $167 \mathrm{ppmv}$ and an EBRT of $12.5 \mathrm{sec}$. The results show that biofilter performance was not significantly affected when influent-P was reduced to $6.6 \mathrm{mg} / \mathrm{L}$ and COD:P ratio reached greater than 3,000. Little phosphorus was detected in the effluents from both Columns $\mathrm{A}$ and $\mathrm{B}$, which indicates that both biofilters were reaching phosphorus-limiting conditions. Ether removal efficiency remained around 84 percent for both Columns $\mathrm{A}$ and $\mathrm{C}$. The removal efficiency in both Columns B and D dropped to around 74 percent, which may be a result of mass transfer limitation due to the lower influent ether concentration and lower EBRT in those two reactors. The biomass yield rates during this period are shown in Table 25, which shows that the biomass growth rate was not affected by phosphorus concentration. The airflow rate and EBRT, however, had a significant effect on biomass yield. The yield rate was about $0.07 \mathrm{gVSS} / \mathrm{gCOD}$ at an EBRT of $25 \mathrm{sec}$, and was only around $0.04 \mathrm{gVSS} / \mathrm{gCOD}$ at an EBRT of $12.5 \mathrm{sec}$.

On day 160 of operation, the influent concentration of phosphorus to Columns $\mathrm{A}$ and $\mathrm{B}$ was further reduced from $6.6 \mathrm{mgP} / \mathrm{L}$ to $3.3 \mathrm{mgP} / \mathrm{L}$, and the influent concentration of phosphorus to Columns $\mathrm{C}$ and $\mathrm{D}$ was doubled again to $52.8 \mathrm{mgP} / \mathrm{L}$. The airflow rates and EBRT remained the same as in the previous stage. For the two biofilters with low EBRT, the ether removal efficiency remained stable at about 75 percent. For the two biofilters with an EBRT of 25 sec, however, ether removal efficiency decreased from 83.4 to 78.8 percent on average when influent$\mathrm{P}$ dropped to $3.3 \mathrm{mg} / \mathrm{L}$ in Column $\mathrm{A}$, and increased from 84.9 to 88.6 percent when influent-P doubled to $52.8 \mathrm{mg} / \mathrm{L}$ in Column $\mathrm{C}$. The fact that biofilter performance was more affected by the phosphorus concentration at EBRT of 25 sec 
can be attributed to the higher biomass growth rate at this condition since higher biomass yield leads to higher phosphorus demand.

Figure 53 profiles ether concentration along the medium depth for Columns A and $\mathrm{C}$. The results show that ether concentrations in the two biofilters drop in a similar manner along the columns except at the bottom of the column, where the profile for Column A flattened due to the depletion of phosphorus, while the ether concentration continued to drop in Column $\mathrm{C}$ since sufficient phosphorus remained in the nutrient flow. These results indicate that phosphorus limitation did not significantly reduce ether removal efficiency. Biofilters achieved stable performance at COD:P ratio up to 3333:1. External mass transfer limitation did not seem to seriously affect the availability of phosphorus within the biofilm, which may relate to the ability of bacteria to uptake and accumulate phosphorus. Biofilter performance was slightly affected when the influent COD:P ratio reached 6667:1 or influent-P concentrations fell below $3.3 \mathrm{mgP} / \mathrm{L}$. Biomass yield was not significantly decreased, however, with this decrease of influent phosphorus. It seems that limiting phosphorus may not be a practical way to control biomass growth in long-term biofilter operation.

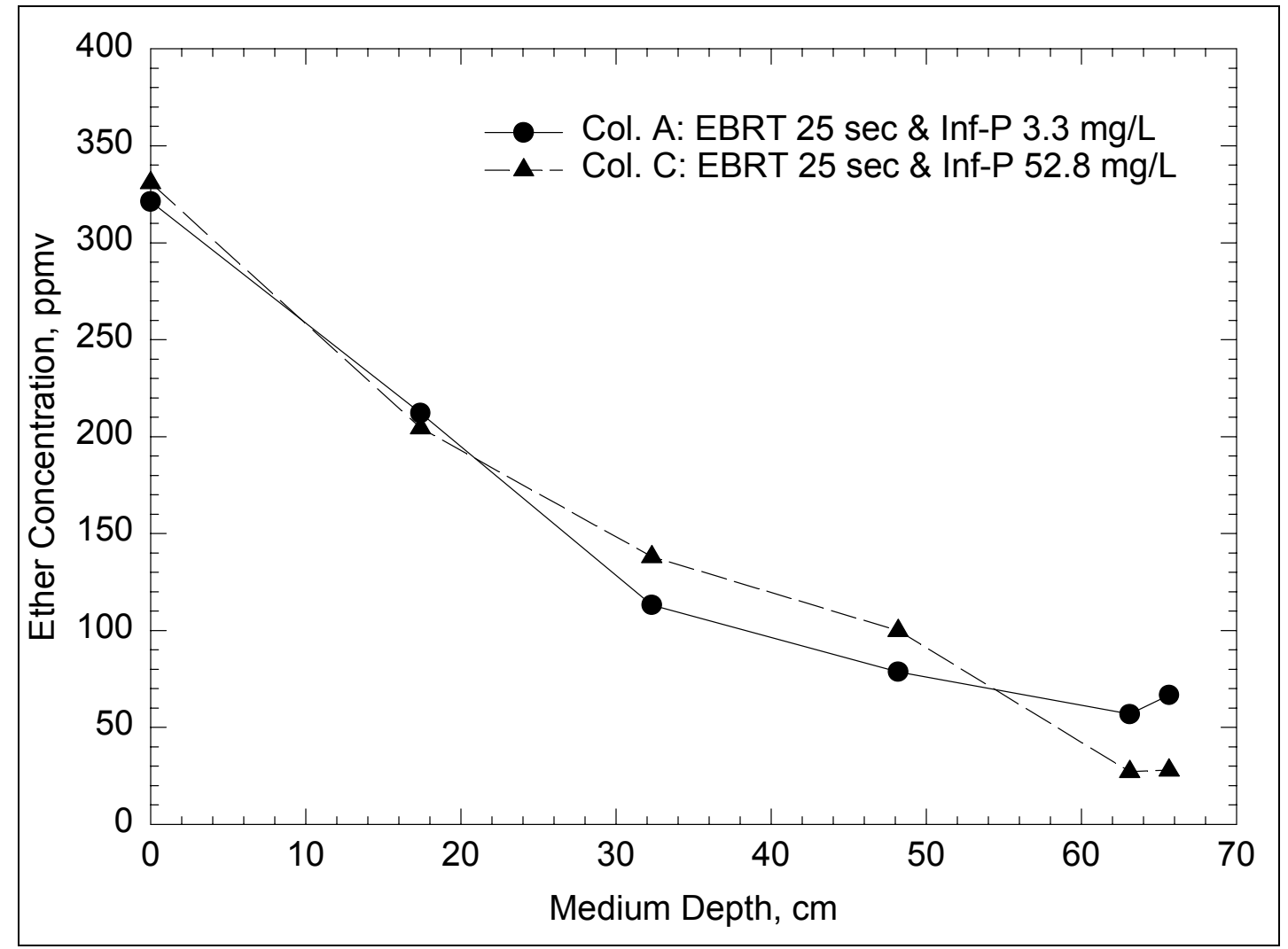

Figure 53. Phosphorous effect on ether profiles along the medium depth at ether loading of 8.9 $\mathrm{kg} \mathrm{COD} / \mathrm{m}^{3} /$ day and EBRT of $25 \mathrm{sec}$. 


\section{Summary}

This study investigated some major factors affecting biomass growth and biomass distributions along the biofilters. Two biomass control approaches, periodical biomass removal through backwashing and phosphorus limitation, were examined. The results show that the observed biomass yield is correlated with organic loading, EBRT, liquid flow rate, and airflow direction. For biofilters using ether as a substrate, biomass and biofilm thickness distribution along the medium depth was uneven with the majority of the biomass concentrated within the top sections of the columns. Biomass distribution is also related to the compounds being treated and probably to Henry's constants for the VOCs. Periodic backwashing was proven to be an effective approach to maintaining long-term stable operation. For ether treatment, optimal backwash frequencies of once a week for influent COD loading from 1.8 to $7.1 \mathrm{~kg} / \mathrm{m}^{3} /$ day and twice a week for COD loading from 8.9 to $10.7 \mathrm{~kg} / \mathrm{m}^{3} /$ day are recommended. The optimum backwash strategy also depends on the kinetics and the mass transfer properties of the compounds being treated. The study on the effect of phosphorus showed that limiting phosphorus does not significantly affect biofilter performance, suggesting that phosphorus is readily available to microorganisms within the biofilm. The presence of excess phosphorus does not have advantages for biotrickling filter treatment. On the other hand, the biomass yield did not decrease with the decrease of influent phosphorus, suggesting that limiting phosphorus may not be a feasible strategy to control biomass growth and reduce backwash frequency. 


\section{Conclusions}

Biofiltration is fast becoming an established APC technology for the removal of VOCs from waste gas streams. The acceptance of this technology in the United States, however, is still uncertain due to the lack of fundamental information. In this study, four biotrickling filters with pelletized media were operated for 6 years to investigate biofiltration fundamentals under highly controlled conditions. This investigation involved studying the effects of some major operating parameters, interfacial mass transfer phenomena, and biomass dynamics. A comprehensive mathematical model was also developed, which incorporated the findings of this study. The following conclusions can be drawn from this study:

1. Biotrickling filters are highly effective in treating biodegradable VOCs in gas streams. When using diethyl ether as a model VOC, the study demonstrated that these biofilters achieved more than 90 percent ether removal, at a low EBHRT of $25 \mathrm{sec}$, and at organic loading rates up to $10.8 \mathrm{~kg} \mathrm{COD} / \mathrm{m}^{3} /$ day. Based on the study on the effect of EBRT and considering the cost factor, an optimal EBRT range of $25 \mathrm{sec}$ to $1 \mathrm{~min}$ is recommended for future biofilter design. Other major operating parameters affecting biofiltration identified included liquid flow rate, the concentration of nitrate, backwash strategy, and air flow direction.

2. The study on the effect of nitrate showed that nitrate diffusion in the biofilms is rate determining and that transfer of oxygen was not rate limiting when using ether as a substrate, suggesting that nitrate was rate limiting as a growth nutrient and not as an electron acceptor. An optimum COD:N ratio of 30:1 is recommended based on this experiment. The results of this study also suggested that, in gas-phase biofilters, the mass transfer of substrates in the gas phase (such as ether and oxygen) might not be limited by the liquid phase as in wastewater systems because direct mass transfer to a non-wetted biofilm may occur. On the other hand, since substrates such as nitrate in the liquid phase can only be transported into the biofilm through wetted areas, mass transfer limitation is more serious. The mathematical model of the biofilter was able to predict the effect of influent nitrate concentration on biofilter performance and to explain the role nitrate plays in the degradation process.

3. The influence of the liquid phase was further investigated by studying both the effect of draining after backwashing and flooding and the effect of the liquid flow rate. The results showed that the variation of liquid flow rate from 1 to $20 \mathrm{~L} /$ day 
has little immediate effect on biofilter performance, suggesting that mass transfer resistance through liquid phase for ether or oxygen was negligible. The physical effect of the water content was important only within a short period after backwashing when the biofilters were fully saturated. A higher liquid flow rate, however, gradually leads to improved biofilter performance through changes in biofilm formation and the improvement of biological activity. The results can again be attributed to the nonsaturated feature of the biofilms in gasphase biotrickling filters. Increasing liquid flow may not affect mass transfer of substrates from the gas phase, but may enhance mass transfer of nutrients into the biofilm, resulting in more active biomass. The mathematical model of the biofilter was able to predict the effect of influent nitrate concentration on biofilter performance and to explain the role nitrate plays in the degradation process.

4. Microelectrode techniques were used, for the first time, to analyze the mass transfer of oxygen within the biofilm from a gas-phase biofilter. Results showed that, unlike most wastewater biofilms in which oxygen is often depleted within a shallow layer, biofilms with thickness as high as $2.2 \mathrm{~mm}$ still have full penetration of oxygen in a gas-phase biotrickling filter. Some high DO zones inside the biofilm were observed, suggesting the existence of passages for oxygen transfer into the deeper sections of the biofilm in a gas-phase biotrickling filter. The gasliquid mass transfer resistance was also found negligible in the biotrickling filter system based on the microelectrode measurement. Microscopic observations showed that a layered structure with void spaces exists within the biofilm. Both the low gas-liquid mass transfer resistance and the special internal structure contribute to the high oxygen penetration within the biofilms in gas-phase biotrickling filters.

5. A long-term study on the effect of Henry's constant using four VOCs as substrates indicated that the VOC removal efficiency generally increases with the decrease of substrates' Henry's constant. The results also suggested that the mass transfer of VOCs between vapor and liquid or between vapor and biofilm was a rate-determining step for the treatment of VOCs with high Henry's constant like toluene and hexane, but not for VOC with low Henry's constants like butanol and ether. However, oxygen transfer may become a rate-limiting step in treating VOCs with low Henry's constant based on the finding of denitrification in the butanol-fed biofilter. Model simulations indicated that when the VOC's Henry's constant is between 0.01 and 10, the biofiltration process is limited by Henry's constant, kinetic parameters, and the diffusivity in the biofilm for the contaminant. However, when Henry's constant is less than approximately 0.01 or greater than 10, the kinetic parameters and the diffusivity in the biofilm become less important. In the case of a Henry's constant greater than 10, little VOC removal can be achieved because of the high mass transfer resistance and limited available substrate in the biofilm to sustain biomass growth. In the case 
of a Henry's constant of less than 0.01 , oxygen transfer becomes a determining factor. In future modeling work, therefore, oxygen limitation and denitrification, if applicable, must be considered when dealing with VOCs with low Henry's constants.

6. This study identified major factors affecting growth and distributions along the biofilters. The results show that the observed biomass yield is correlated with organic loading, EBRT, liquid flow rate, and airflow direction. For biofilters using ether as a substrate, there was an uneven biomass and biofilm thickness distribution along the medium depth, with the majority of the biomass concentrated in the top sections of the columns. Biomass distribution is also related to the compounds being treated and probably Henry's constants of the VOCs.

7. Two biomass control approaches - periodical biomass removal through backwashing and phosphorus limitation - were investigated. Periodic backwashing was proven to be an effective approach to maintain long-term stable operation. The optimal backwash frequency depends on VOC loadings, as well as the kinetics and the mass transfer properties of the contaminants being treated. The study on the effect of phosphorus showed that limiting phosphorus does not significantly affect biofilter performance, suggesting that phosphorus is readily available to microorganisms within the biofilm. The presence of excess phosphorus does not have advantages for biotrickling filter treatment. On the other hand, the biomass yield did not decrease with the decrease of influent phosphorus, suggesting that limiting phosphorus may not be a practical way to control biomass growth and reduce backwash frequency. 


\section{References}

Alonso, C., Modeling of VOC Degradation in Gas Streams (Ph.D Dissertation, University of Cincinnati, $\mathrm{OH}, 1999)$.

Alonso, C., X. Zhu, M.T. Suidan, B.R. Kim, and B.J . Kim, "Parameter Estimation in Biofilter Systems," Environ. Sci. Tech., vol 34, no. 11 (2000).

Alonso, C., M.T. Suidan, B.R. Kim, and B.J . Kim, "Dynamic mathematical model for the biodegradation of VOCs in a biofilters: biomass accumulation study," Environ. Sci. Tech., vol 32 (1998).

Alonso, C., X. Zhu, M.T. Suidan, B.R. Kim, and B.J . Kim, "Effect of Nitrate on VOC Removal in a Gas Phase Biofilter," Procedings of 70th Annual Conference \& Exposition of Water Environment Federation, Chicago, IL (1997a).

Alonso, C., M.T. Suidan, G.A. Sorial, F.L. Smith, P. Biswas, P.J . Smith, and R.C. Brenner, "Gas Treatment in Trickle-Bed Biofilters: Biomass, How Much is Enough?", Biotech. Bioeng., vol 54 (1997b).

American Public Health Association (APHA), Standard Methods for the Examination of Water and Wastewater, $18^{\text {th }}$ ed. (APHA, Washington, DC, 1992).

Auria, R., A.C. Aycaguer, and J .S. Devinny, "Influence of Water Content on Degradation Rates for Ethanol in Biofiltration,"J . Air \& Waste Management Assoc., vol 48 (1998).

Austin, T., "VOCs: The New Effluent," Civil Engineering, vol 62, no. 3 (1992).

Bird R.B., W.E. Stewart, and E.N Lightfoot, Transport Phenomena (J ohn Wiley \& Sons, 1960).

Bodker, J . and S. Rydin, "Biol ogical waste gas treatment using a vertical filter," Proceedings of the 1996 Conference on Bi ofiltration, Los Angeles, CA (1996).

Bohn, H.L., “Consider Biofiltration for Decontaminating Gases," Chem. Eng. Prog. (April 1992).

Caldwell, D.E., D.R. Korber, and J .R. Lawrence, "Confocal laser microscopy and digital image analysis in microbial ecology," Adv. Microbial. Ecol., vol 12 (1992a).

Caldwell, D.E., D.R. Korber, and J .R. Lawrence, "I maging of bacterial cells by fluorescence exclusion using confocal laser microscopy,"J . Microbiological Methods, vol 15 (1992b).

Dawson, D.S., "Biological Treatment of Gaseous Emissions," Water Environmental Research, vol 65, no. 4 (1993). 
De Heyder, B., A. Overmeire, H. Van Langenhove, W. Verstraete, "E thene Removal from a Synthetic Waste Gas Using a Dry Biobed," Biotechnol. Bi oeng., vol 44 (1994).

Devinny, J .S., M.A. Deshusses, T.S. Webster, Biofiltration for Air Pollution Control (Lewis Publishers, 1999).

Diks, R.M.M., S.P.P. Ottengraf, and S. Vrijland, "The Existence of a Biological Equilibrium in a Trickling Filter for Waste Gas Purification," Biotechnol. Bioeng., vol 44 (1994).

Diks, R.M.M. and S.P.P. Ottengraf, "Verification Studies of a Simplified Model for the Removal of Dichloromethane from Waste Gases Using a Biological Trickling Filter (Parts I and II)," Bioprocess Eng., vol 6 (1991).

Dowben, R.M. and J .E. Rose, "A metal-filled microel ectrode," Science, vol 118 (1953).

Du, X., Optimum nitrogen concentration supporting maximum crudeoil biodegradation in microcosms (M.S. thesis, University of Cincinnati, OH, 1999).

E bihara, T., Characterization and enhancement of microbial biofilms in porous media for the biodegradation of polycyclic aromatic hydrocarbons (Ph.D dissertation, University of Cincinnati, $\mathrm{OH}, 1999)$.

Findlay, R.H., G.M. King, and L. Watling, "Efficacy of Phospholipid Analysis in Determining Microbial Biomass in Sediments," Applied and Environmental Microbiology, vol 55 (1989).

Fu Y.-C., Characterizing oxygen profiles and determining oxygen diffusi vity in biofilm during biodegradation of azo dye (PhD dissertation, University of Cincinnati, OH, 1993).

Gaudy, J r., A.F. and E.T. Gaudy, Microbiology for Environmental Scientists and Engineers (McGraw-Hill, 1980).

Gee, C.S., J .T. Pfeffer, and M.T. Suidan, “Nitrosomonas and Nitrobacter interactions in biological nitrification,"J ournal of Environmental Engineering, vol 116, no 1, 4-17 (1990).

Hach Company, Water Analysis Handbook (Hach Company, Loveland, CO, 1992).

Hartmans, S. and J . Tramper, “Dichloromethane Removal from Waste Gases with a Trickle Bed Bioreactor," J . Bioprocess Eng., vol 6 (1991).

Hodge, D.S. and J .S. Devinny, "Biofilter Treatment of Ethanol Vapors," Environmental Progress, vol 13, no. 3 (1994).

Hodge, D.S., V.F. Median, R.L. I slander, and J .S. Devinny, "Treatment of Hydrocarbon Fuel Vapors in Biofilters," Environmental Technology, vol 12 (1991).

Holubar, P., C. Andorfer, and R. Braun, "Prevention of Clogging in Trickling Filters for Purification of Hydrocarbon-contaminated Waste Air," Proceedings of 1995 Conference on Biofiltration, Los Angeles, CA (1995). 
J ohnson, C.T. and M.A. Deshusses, "Evaluation of a Rapid Methodology to Determine Elimination Capacities in Biofilters for VOC Treatment," Proceedings of 1995 Conference on Biofiltration, Los Angeles, CA (1996).

Kempbell, D.H., J .T. Wilson, H.W. Read, T.T. Stocksdale, "Removal of Volatile Aliphatic Hydrocarbon in a Soil Bioreactor,"J APCA, vol 37 (1987).

Kinney, K.A., D.P.Y. Chang, E.D. Shroeder, and K.M. Scow, "Performance of a directionallyswitching biofilter treating toluene contaminated air," Proceedings of the 89th annual Meeting \& Exhibition of Air and Waste Management Association, Pittsburgh, PA (1996).

Kirchner, K., S. Wagner, and H.J . Rehm., "Exhaust Gas Purification Using Biocatalysts (Fixed Bacteria Monocultures) - The Influence of Biofilm Diffusion Rate $\left(\mathrm{O}_{2}\right)$ on the Overall Reaction Rate," Appl. Microbiol. Biotechnol., vol 37 (1992).

Kirchner, K., U. Schlachter, H.J . Rehm, "Biological Purification of Exhaust Air Using Fixed Bacterial Monocultures," Appl. Microbiol. Biotechnol., vol 31, 629-632 (1989).

Kirchner, K., P. Kramer, H.J . Rehm, "Absorption and Oxidation of Pollutants Using Bacterial Cultures (Monocultures)," Int. Chem. Eng., vol 25, 428-435 (1985).

Lee, B., "Highlights of Clean Air Act Amendments of 1990," J . Air and Waste Manag. Assoc., vol 41, no. 1 (1991).

Leson, G. and A.M. Winer, "Biofiltration: An InnovativeAir Pollution Control Technology for VOC Emissions,"J . Air and Waste Manag. Assoc., vol 41, no. 8 (1991).

Linsenmeier, R.A. and C.M. Yancey, "I mproved fabrication of double-barreled recessed cathode $\mathrm{O}_{2}$ microelectrodes,"J . Appl. Physiol., vol 63, no. 9 (1987).

Miller, D.E. and L.W. Canter, "Control of Aromatic WasteAir Streams by Soil Bioreactors," Environmental Progress, vol 10, no. 4 (1991).

Morgenroth, E., E.D. Schroeder, D.P.Y. Chang, and K.M. Scow, "Nutrient limitation in a compost biofilter degrading hexane,"J . Air and Waste Manag. Assoc., vol 46 (1996).

Ockeloen, H.F., T.J . Overcamp, and C.P.L. Grady, J r., “Engineering Model for Fixed Film Bioscrubers,"J . of Environmental Engineering, vol 122, no. 3 (1996).

Ottengraf, S.P.P., "Biological Systems for Waste Gas Elimination," Trends Biotechnol., vol 5 (1987).

Ottengraf, S.P.P., Exhaust Gas Purification in Biotechnol ogy, Vol 8, H.J . Rehn, and G. Reed, eds, VHC Verlagsgesellsch, Weinham (1986).

Ottengraf, S.P.P., J JJ .P. Meesters, A.H.C. Van den Oever, H.R. Rozema, "Biological Elimination of Volatile Xenobiotic Compounds in Biofilters," Bioprocess Eng., vol 1 (1986).

Ottengraf, S.P.P. and A.H.C. Van den Oever, "Kinetics of Organic Compound Removal from Waste Gases With a Biological Filter," Bi otechnol. Bi oeng., vol 25 (1983). 
Rittmann, B.E. and P.L. McCarty, "Model of Steady-state-biofilm Kinetics," Biotechnol. Bioeng., vol 22 (1980).

Rihn, M.J ., X. Zhu, M.T. Suidan, B.J . Kim, and B.R. Kim, "The effect of nitrate on VOC removal in trickle bed biofilters," Water Research, vol 31, no. 12 (1997).

Rittmann, B.E. and J .A. Manem, "Development and Experimental Evaluation of a Steady-State, Multi-Species Biofilm Model," Biotechnol. Bioeng., vol 39 (1992).

Severin, B.F., J . Shi, and T. Hayes, "Destruction of Gas I ndustry VOCs in a Biofilter," Proceedings of the IGT 6th International Symposium on Gas, Oil, and Environmental Technol ogy, Colorado Springs, CO (1993).

Shareefdeen, Z., B.C. Baltzis, Y.S. Oh, and R. Bartha, "Bi ofiltration of Methanol Vapor," Biotechnol. Bioeng., vol 41 (1993).

Smith, F.L., G.A. Sorial, M.T. Suidan, A. Pandit, P. Biswas, and R.C. Brenner, "F urther Evaluation of Trickle Bed Biofilter Performance as a Function of Loading, Residence Time, and Biomass Control," Proceedings of 68th Annual Conference \& Exposition of Water Environment Federation, Miami Beach, FL (1995).

Smith, F.L., M.T. Suidan, G.A. Sorial, P. Biswas, and R.C. Brenner, “Trickle bed biofilter performance: biomass control and $\mathrm{N}$-nutrient effects," Proceedings of the Water Environment Federations 67th Annual Conferenceand Exposition, Chicago, IL, October 15-19 (1994).

Smits, M.C.J ., S.P.P. Ottengraf, and J .C. van den Heuvel, "Effect of the Superficial Liquid Velocity on the Nitrification of Ammonia Polluted Air in a Bio-Trickling Filter," Proceedings of 1995 Conference on Biofiltration, Los Angeles, CA (1995).

Sorial, G.A., F.L. Smith, M.T. Suidan, A. Pandit, P. Biswas, and R.C. Brenner, “Trickle bed bi ofilter performance for treatment of contaminant air," Proceedings of 1996 Conference on Biofiltration, Los Angeles, CA (1996).

Sorial, G.A., F.L. Smith, M.T. Suidan, and P. Biswas, "Evaluation of trickle bed biofilter media for toluene removal,"J ournal of the Air \& Waste Management Assoc., vol 45, no. 3 (1995).

Sorial, G.A., F.L. Smith, P.J . Smith, M.T. Suidan, P. Biswas, and R.C. Brenner, "Biofilters Treat Contaminated Air," Water Environment and Technology, vol 5, no. 4 (1994a).

Sorial, G.A., F.L. Smith, M.T. Suidan, and P. Biswas, and R.C. Brenner, "Evaluation of Performance of trickle bed biofilters - impact of periodic removal of accumulated biomass," Proceedings of the 87th annual Meeting \& Exhibition of Air and Waste Management Association, Cincinnati, OH, J une 19-24 (1994b).

Sorial, G.A., F.L. Smith, P.J . Smith, M.T. Suidan, P. Biswas, and R.C. Brenner, "Development of Aerobic Biofilter Design Criteria for Treating VOCs," Proceedings of the 86th annual Meeting \& Exhibition of Air and Waste Management Association, Denver, CO (1993a). 
Sorial, G.A., F.L. Smith, P.J . Smith, M.T. Suidan, P. Biswas, and R.C. Brenner, "Evaluation of bi ofilter media for treatment of air streams containing VOCs," Proceedings of the Water Environment Federations 66th Annual Conference and Exposition, Facility Operations Symposia, Volume X, 429-439 (1993b).

Speital J r., G.E. and D.S. McLay, "Biofilm Reactors for Treatment of Gas Streams Containing Chlorinated Solvents,"J . Environmental Enginering, vol 119, no 4 (1993).

Suidan, M.T. and Y.T. Wang, “U nified Analysis of Biofilm Kinetics,”J . Environ. Eng., vol 111 (1985).

Suidan, M.T., B.E. Rittmann, and U.K. Traegner, "Criteria Establishing Biofilm-Kinetic Types," Water Research, vol 21 (1987).

Surman, S.B., J .T. Walker, D.T. Goddard, L.H.G. Morton, C.W. Keevil, W. Weaver, A. Skinner, K. Hanson, Caldwell, and J . Kurtz, "Comparison of microscope techniques for the examination of biofilms," J . Microbiological Methods, vol 25 (1996).

Togna, A.P. and M. Singh, "Biological Vapor-Phase Treatment Using Biofilter and Biotrickling Filter Reactors: Practical Operating Regimes," Environmental Progress, vol 13, no. 2 (1994).

Utgikar, U., Y. Shan, and R. Govind, "Biodegradation of Volatile Organic Compounds in Aerobic and Anaerobic Biofilters," in Remedial Action, Treatment, and Disposal of Hazardous Waste, Proceedings of 17th Annual Hazardous Research Symposium, Cincinnati, OH (1991).

Van Lith, C., S.L. David, and R. Marsh, "Design Criteria for Biofilters," Trans. Inst. Chem. Eng., vol 68(B) (1990).

Van Lith, C., G. Leson, and R. Michelsen, "Evaluation Designs for Biofilters," J . Air \& Waste Management Assoc., vol 47 (1997).

Venosa, A.D., M.T. Suidan, B.A. Wrenn, J R. Haines, K.L Strohmeier, E. Holder, and L. Eberhart, "Nutrient application strategies for oil spill bioremediation in the field," in Twentieth Annual RREL Research Symposium, U.S. EPA, Cincinnati, OH, EPA/600/R-94/011 (1994).

Verschueren, K., Handbook of Environmental Data on Organic Chemicals, $3^{\text {rd }}$ ed. (Van Nostrand Reinhold, 1999).

Weckhuysen, B., L. Vriens, and H. Verachtert, "The effect of nutrient supplementation on the biofiltration removal of butanol in contaminated air," Appl. Microbial Biotechnol., vol 39 (1993).

Whalen W.J ., J . Rilay and P. Nair, "A microelectrode for measuring intracellular $\mathrm{Po}_{2}$,"J . Appl . Physiol., vol 23 (1967).

Williamson, K. and P.L. McCarty, "A model of substrate utilization by bacterial films," J . WPCF, vol 48 (1976a). 
Williamson, K. and P.L. McCarty, "Verification studies of the biofilm model for bacterial substrate utilization,"J . WPCF, vol 48 (1976b).

Yaws, C.L., Chemical Properties Handbook: physical, thermodynamic, environmental, transport, safety, and related properties for organic and inorganic chemicals (M cGraw-Hill, 1999).

Yu, T. and P.L. Bishop, "Stratification and redox potential change in an aerobic and sulfatereducing bi ofilm studied using microel ectrodes," Proceedings of the 70th Annual WEF Conference, Chicago, IL, October 18-22 (1997).

Zhang, T.C., I nfluence of bi ofilm structure on transport and transformation processes in bi ofilms (Ph.D. Dissertation, University of Cincinnati, OH (1994).

Zhu, X., M.J . Rihn, M.T. Suidan, B.J . Kim, and B.R. Kim., "The Effect of Nitrate on VOC Removal in Trickle Bed Biofilters," Water Science and Technol ogy, vol 34, no. 3-4 (1996a).

Zhu, X., M.J . Rihn, M.T. Suidan, B.J . Kim, and B.R. Kim, "Role of Nitrate in Trickle Bed Biofilters: Nutrient or Electron Acceptor," Proceedings of the69th WEF Annual Conference and Exposition, Dallas, TX (1996b).

Zhu, X, M.T. Suidan, G.A. Sorial, B.J . Kim, and B.R. Kim, "Role of Phosphorus on VOC Removal in Trickle Bed Biofilters," Proceedings of the 70th WEF Annual Conference and Exposition, Chicago, IL (1997). 


\section{CERL Distribution}

\section{Chief of Engineers}

ATTN: CEHEC-IM-LH (2)

Operations Support Command

ATTN: SOSMA-ISE-P (2)

Engineer Research and Development Center (Libraries) ATTN: ERDC, Vicksburg, MS

ATTN: Cold Regions Research, Hanover, $\mathrm{NH}$

ATTN: Topographic Engineering Center, Alexandria, VA

Defense Tech Info Center 22304

ATTN: DTIC-O

8

$9 / 01$ 


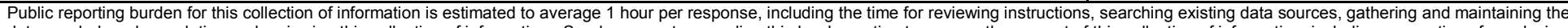

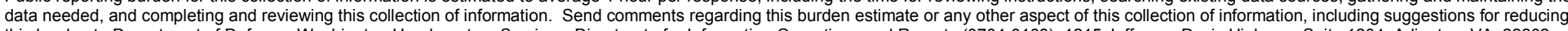

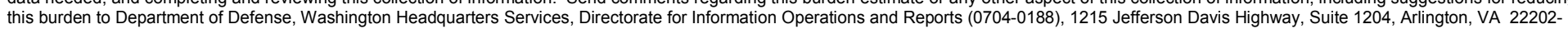

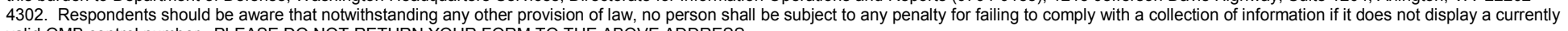
valid OMB control number. PLEASE DO NOT RETURN YOUR FORM TO THE ABOVE ADDRESS.
1. REPORT DATE (DD-MM-YYYY)
2. REPORT TYPE
$11-2001$
3. DATES COVERED (From - To)

4. TITLE AND SUBTITLE

Final

5a. CONTRACT NUMBER

A Fundamental Study of Biofiltration Processes for VOC Removal From Waste Gas Streams

5b. GRANT NUMBER

5c. PROGRAM ELEMENT NUMBER

6. AUTHOR(S)

Byung J. Kim, Makram T. Suidan, Xueqing Zhu, and Cristina Alonso

\section{5d. PROJECT NUMBER}

622720 A 896

5e. TASK NUMBER

5f. WORK UNIT NUMBER

CNE-T281

8. PERFORMING ORGANIZATION REPORT NUMBER

ERDC/CERL TR-01-48

Construction Engineering Research Laboratory (CERL)

P.O. Box 9005

Champaign, IL 61826-9005

9. SPONSORING / MONITORING AGENCY NAME(S) AND ADDRESS(ES)

10. SPONSOR/MONITOR'S ACRONYM(S)

Headquarters, U.S. Army Corps of Engineers

$441 \mathrm{G}$ Street, NW.

Washington, DC 20314-1000

11. SPONSOR/MONITOR'S REPORT NUMBER(S)

\section{DISTRIBUTION / AVAILABILITY STATEMENT}

Approved for public release; distribution is unlimited.

\section{SUPPLEMENTARY NOTES}

Copies are available from the National Technical Information Service, 5285 Port Royal Road, Springfield, VA 22161.

\section{ABSTRACT}

Most volatile organic compounds (VOCs) are deemed carcinogenic, and some are precursors to ozone production. Large amounts of VOCs are emitted to the atmosphere from chemical industries, food processing industries, and waste management facilities. The Clean Air Act Amendments of 1990 has meant that control and removal of VOCs from contaminated gas streams have become of increasing concern in recent years. Biological treatment, especially biofiltration, has emerged as a promising air pollution control technology for VOC removal because of its cost-effectiveness for certain waste gas streams when compared with other conventional VOC control options.

Biofiltration uses microorganisms to degrade various pollutants. A waste gas stream is purified by passage through a biologically active medium under aerobic conditions. As the waste gas moves through the biofilter, organic compounds pass into the biofilms surrounding the supporting medium and are oxidized into mineral end products or incorporated into the biomass.

This report enhances understanding of fundamentals of biofilter operation for air treatment through a bench-scale evaluation of a biotrickling filter. This report is a companion to ERDC/CERL TR-00-9, which provided fundamentals of the bioscrubber. This study will enable pilot-scale demonstration of new generation biofilter technology beginning in fiscal year 2002.

\section{SUBJECT TERMS}

volatile organic compounds (VOCs) biofiltration system industrial waste

\begin{tabular}{|l|l|l|}
\hline \multicolumn{2}{|l|}{ 16. SECURITY CLASSIFICATION OF: } \\
\hline $\begin{array}{c}\text { a. REPORT } \\
\text { Unclassified }\end{array}$ & $\begin{array}{c}\text { b. ABSTRACT } \\
\text { Unclassified }\end{array}$ & $\begin{array}{c}\text { c. THIS PAGE } \\
\text { Unclassified }\end{array}$ \\
\hline
\end{tabular}

air pollution control technologies

\begin{tabular}{|c|c|c|}
\hline $\begin{array}{c}\text { 17. LIMITATION } \\
\text { OF ABSTRACT }\end{array}$ & $\begin{array}{c}\text { 18. NUMBER } \\
\text { OF PAGES }\end{array}$ & $\begin{array}{c}\text { 19a. NAME OF RESPONSIBLE PERSON } \\
\text { Dr. Byung J. Kim }\end{array}$ \\
\cline { 3 - 3 } SAR & 110 & $\begin{array}{c}\text { 19b. TELEPHONE NUMBER (in- } \\
\text { clude area code) } \\
\end{array}$ \\
& & $(217) 373-3481$
\end{tabular}

Standard Form 298 (Rev. 8-98)

Prescribed by ANSI Std. 239.18 